\title{
ESTUDO DO COMPORTAMENTO ESTRUTURAL DA CAIXA ESPIRAL DE UMA TURBINA TIPO KAPLAN POR MODELO FÍSICO E MÉTODO NUMÉRICO
}

HAROLDO DE MAYO BERNARDES

Dissertação apresentada à Escola de Engenharia de São Carlos, da Universidade de São Paulo, como parte dos requisitos para a obtenção do Título de Mestre em Engenharia de Estruturas.

ORIENTADOR: Prof. Dr. Márcio Antônio Ramalho

São Carlos

1995

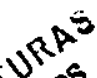




\section{Bermardes, Haroldo de Mayo}

B518e Estudo do comportamento estrutural da caixa espiral de uma turbina tipo Kaplan por modelo físico e método numérico / Haroldo de Mayo Bernardes. - São Carlos, 1995.

$132 \mathrm{p}$.

Dissertação (Mestrado) - Escola de Engenharia de São Carlos Universidade de São Paulo, 1995.

Orientador: Prof. Dr. Márcio Antonio Ramalho

1. Barragens de concreto. 2. Método dos elementos finitos. 3. Estruturas-análise experimental. I. Título 
Ao Eng. Wilson de Araujo Costa,

para mim, um profissional "modelo".

Aos meus pais,

Douglas Dionysio Bernardes e

Horaisa de Mayo Bernardes,

que me ensinaram o valor de lutar.

À minha esposa,

Maria Rosangela de Oliveira,

que, a meu lado, luta. 


\section{AGRADECIMENTOS}

Ao Professor Márcio Antônio Ramalho, pela orientação e pela amizade, nascida no transcorrer do trabalho.

À Companhia Energética de São Paulo - CESP, pela autorização para utilizar e divulgar os dados, e à Coordenadoria de Aperfeiçoamento de Pessoal de Nível Superior - CAPES, pela bolsa concedida.

Aos colegas da UNESP de Ilha Solteira, professores, funcionários e alunos, pela autorização para o necessário afastamento, pelo esforço adicional para suprir minha ausência, e pelo apoio em diversas etapas do trabalho. Aos colegas da EESC-USP, com quem tive o prazer e a honra de trabalhar durante esse período.

Ao Eng. Lélio Naor Lindqüist, pelo incentivo, apoio, e amizade, Eng. Juan Tomas Resk, da Internacional Engenharia, Eng. Mauro Fernandes Gabriel, exaluno, Sr. José Aldir Pereira e Sra. Helena Zani Marinho, pelos desenhos, Sr. Deoclécio Mitsuiti Kosaka, pela diagramação, e à minha esposa, principalmente pela paciência e pela revisão.

Infelizmente, não é possível citar todos a quem devo gratidão pela colaboração na execução deste trabalho. Guardarei esse sentimento, retribuindo a cada um oportunamente. 


\section{SUMÁRIO}

LISTA DE FIGURAS ….............................................................. i

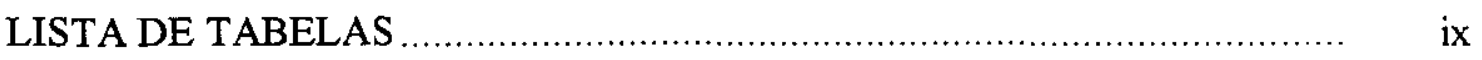

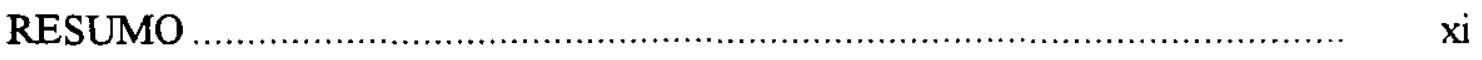

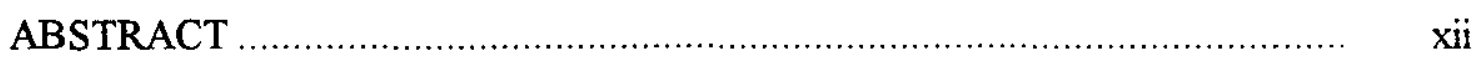

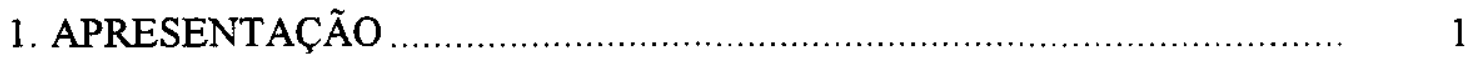

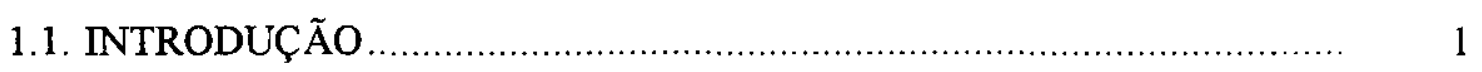

1.2. DESCRIÇÃO SUCINTA DOS CAPÍTULOS ......................................... 8

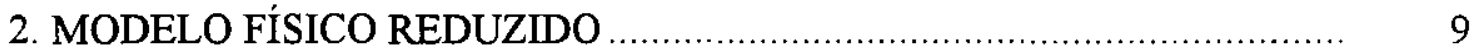

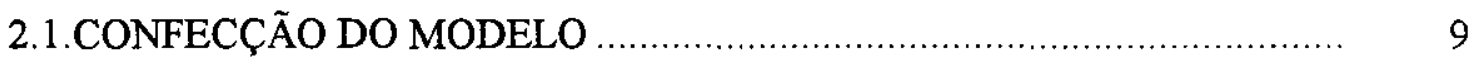

2.2.FATORES DE ESCALA E ANÁLISE DIMENSIONAL ...................... 15

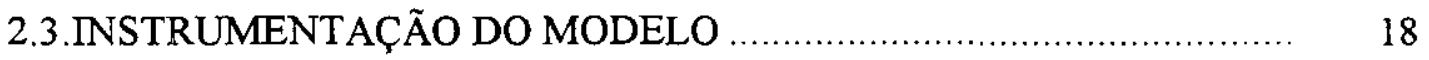

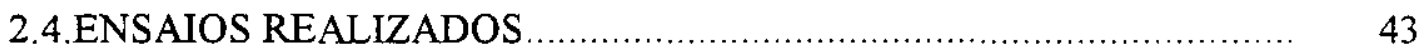

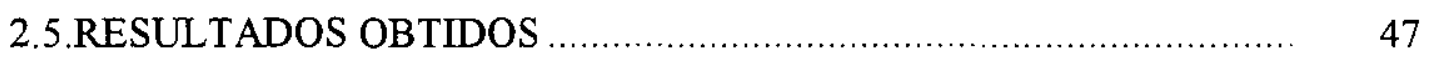

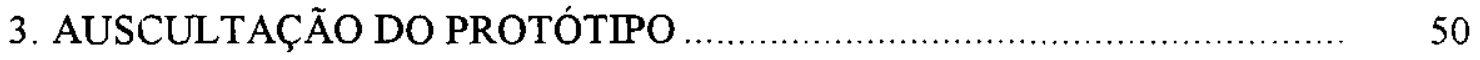


3.2. O SISTEMA SEGURANÇA DE BARRAGEM.

3.3. AUSCULTAÇÃO DA BARRAGEM NOVA AVANHANDAVA

3.4. INSTRUMENTAÇÃO PARA TENSÕES NAS ESTRUTURAS DE CONCRETO DE NOVA AVANHANDAVA.

3.5. PONTOS INSTRUMENTADOS.

4. MODELAGEM POR ELEMENTOS FINITOS

4.1. MODELAGEM TRIDIMENSIONAL

4.2. MODELO NUMÉRICO BIDIMENSIONAL

5. COMPARAÇÕES DOS RESULTADOS

5.2. COMPARAÇÃO ENTRE MODELO FÍSICO E MODELO NUMÉRICO BIDIMENSIONAL

5.3. COMPARAÇÃO ENTRE MODELO FÍSICO E MODELO NUMÉRICO TRIDIMENSIONAL.

5.4. COMPARAÇÃO ENTRE MODELOS NUMÉRICOS BIDIMENSIONAL E TRIDIMENSIONAL.

5.5. COMPARAÇÃO ENTRE MODELO NUMÉRICO TRIDIMENSIONAL E PROTÓTIPO

5.6. RESUMO DAS COMPARAÇÕES .

6. CONCLUSÕES 


\section{LISTA DE FIGURAS}

FIGURA 01 - Plano geral das estruturas de concreto da Barragem Nova Avanhandava, mostrando o sentido do fluxo do Rio Tietê e o posicionamento do bloco Tomada d'Água/Casa de Força 2 (TA-2/CF-2)

FIGURA 02 - Equipamento utilizado para movimentar o modelo.

FIGURA 03 - Aspecto da maquete preliminar, vista a jusante, sem a parte superior da caixa espiral.

FIGURA 04 - Fase de ajustagem dos diversos blocos sobre o berço de madeira. Na parte inferior, base em aço para montagem dos ensaios.

FIGURA 05 - Fase de ajustagem dos blocos para posteriormente serem instrumentados e colados.

FIGURA 06 - Fase de ajustes das peças com um paramento de montante......

FIGURA 07 - Fase de ajustes das peças, vista com dois paramentos de montante

FIGURA 08 - Montagem da grelha espacial que forma a parte da fundação. . 
FIGURA 09 - Corte transversal do modelo físico reduzido, mostrando a Tomada d'Água, à esquerda; Caixa Espiral, ao centro; Tubo de Sucção e Canal de Fuga, abaixo e à direita; e rocha de fundação

FIGURA 10 - Detalhes da instrumentação em corte transversal do modelo. ..

FIGURA 11 - Vista do dispositivo de montagem dos defletômetros, utilizados para as medidas dos deslocamentos.

FIGURA 12 - Vista lateral do modelo montado sobre a base. Vê-se, já montada, a estrutura para suporte dos defletômetros.

FIGURA 13 - Aquisição de dados.

FIGURA 14 - Vista do painel de entrada para o sistema de aquisição de dados.

FIGURA 15 - Preparação do bloco compensador, onde são vistos os extensômetros colados e a fase de ligação dos fios de conexão.

FIGURA 16 - Vista do bloco compensador, já montado, sobre um berço de espuma de plástico e os cabos de ligação.

FIGURA 17 - Corte no nivel EE do bloco Tomada d'Água/Casa de Força, mostrando as posições das seç̧ões R1 a R5 da Caixa Espiral..

FIGURA 18 - Secção R3 da Caixa Espiral, mostrando detalhes da instrumentação do modelo

FIGURA 19 - Secções R2 e R5 da Caixa Espiral, mostrando detalhes da instrumentação do modelo.

FIGURA 20 - Seç̧ões R1 e R4 da Caixa Espiral, mostrando detalhes da instrumentação do modelo. 
FIGURA 21 - Bloco da Caixa Espiral e Canal de Fuga já usinado.

FIGURA 22 - Vista da instrumentação com extensômetros elétricos de resistência instalada no teto da caixa espiral

FIGURA 23 - Fase de instrumentação e montagem, vista do interior da caixa espiral.

FIGURA 24 - Corte no nível AA do modelo físico reduzido

FIGURA 25 - Detalhes da instrumentação do contato estrutura-fundação do modelo no nível AA

FIGURA 26 - Corte no nível BB do modelo fisico reduzido.

FIGURA 27 - Detalhes do dinamômetro para medida da força de protensão nos pré-distribuidores do modelo

FIGURA 28 - Corte no nível DD do modelo físico reduzido

FIGURA 29 - Detalhes da instrumentação da caixa espiral do modelo no nível DD

FIGURA 30 - Detalhes da instrumentação da Caixa Espiral do modelo no nível EE.

FIGURA 31 - Corte no nivel FF do modelo físico reduzido.

FIGURA 32 - Detalhes da instrumentação da Caixa Espiral do modelo no nivel FF.

FIGURA 33 - Vista do dispositivo de aplicação de carga hidrostática nos paramentos de montante.

FIGURA 34 - Fase de montagem e proteção da instrumentação com uma camada de silicone (SYL-GARD 170 A/B) para preeenchimento com mercúrio do carregamento hidráulico..... 
FIGURA 35 - Vista do corpo de prova do material de fundação, para determinação das propriedades elásticas.

FIGURA 36 - Vista do conjunto de ensaio, mostrando-se o cabeamento, o dispositivo de fixação dos defletômetros e os demais dispositivos.

FIGURA 37 - Secção do tensômetro para concreto armado (RC).

FIGURA 38 - Secção do tensômetro para concreto (TC).

FIGURA 39 - Perspectiva do recesso para instalação dos Tensômetros para concreto.

FIGURA 40 - Localização do TC-304

FIGURA 41 - Localização dos TC-305, TC-306 e TC-307.

FIGURA 42 - Localização dos TC-312, TC-313 e TC-314.

FIGURA 43 - Vista geral do modelo numérico tridimensional indeformado.

FIGURA 44 - Vista lateral do modelo numérico tridimensional indeformado.

FIGURA 45 - Modelo numérico tridimensional deformado sob a ação do peso da máquina.

FIGURA 46 - Modelo numérico tridimensional deformado sob a ação da protensão dos pré-distribuidores.

FIGURA 47 - Modelo numérico tridimensional deformado sob a ação da carga hidrostática nos paramentos de montante

FIGURA 48 - Modelo numérico tridimensional deformado pela ação da pressão hidrostática interna a montante e a jusante. 
FIGURA 49 - Modelo numérico tridimensional da secção R3 indeformado. .

FIGURA 50 - Modelo numérico tridimensional da secção R3 deformada sob a ação do peso da máquina.

FIGURA 51 - Modelo numérico tridimensional da secção R3 deformada sob a ação da protensão dos pré-distribuidores

FIGURA 52 - Modelo numérico tridimensional da secção R3 deformada sob a ação da carga hidrostática nos paramentos de montante.

FIGURA 53 - Modelo numérico tridimensional da secção R3 deformado sob a ação da pressão hidrostática interna a montante e a jusante. .

FIGURA 54 - Modelo numérico tridimensional da secção R3 mostrando as isotensões para tensão normal na direção $Z$ sob a ação do peso da máquina.

FIGURA 55 - Modelo numérico tridimensional da secção R3 mostrando as isotensões para tensão normal na direção $Z$ sob a ação da protensão dos pré-distribuidores.

FIGURA 56 - Modelo numérico tridimensional da secção R3 mostrando as isotensões para tensão normal na direção $Z$ sob a ação da carga hidrostática nos paramentos de montante.

FIGURA 57 - Modelo numérico tridimensional da secção R3 mostrando as isotensões para tensão normal na direção $Z$ sob a ação da pressão hidrostática interna a montante e a jusante.

FIGURA 58 - Modelo numérico tridimensional da secção R3 mostrando as isotensões para tensão normal na direção $\mathrm{Y}$ sob a ação do peso da máquina. 
FIGURA 59 - Modelo numérico tridimensional da secção R3 mostrando as isotensões para tensão normal na direção $Y$ sob a ação da protensão dos pré-distribuidores.

FIGURA 60 - Modelo numérico tridimensional da secção R3 mostrando as isotensões para tensão normal na direção $Y$ sob a ação da carga hidrostática nos paramentos de montante.

FIGURA 61 - Modelo numérico tridimensional da seç̧ão R3 mostrando as isotensões para tensão normal na direção $Y$ sob a ação da pressão hidrostática interna a montante e a jusante

FIGURA 62 - Modelo numérico bidimensional da secção R3 indeformado....

FIGURA 63 - Modelo numérico bidimensional da seç̧ão R3 deformado sob a ação do peso da máquina.

FIGURA 64 - Modelo numérico bidimensional da secção R3 deformado sob a ação da força de protensão dos pré-distribuidores.

FIGURA 65 - Modelo numérico bidimensional da secção R3 deformado sob a ação da pressão hidrostática interna.

FIGURA 66 - Modelo numérico bidimensional da secção R3 mostrando as isotensões para tensão normal na direção $\mathrm{Y}$ sob a ação do peso da máquina.

FIGURA 67 - Modelo numérico bidimensional da secção R3 mostrando as isotensões para tensão normal na direção $Y$ sob a ação da protensão dos pré-distribuidores

FIGURA 68 - Modelo numérico bidimensional da secção R3 mostrando as isotensões para tensão normal na direção $\mathrm{Y}$ sob a ação da pressão hidrostática interna 
FIGURA 69 - Modelo numérico bidimensional da secção R3 mostrando as isotensões para tensão normal na direção $Z$ sob a ação do peso da máquina.

FIGURA 70 - Modelo numérico bidimensional da secção R3 mostrando as isotensões para tensão normal na direção $Z$ sob a ação da protensão dos pré-distribuidores.

FIGURA 71 - Modelo numérico bidimensional da secção R3 mostrando as isotensões para tensão normal na direção $Z$ sob a ação da pressão hidrostática interna.

FIGURA 72 - Gráfico Tensões (MPa) X Pontos instrumentados da secção R3, comparando resultados dos modelos físico (MFR-1) e numérico bidimensional (BI-1), sob a ação do peso da máquina e protensão dos pré-distribuidores.

FIGURA 73 - Gráfico Tensões (MPa) X Pontos instrumentados da secção $R 3$, comparando resultados dos modelos físico (MFR-3) e numérico bidimensional (BI-3), sob a ação da pressão hidrostática interna a montante e a jusante.

FIGURA 74 - Gráfico Tensões (MPa) X Pontos instrumentados da seç̧ão R3, comparando resultados dos modelos físico (MFR-1) e numérico tridimensional (TRI-1), sob a ação do peso da máquina e pressão dos pré-distribuidores.

FIGURA 75 - Gráfico Tensão Medida (MPa) X Pontos instrumentados da secção R3, comparando resultados dos modelos físico (MFR2) e numérico tridimensional (TRI-2), sob a ação da carga hidrostática nos paramentos de montante. 
FIGURA 76 - Gráfico Tensão (MPa) X Pontos instrumentados da seç̧ão R3, comparando resultados dos modelos físico (MFR-3) e numérico tridimensional (TRI-3), sob a ação da pressão hidrostática interna a montante e a jusante

FIGURA 77 - Gráfico Tensão (MPa) X Pontos instrumentados da secção R3, comparando resultados dos modelos numéricos bidimensional (BI-11) e tridimensional (TRI-11), sob a ação do peso da máquina

FIGURA 78 - Gráfico Tensão (MPa) X Pontos instrumentados da secção R3, comparando resultados dos modelos numéricos bidimensional (BI-12) e tridimensional (TRI-12), sob a ação da protensão dos pré-distribuidores.

FIGURA 79 - Gráfico Tensão (MPa) X Pontos instrumentados da secção R3, comparando resultados dos modelos numéricos bidimensional (BI-3) e tridimensional (TRI-3), sob a ação da pressão hidrostática interna a montante e a jusante

FIGURA 80 - Gráfico Tensão (MPa) medida durante o enchimento do reservatório (PROTIGO) e operação (PROTUAL) X Pontos com Tensômetros para Concreto no protótipo.

FIGURA 81 - Gráfico Tensão (Mpa) X Pontos com Tensômetros para Concreto, comparando resultados do modelo numérico tridimensional (TRI-TOTAL) e do protótipo (PROTUAL) ..... 


\section{LISTA DE TABELAS}

TABELA 1 - Posições dos pontos nas respectivas regiões

TABELA 2 - Tensão (MPa) X Pontos instrumentados da secção R3, comparando resultados dos modelos fisico (MFR-1) e numérico bidimensional (BI-1), sob a ação do peso da máquina e protensão dos pré-distribuidores.

TABELA 3 - Tensões (MPa) X Pontos instrumentados da secção R3, comparando resultados dos modelos fisico (MFR-3) e numérico bidimensional (BI-3), sob a ação da pressão hidrostática interna a montante e a jusante

TABELA 4 - Tensão (MPa) X Pontos instrumentados da secção R3, comparando resultados dos modelos físico (MFR-1) e numérico tridimensional (TRI-1), sob a ação do peso da máquina e protensão dos pré-distribuidores 
TABELA 5 - Tensão (MPa) X Pontos instrumentados da seç̧ão R3, comparando resultados dos modelos físico (MFR-2) e numérico tridimensional (TRI-2), sob a ação da carga hidrostática nos paramentos de montante.

TABELA 6 - Tensão (MPa) X Pontos instrumentados da secção R3, comparando resultados dos modelos fisico (MFR-3) e numérico tridimensional (TRI-3), sob a ação da pressão hidrostática interna a montante e a jusante

TABELA 7 - Tensão (MPa) X Pontos instrumentados da secção R3, comparando resultados dos modelos numéricos bidimensional (BI-11) e tridimensional (TRI-11), sob a ação do peso da máquina.

TABELA 8 - Tensão (MPa) X Pontos instrumentados da seç̧ão R3, comparando resultados dos modelos numéricos bidimensional (BI-12) e tridimensional (TRI-12), sob a ação da protensão dos pré-distribuidores

TABELA 9 - Tensão (MPa) X Pontos instrumentados da secção R3, comparando resultados dos modelos numéricos bidimensional (BI-3) e tridimensional (TRI-3), sob a ação da pressão hidrostática interna a montante e a jusante

TABELA 10 - Tensão (Mpa) medida durante o enchimento do reservatório (PROTIGO) e operação (PROTUAL) X Pontos instrumentados com Tensômetros para Concreto no protótipo.

TABELA 11 - Tensão (MPa) X Pontos instrumentados com Tensômetros para Concreto no protótipo, comparando resultados do modelo numérico tridimensional (TRI-TOTAL) e do protótipo (PROTUAL). 


\section{RESUMO}

BERNARDES, H.M. Estudo do comportamento estrutural da caixa espiral de turbina

Kaplan por modelo físico e método numérico. São Carlos, 1995. 132p. Dissertação (Mestrado) - Escola de Engenharia de São Carlos, Universidade de São Paulo.

O presente trabalho se propõe a estabelecer uma comparação entre os resultados de ensaios em modelo fisico da Caixa Espiral de uma turbina tipo Kaplan, caso da Barragem Nova Avanhandava, e os resultados de auscultação do protótipo, através de uma comparação intermediária com modelos numéricos, baseados no Método dos Elementos Finitos. São mostrados os procedimentos seguidos na construção e ensaios do modelo físico, os métodos utilizados na coleta e análise de dados de auscultação da barragem, e as modelagens plana e tridimensional para processamento numérico.

Palavras-chave: Método dos Elementos Finitos - Análise Experimental - Barragens de Concreto - Modelagem 


\begin{abstract}
BERNARDES, H.M. The study of the structural behavior of the Kaplan turbine spiral box by physical model and numeric method. São Carlos, 1995. 132p. Dissertação (Mestrado) - Escola de Engenharia de São Carlos, Universidade de São Paulo
\end{abstract}

This work aims to establish a comparison between the results of tests on a physical model of the spiral box of a turbine Kaplan type (that is the case of Nova Avanhandava Power Plant), and the results of auscultation of the prototype by means of an intermediary comparison using numeric models based on the Finite Element Method. It is presented the proceedings followed in the construction and tests of the physical model, the methods used in the collection and analysis of data of the auscultation of the dam, and the plane and tridimensional modelling for numeric processing

Key-words: Finite Element Method - Experimental Analysis - Concrete Dams Modelling 


\section{CAPÍTULO 1}

\section{APRESENTAÇÃO}

\subsection{INTRODUÇÃO}

Este trabalho se refere à análise de tensões, em regime elástico, sob a ação de cargas hidrostáticas, sobrecarga devida ao peso da unidade geradora e força de protensão na caixa espiral de uma turbina tipo Kaplan, caso da Usina Nova Avanhandava, objetivando comparar resultados de ensaios sobre modelo físico e de auscultação do protótipo por intermédio de modelos matemáticos.

Construída entre 1979 e 1982, com 302,4 MW de capacidade nominal, a usina localiza-se no Rio Tietê, em Buritama, distante cerca de $550 \mathrm{Km}$ na direção noroeste da capital do estado de São Paulo, e é propriedade da Companhia Energética de São Paulo (CESP).

O Aproveitamento Múltiplo de Nova Avanhandava, do qual a usina é parte, além da exploração do potencial hidrelétrico, garantiu a navegabilidade do curso fluvial e a conseqüente implantação da Hidrovia Tietê-Paraná, através da construção de uma eclusa.

Além de três conjuntos Tomada d'Água/Casa de Força (TA/CF), as obras de concreto consistem de vertedouro de superficie com 4 comportas segmento, muros de transição e a eclusa, totalizando um volume de 763 mil m3 de material lançado, de acordo com publicação do COMITÊ BRASILEIRO DE GRANDES BARRAGENS (1982). Na Figura 1 pode ser visto o arranjo dos blocos de concretage 


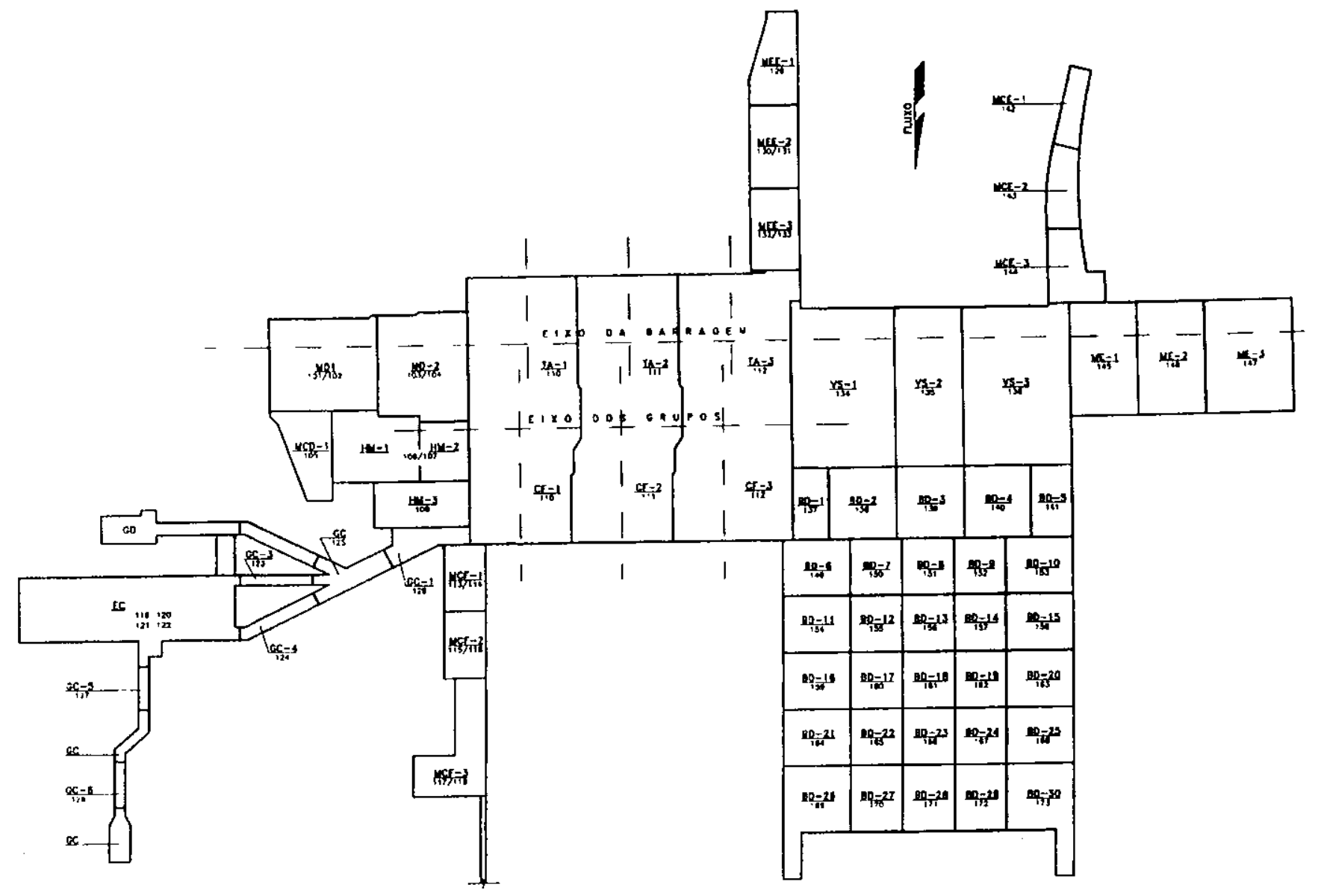

FIGURA 1 - Plano Geral das estruturas de concreto da Barragem Nova Avanhandava, mostrando o sentido fluxo do Rio Tietê e o posicionamento do bloco Tomada d'Água/Casa de Força 2 (TA-2/CF-2) 
A Casa de Força é dividida em 3 blocos onde se localizam as 3 unidades geradoras, tipo Kaplan, com diâmetro de 7,50 m, capacidade de 100,8 MW, e caixa espiral de concreto armado.

A análise da estrutura da caixa espiral é tarefa considerada complexa, conforme MASON (1988), devido à sua geometria e às pequenas tolerâncias definidas pelos fabricantes de unidades geradoras.

Com o objetivo de estudar as tensões, construiu-se o modelo físico reduzido de um dos blocos que contém uma unidade geradora, com sua respectiva tomada d'água, caixa espiral, tubo de sucção e canal de fuga, e é chamado de Conjunto Tomada d'Água/Casa de Força (TA/CF).

Segundo VARGAS (1985), a utilização de modelos pelo homem corresponde à tentativa de aproximar algo que está em sua mente a algo que está fora dela. Um modelo pode ser um conjunto de proposições que descrevem fenômenos, como os símbolos lingüísticos, ou um conjunto de imagens que representam teorias, como o modelo atômico de Bohr. Em aplicações tecnológicas, é comum ser um objeto físico construído em determinada escala, representando um protótipo submetido a fenômenos naturais (modelo físico) ou um conjunto de números que tenha a estrutura ou forma semelhante à de uma realidade física (modelo matemático).

A utilização de modelos físicos de estruturas para construção de barragens teve início com a proliferação de grandes obras que seguiu o início do aproveitamento em escala industrial da energia hidrelétrica.

UNITED STATES Bureau of Reclamation (USBR) (1976) cita a construção, nos Estados Unidos, do modelo em concreto da barragem experimental Stevenson Creek, em escala 1/12, e do modelo da Barragem Gibson, pelo Comittee on Arch Dam Investigation, criado em 1922. Os trabalhos foram realizados com a colaboração do USBR.

A mesma fonte relata a construção, em 1930, do modelo da Barragem Hoover, com o objetivo de verificar os métodos analíticos. Segundo SABNIS et al. 
(1983) tratava-se de um modelo em escala 1/240.

De acordo com publicação do UNITED STATES Department of the Interior (1987), do qual o USBR é parte, o objetivo inicial do órgão subordinado era "prover a recuperação das terras áridas e semi-áridas do oeste". A expansão dos objetivos possibilitou valiosas contribuições para a construção de hidrelétricas.

Em 1926, A. Mesnager e J. Veyrier desenvolveram modelos das barragens La Bromme e Marège, conforme reportam ROCHA \& SERAFIM (1986).

Segundo HETÉNYI (1950) o modelo dessa barragem, contruída no Boulder Canyon, Estados Unidos, representou um marco no estudo de estruturas através de modelos físicos.

Em Lisboa, no ano de 1946, foi criado o Laboratório Nacional de Engenharia Civil (LNEC), seguindo a tendência de proliferação das análises experimentais. O método de ensaio de modelos em gesso de barragens abóboda, desenvolvido pelo LNEC, obteve grande sucesso, conforme VARGAS (1985).

Vários ensaios de modeios de barragens em abóboda foram realizados no LNEC, como relatam ROCHA \& SERAFIM (1986). São exemplos os de Santa Luzia(1947), Castelo do Bode (1950), Cabril (1950), Venda Nova (1950), Bouçã (1955), Salamonde (1955), Ait Chouarhit (1955), Caniçada (1956), Aldeadavila (1958), Slettedalen (1958), Zaouia N'Ourbaz (1958), Alvito (1959), Eume (1959), e outros.

Nos Estados Unidos, de acordo com ROCHA et al. (1964), o USBR, em Denver, Colorado, construiu modelos das barragens Parker (1939), Seminoe (1939), Hungry Horse (1956), e outras.

Curso ministrado pelo Núcleo de Ligação Industrial da Escola Politécnica da UNIVERSIDADE DE SÃO PAULO (USP) (1989) afirma que a utilização de métodos experimentais, no projeto e controle de barragens de concreto, difundiu-se particularmente após a II Guerra, ao longo das décadas de 40, 50 e 60. 
No Brasil, a Barragem Salto Funil, em arco de dupla curvatura, localizada no Rio Paraíba, foi, provavelmente, a primeira barragem a contar com estudos em modelo físico estrutural. Como consta em publicação do BRAZILIAN COMITTEE ON LARGE DAMS (1982), construiu-se um modelo tridimensional dessa barragem, na escala 1/200, ensaiado no LNEC em 1960

Em função da geografia das principais bacias hidrográficas brasileiras, que normalmente constituem vales abertos, as grandes barragens foram concebidas com esquemas estruturais do tipo gravidade, ao invés das abóbodas, difundidas na Europa.

A partir do início dessas construções, o país teve que responder aos desafios tecnológicos surgidos.

No estado de São Paulo, a construção do então chamado Complexo Hidrelétrico de Urubupungá, que incluia as usinas de Jupiá e Ilha Solteira, no Rio Paraná e Água Vermelha, no Rio Grande, levou a CESP a criar o Laboratório Central de Engenharia Civil (LCEC), localizado na cidade de Ilha Solteira. Com cerca de 400 funcionários e 20 engenheiros, o LCEC foi concebido nos moldes do LNEC, de Portugal, com o objetivo de centralizar as atividades de investigação prática da CESP e é, até hoje, um dos maiores laboratórios de engenharia da América Latina.

Em regime de cooperação, a CESP e a Escola de Engenharia de São Carlos (EESC) ensaiaram, no final dos anos 60, um modelo estrutural da Viga Munhão e Vertedouro da Usina Ilha Solteira.

O modelo do Conjunto Tomada d'Água/Casa de Força da Usina Nova Avanhandava foi construído no LCEC, entre os anos de 1979 e 1980.

ROCHA*, consultor do LNEC, em uma de suas passagens pelo laboratório de Ilha Solteira, afirmou tratar-se do primeiro modelo do gênero para uma barragem tipo gravidade, com tal grau de detalhamento, feito em todo o mundo.

${ }^{*}$ ROCHA, M. (PORTUGAL. Laboratório Nacional de Engenharia Civil) Comunicaçâo pessoal. 
De fato, o ensaio relatado por SILVEIRA et al. (1987) da Casa de Força de Carrapatelo, por exemplo, se deu sobre modelo na escala $1 / 200$, e o objeto do estudo não eram as tensões na caixa espiral, mas nas fundações.

Para o controle das condições de segurança de grandes barragens, dadas as proporções que um acidente pode alcançar e a responsabilidade envolvida, não basta a confecção de modelos. Realiza-se o controle da segurança, através de sistemas apropriados de observação do comportamento estrutural frente às ações que podem ocorrer durante as várias fases de existência da obra, como o sistema descrito em documento do UNITED STATES Bureau of Reclamation (1987).

Utilizando dados de tensões medidas na caixa espiral da Usina Nova Avanhandava, OLIVEIRA et al. (1986) realizaram uma análise comparativa, mostrando que as tensões medidas apresentaram-se inferiores ao previsto em projeto.

Além da utilização de modelos e de leituras de instrumentação no protótipo, os modelos matemáticos são uma ferramenta para analisar as estruturas de barragens.

As barragens gravidade podem ser imaginadas como uma série de vigas em balanço justapostas. A tendência de giro ocasionado em cada viga pela diferença de rigidez com a vizinha, inspirou o nome em inglês Trial-Load Twist para esse método de cálculo, mencionado pelo UNITED STATES Bureau of Reclamation (1976).

$\mathrm{Na}$ segunda metade deste século passaram por grande desenvolvimento os métodos de análise numérica aplicados a barragens (ZAGOTTIS, 1976). O Método das Diferenças Finitas e o Método dos Elementos Finitos (MEF) difundemse nos anos 60. Na década de 70 surge o Método dos Elementos de Fronteira, ou de Contorno, e na de 80 o Método dos Elementos Discretos.

Devido à sua versatilidade, a utilização de programas baseados no MEF generalizou-se particularmente após o surgimento do microcomputador, no final da década de 70 , fato que levou à drástica redução dos custos de processamento 
Segundo PEDRO* apud PEDRO et al. (1988), "...o enorme progresso verificado na capacidade dos computadores digitais permitiu o grande desenvolvimento dos métodos matemáticos nas últimas décadas. A utilização de métodos experimentais, no entanto, é ainda desejável em muitos casos, designadamente na fase final do projeto de grandes estruturas, em estudos de investigação e no ensino".

$\mathrm{Na}$ análise de barragens podem ser usados programas com elementos finitos bidimensionais ou tridimensionais, a fim de se determinar deslocamentos, tensões e deformações provocados por forças concentradas, campos de pressão, forças gravitacionais e magnéticas, gradientes de temperatura e deslocamentos impostos.

MACKERLE (1986) mostra informações sobre 41 programas para microcomputador baseados no Método dos Elementos Finitos. Em outro artigo, MACKERLE (1988) faz um adendo com informações sobre mais 33 programas.

Contando com a disponibilidade de um desses programas, o SAP-90, da série SAP (Structural Analysis Program) iniciada em 1970 para equipamentos de grande porte, foi possível desenvolver um modelo numérico do conjunto TA/CF de Nova Avanhandava. Conforme WILSON \& HABIBULLAH (1989), seus criadores, o programa possibilita a utilização de elementos finitos lineares, de superficie e sólidos bi e tridimensionais.

O objetivo do presente trabalho é comparar os resultados da análise de tensões através de modelos com os resultados da auscultação do protótipo. Como o número de pontos instrumentados no modelo físico reduzido é muito superior ao existente no protótipo, e suas posições não são coincidentes, utilizou-se uma análise

${ }^{*}$ PEDRO, J.O. (1986) Análise experimental de tensões. Lisboa, LNEC/Associação Portuguesa de Análise Experimental de Tensões apud PEDRO, J.O.; DUARTE, R.C.T.; PINA, C.A.B. (1988) Actividade do Laboratório Nacional de Engenharia Civil no domínio da mecânica estrutural: situação atual e perspectivas de desenvolvimento. Lisboa, Laboratório Nacional de Engenharia Civil, p.2 (Laboratório Nacional de Engenharia Civil. Memória, 723) 
numérica, através do software SAP-90, na tentativa de obter um parâmetro intermediário de comparação.

\subsection{DESCRIÇÃO SUCINTA DOS CAPÍTULOS}

Com o objetivo de proporcionar uma apresentação clara e objetiva, o trabalho será dividido na forma que se apresenta a seguir.

No capítulo 2 serão descritos os ensaios procedidos e os resultados obtidos com as leituras das deformações. Os resultados não chegaram a ser totalmente analisados.

O capítulo 3 trata dos instrumentos instalados no conjunto TA/CF da Usina Nova Avanhandava e de levantamento das leituras neles realizadas, visando proceder comparação com os resultados obtidos no modelo fisico reduzido.

No capítulo 4 é feita a descrição da montagem do modelo numérico e de seu processamento, com comentários acerca dos critérios que prevaleceram ao estabelecerem-se os parâmetros envolvidos.

As comparações entre os resultados obtidos no ensaio do modelo físico, no processamento matemático e na auscultação da caixa espiral são apresentadas no capítulo 5 , e as conclusões compõem o capítulo 6 . 


\section{CAPÍTULO 2 \\ MODELO FÍSICO REDUZIDO}

\subsection{CONFECÇÃO DO MODELO}

O modelo físico da unidade típica do conjunto Tomada d'Água/Casa de Força da Usina Nova Avanhandava foi construído em material acrílico, visando ensaio em regime elástico, conforme constam em relatórios da CESP (1980a,b,c,d,e), no qual foram obtidas deformações a partir da aplicação de 3 casos de carregamentos externos.

HOSSDORF (1974) considera que o problema básico da análise experimental de estruturas é o estabelecimento, por meios diretos, do equilíbrio das cargas externas com as tensões internas. A determinação das deformações, normalmente, é apenas um estágio intermediário para a determinação das tensões, pela utilização das relações da Teoria da Elasticidade.

Para medir as deformações são utilizadas técnicas consagradas, como foto-elasticidade ou extensômetros elétricos, cujo surgimento nos anos 40, para SABNIS et al. (1983), estabeleceu a base para o surgimento da moderna análise experimental de estruturas por meio de modelos.

Também através da medição das deformações, é possível determinar-se as propriedades elásticas dos materiais utilizados nos modelos estruturais, como o módulo de elasticidade (E) e o coeficiente de Poisson ( $v$ ). 
HOSSDORF (1974) destaca também que, usualmente, o estado de deformação nos modelos é medido apenas na superfície, devido a razões de ordem técnica. Assim sendo, nos ensaios em geral não são consideradas as tensões atuando nas direções perpendiculares à superfície, exceto nos pontos de aplicação de forças.

AZEVEDO et al. (1987) descrevem equipamentos utilizados no LNEC, para a aplicação de cargas em modelos obedecendo a uma proporção em relação ao protótipo.

Dentre as cargas atuantes numa barragem, o peso próprio, por tratar-se de carga volumétrica, é das que apresenta maior grau de dificuldade para a simulação.

SERAFIM \& COSTA (1960) apresentam métodos de consideração do peso próprio em modelos de barragens, como o método da inversão, de imersão num líquido denso, de aplicação de cargas concentradas ao modelo e da construção por fases.

No ensaio do modelo de Nova Avanhandava não foi levada em consideração a atuação do peso próprio, pelas dificuldades operacionais de aplicação de quaisquer dos métodos conhecidos. Os extensômetros foram calibrados antes dos ensaios, de modo a desconsiderar as deformações causadas pelo peso próprio. No entanto, sua ação tornou necessário o uso de equipamento especial para a movimentação do modelo no interior do laboratório, como mostra a Figura 2.

Devido à complexidade da sua geometria, a confeç̧ão do modelo exigiu 12 pranchas fornecidas pela projetista com desenhos detalhados através de diversos cortes. Ainda assim, foi necessário fazer inicialmente uma maquete em cortiça, a fim de facilitar a visualização em três dimensões, mostrada na Figura 3.

Algumas simplificações julgadas secundárias foram adotadas. Estruturas leves situadas sobre a Casa de Força foram suprimidas e o número de palhetas do pré-distribuidor foi reduzido de 15 para 8 . 


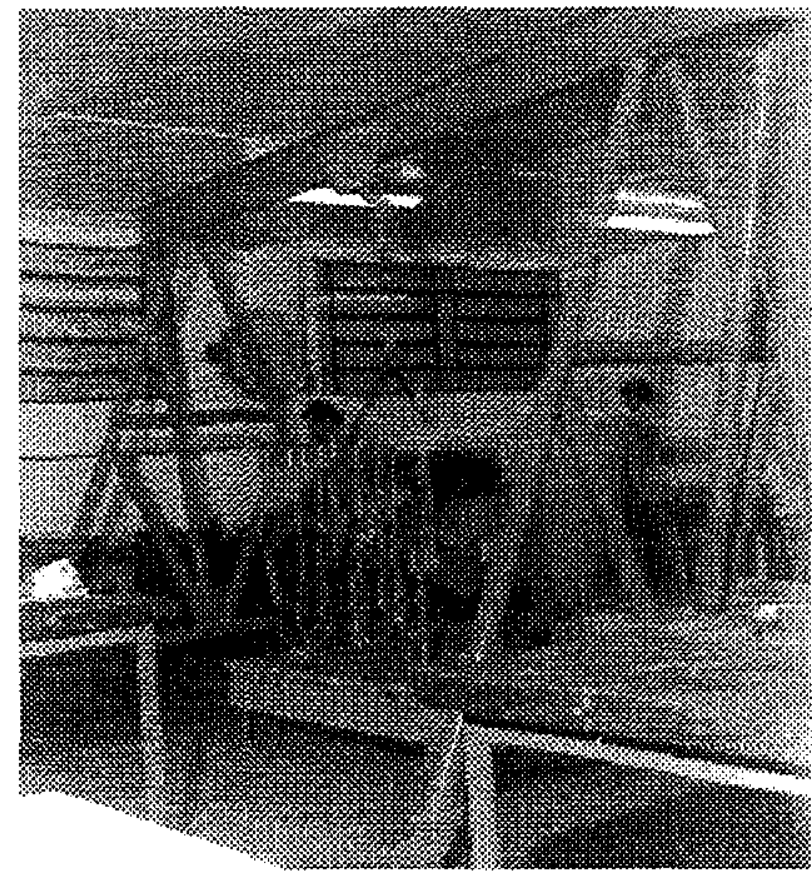

FIGURA 2 - Equipamento utilizado para movimentar o modelo. (Fonte: CESP)

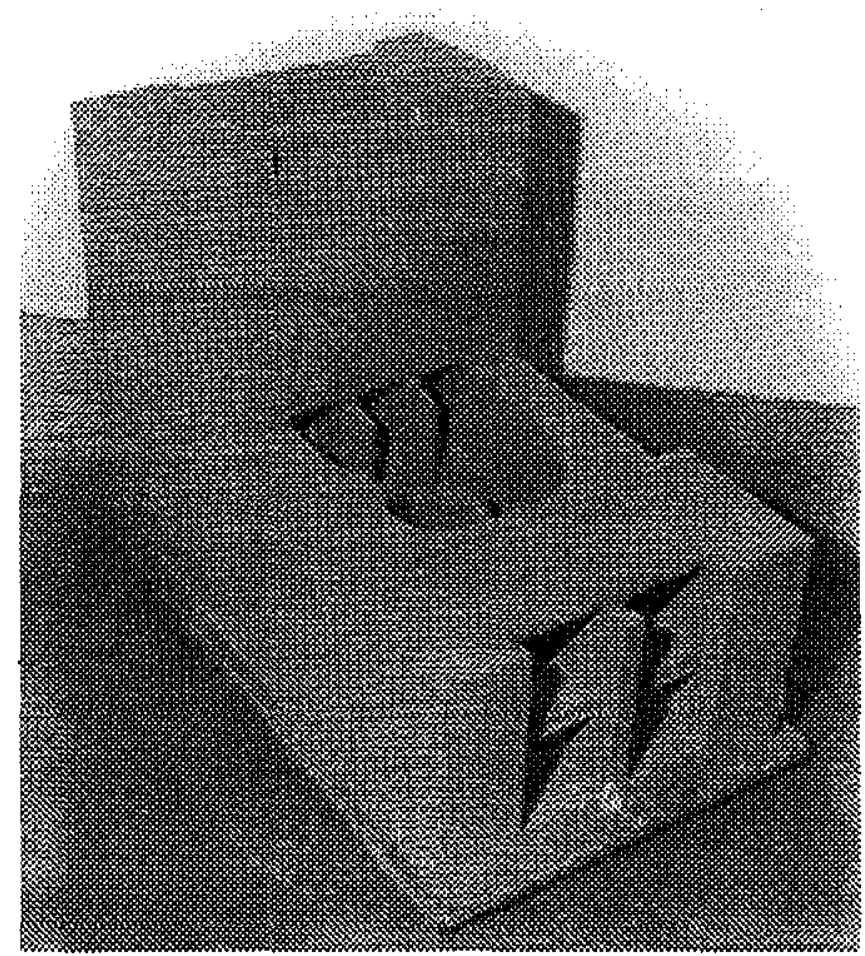

FIGURA 3 - Aspecto da maquete preliminar, vista a jusante, sem a parte superior da caixa espiral. (Fonte: CESP) 
Foram utilizadas placas de acrílico de espessuras variando de $5 \mathrm{~mm}$ a $40 \mathrm{~mm}$, coladas com resina acrílica polimerizável, formando blocos posteriormente recortados e entalhados de modo a obter-se as formas e dimensões desejadas, como na seqüência mostrada nas Figuras 4 a 7 .

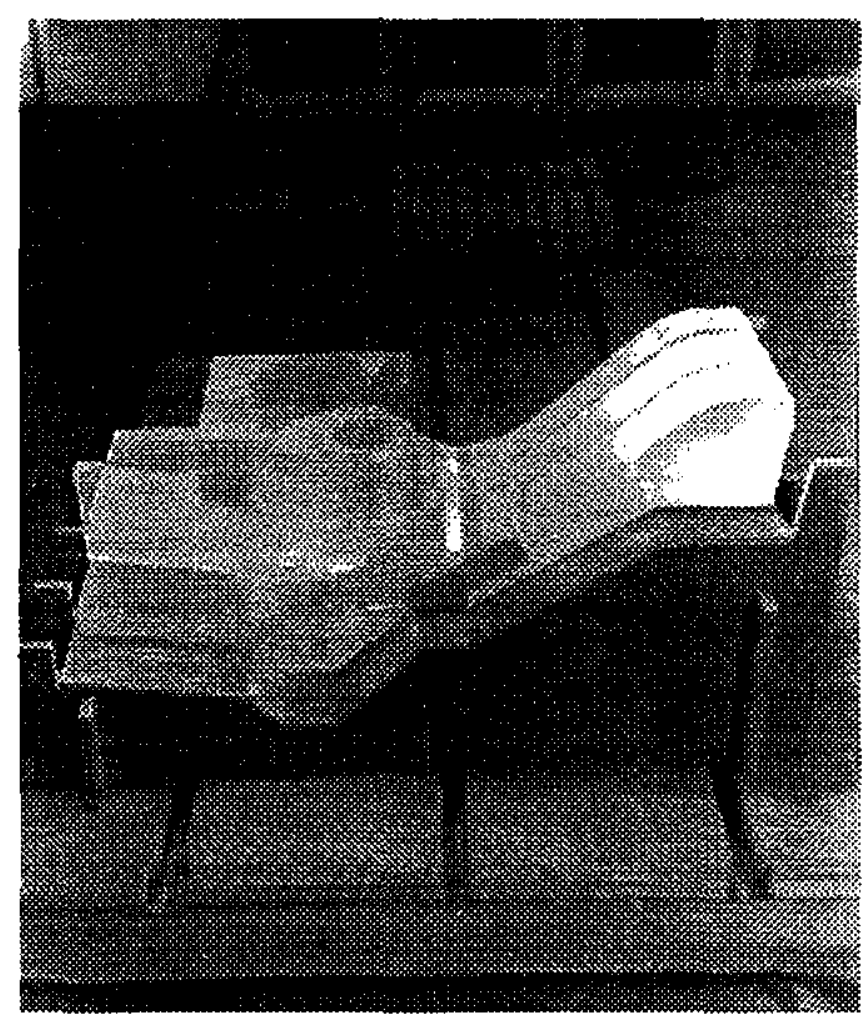

FIGURA 4 - Fase de ajustagem dos diversos blocos sobre o berço de madeira. Na parte inferior, base em aço para montagem dos ensaios. (Fonte: CESP) 


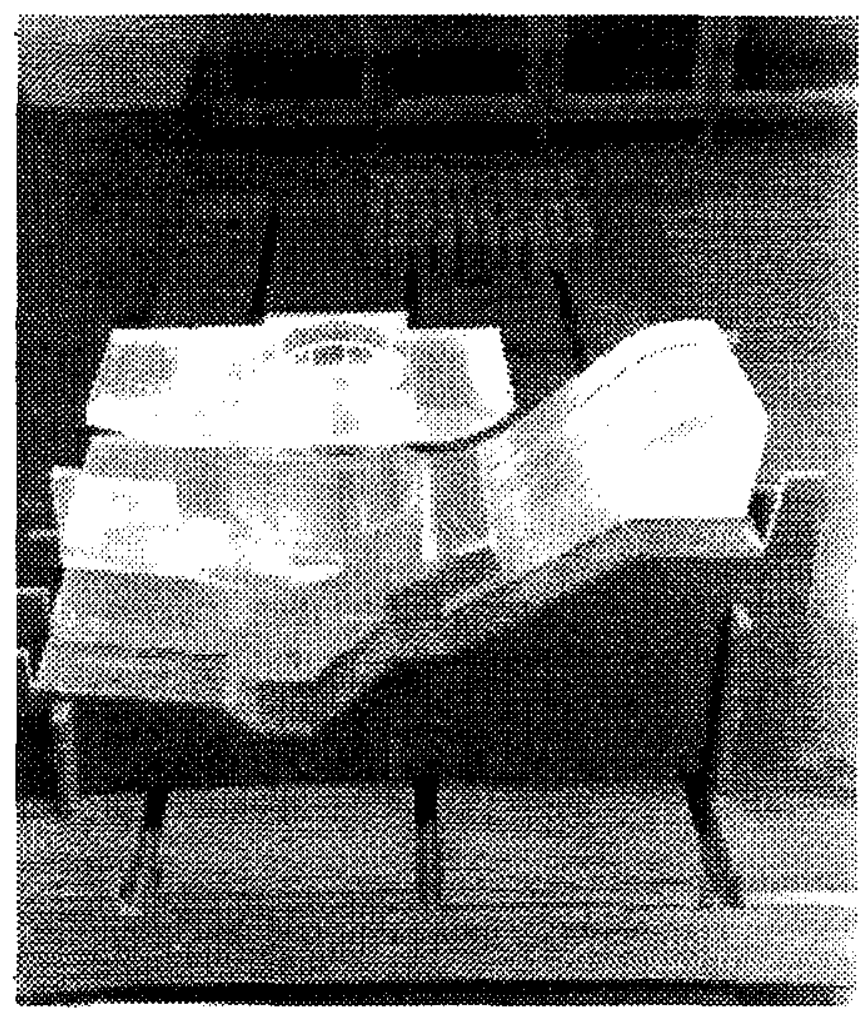

FIGURA 5 - Fase de ajustagem dos blocos para posteriormente serem instrumentados e colados. (Fonte: CESP)

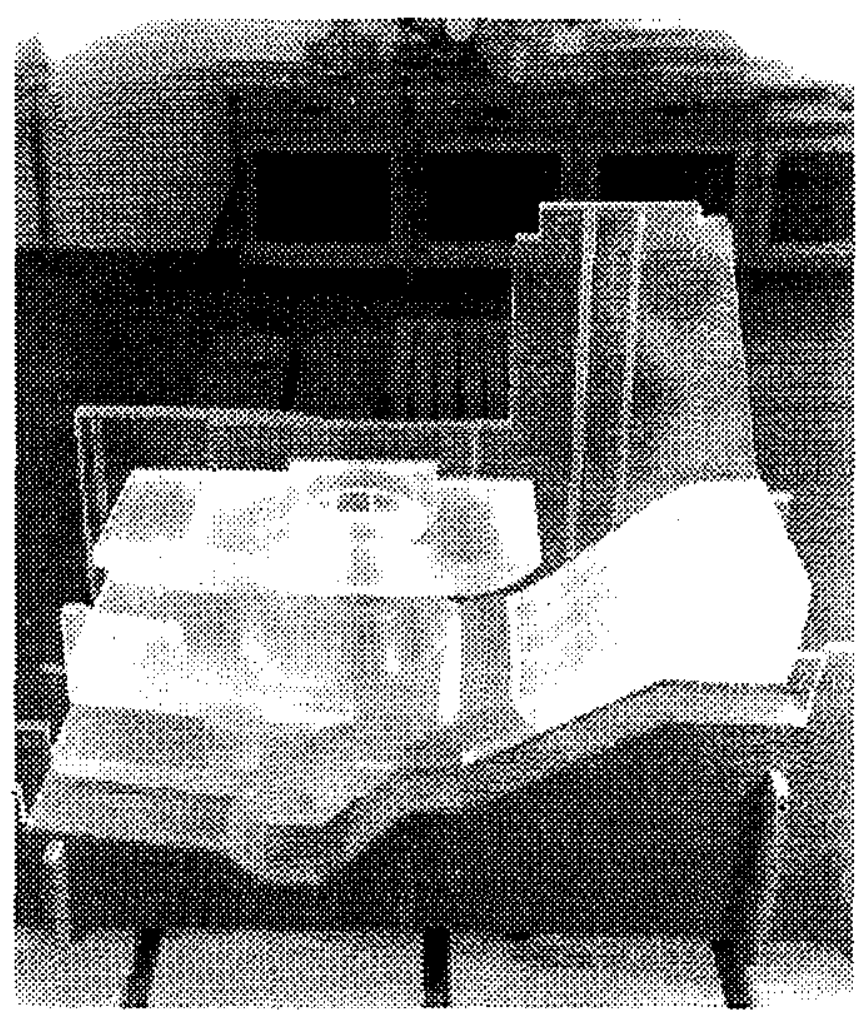

FIGURA 6 - Fase de ajustes das peças com um paramento de montante. (Fonte: CESP) 


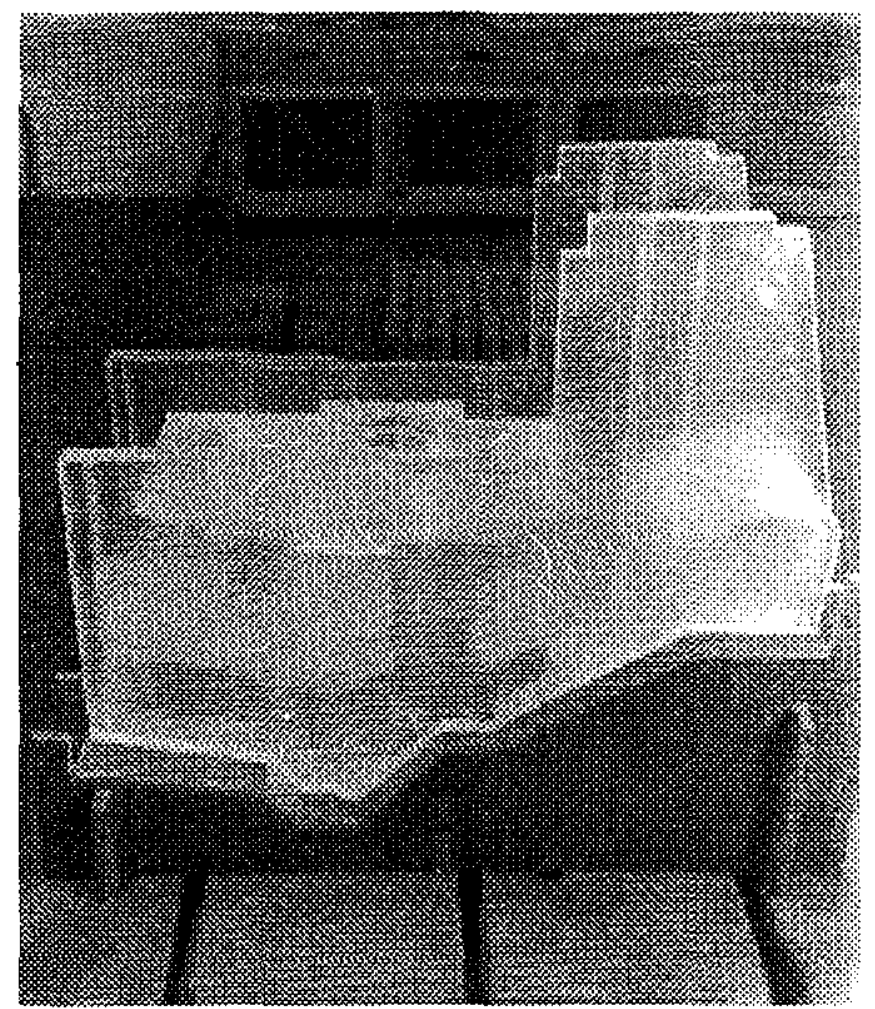

FIGURA 7 - Fase de ajustes das peças, vista com dois paramentos de montante. (Fonte: CESP)

O material utilizado apresenta módulo de elasticidade de $3.000 \mathrm{MPa}$, o que lhe confere boa trabalhabilidade com máquinas usuais de carpintaria.

A fundação, constituída de rocha com $1 / 3$ a $1 / 2$ do módulo de elasticidade do concreto, foi representada através de uma greiha espacial composta de barras de acrílico.

O afastamento entre barras foi determinado de modo a preservar a relação entre os módulos de elasticidade, sendo que, o da grelha, ficou na faixa de 950 a $1.267 \mathrm{MPa}$, portanto próximo de $1 / 3$ do valor da constante para o acrílico maciço. Na Figura 8 pode ser vista a montagem da grelha. 


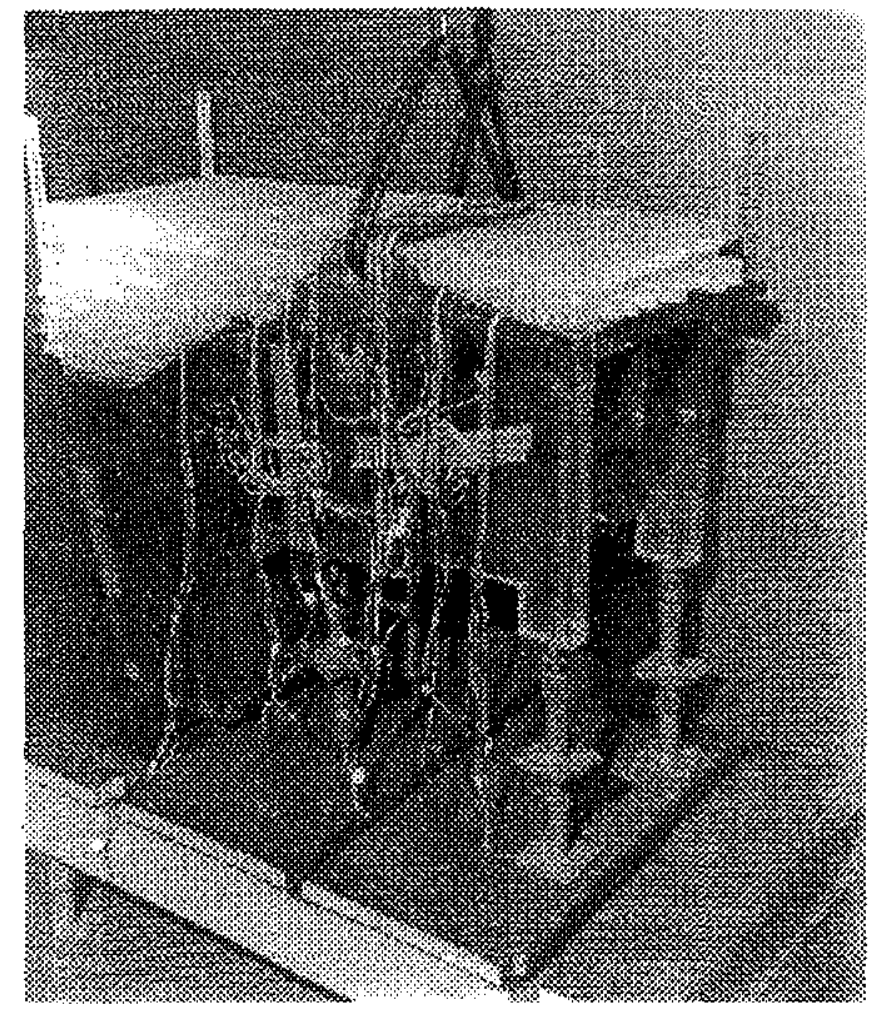

FIGURA 8 - Montagem da greiha espacial que forma a parte da fundação. (Fonte: CESP)

\subsection{FATORES DE ESCALA E ANÁLISE DIMENSIONAL}

É necessário que haja semelhança entre modelo fisico e protótipo para que o primeiro possa representar o segundo, através de condições estabelecidas pela Análise Dimensional.

O modelo de Nova Avanhandava foi construído geométricamente semelhante ao protótipo, na escala 1/75.

As relações de semelhança entre modelo e protótipo podem ser obtidas a partir do Teorema $\pi$ de Vaschy-Buckingham, ou diretamente das relações da mecânica estrutural (CESP,1980a e CARNEIRO,1993), como se segue: 
a)Escala geométrica $\mathrm{SL} \quad \mathrm{Lp}=\mathrm{SL} . \mathrm{Lm}$ portanto $\mathrm{SL}=\frac{\mathrm{Lp}}{\mathrm{Lm}}$,

onde: $\mathrm{Lp}=$ comprimentos no protótipo;

$\mathrm{Lm}=$ comprimentos no modelo.

b)Escala de deformações $S \varepsilon \quad \varepsilon p=S \varepsilon . \varepsilon m$ portanto $S \varepsilon=\frac{\varepsilon p}{\varepsilon m}=\frac{\left(\frac{\Delta L}{L}\right)_{p}}{\left(\frac{\Delta L}{L}\right)_{m}}$

$$
\frac{\varepsilon p}{\varepsilon \mathrm{m}}=\left(\frac{\Delta \mathrm{Lp}}{\Delta \mathrm{Lm}}\right)\left(\frac{\mathrm{Lm}}{\mathrm{Lp}}\right)=\mathrm{SL} \frac{1}{\mathrm{SL}}=1
$$

onde: $\varepsilon p=$ deformações no protótipo;

$\varepsilon=$ deformações no modelo.

c) Escala de tensões $S \sigma \sigma p=S \sigma \cdot \sigma \mathrm{m}$ portanto $S \sigma=\frac{\sigma p}{\sigma \mathrm{m}}=\frac{(\varepsilon p)(E \mathrm{p})}{(\varepsilon \mathrm{m})(\mathrm{Em})}=\frac{E p}{E \mathrm{~m}}$ onde: $\mathrm{Ep}=$ módulos de elasticidade no protótipo;

$\mathrm{Em}=$ módulos de elasticidade no modelo; $\sigma \mathrm{p}=$ tensões no protótipo;

$\sigma \mathrm{m}=$ tensões no modelo.

d)Escala de forças $S_{P} P p=S p . P m$ portanto $S p=\frac{P p}{P m}=\frac{(\sigma p)(A p)}{(\sigma m)(A m)}=S \sigma \cdot S_{L}^{2}$ onde: $\mathrm{Pp}=$ forças no protótipo;

$\mathrm{Pm}=$ forças mo modelo;

$\mathrm{Ap}=$ áreas no protótipo;

Am=áreas no modelo.

e)Escala de peso específico $S \rho \quad \rho p=S \rho . \rho m$ portanto $S p=\frac{\left(\frac{P p}{V p}\right)}{\left(\frac{P m}{V m}\right)}=\frac{S \sigma}{S_{L}}$ onde: $\mathrm{Vp}=$ volumes no protótipo;

$\mathrm{Vm}=$ volumes no modelo. 


\section{f)Escala de pressão $\mathrm{Sp}$}

$$
\mathrm{Sp}=\mathrm{S} \sigma
$$

Optou-se pela escala geométrica $1 / 75$ a fim de se obter um modelo com proporções adequadas, satisfazendo as necessidades de usinagem e instalação de instrumentos sem consumir muito material e permitindo a simulação de cargas com equipamento relativamente leve.

A escala de tensões entre protótipo e modelo, considerando o módulo de elasticidade do concreto igual a $30.000 \mathrm{MPa}$, é a seguinte:

$$
\mathrm{S} \sigma=\frac{\sigma \mathrm{p}}{\sigma \mathrm{m}}=\frac{\mathrm{Ep}}{\mathrm{Em}}=\frac{30.000}{3.000}=10
$$

A escala de forças será, então:

$$
\mathrm{Sp}=\mathrm{S} \sigma \times \mathrm{S}_{\mathrm{L}}^{2}=10 \times 75^{2}=56.250
$$

E a escala de pesos específicos ficará:

$$
\mathrm{S} \rho=\frac{\rho_{\mathrm{P}}}{\rho_{\mathrm{m}}}=\frac{\mathrm{S}_{\mathrm{p}}}{\mathrm{S}_{\mathrm{L}}}=\frac{10}{75}=\frac{1}{7,5} \text { ou } \quad \rho \mathrm{m}=7,5 \times \rho \mathrm{p}
$$

Como o protótipo é carregado com água, $\rho p=10^{-8} \mathrm{~N} / \mathrm{m}^{3}$, o líquido usado para carregar o modelo deveria ter $\rho \mathrm{m}=7,5 \times 10^{-8} \mathrm{~N} / \mathrm{m}^{3}$. No entanto, foi utilizado mercúrio, $\rho \mathrm{Hg}=1,36 \times 10^{-7} \mathrm{~N} / \mathrm{m}^{3}$, de modo que a escala ficou alterada, exigindo a consideração de um fator de correção $(\mathrm{K})$, como se segue: 


$$
\mathrm{K}=\frac{\rho_{\mathrm{m}}}{\rho_{\mathrm{Hg}_{\mathrm{g}}}}=\frac{7,5}{13,6}=0,55
$$

Portanto, as tensões no protótipo serão dadas por:

$$
\sigma \mathrm{p}=\mathrm{S} \sigma \times \mathrm{K} \times \sigma \mathrm{m}
$$

Substituindo os valores, temos:

$$
\begin{aligned}
& \sigma p=10 \times 0,55 \times \sigma \mathrm{m} \\
& \sigma p=5,5 \times \sigma \mathrm{m}
\end{aligned}
$$

\subsection{INSTRUMENTAÇÃO DO MODELO}

No modelo de Nova Avanhandava a instrumentação foi instalada visando a medição de deslocamentos e forças, em diversos pontos, e deformações, na região da caixa espiral.

Foram utilizados 401 extensômetros elétricos, em 159 pontos, mostrados na Figura 9.

Os deslocamentos foram medidos por meio de 32 defletômetros mecânicos de sensibilidade $0,01 \mathrm{~mm}$ e curso de $25 \mathrm{~mm}$, instalados nas faces laterais, 


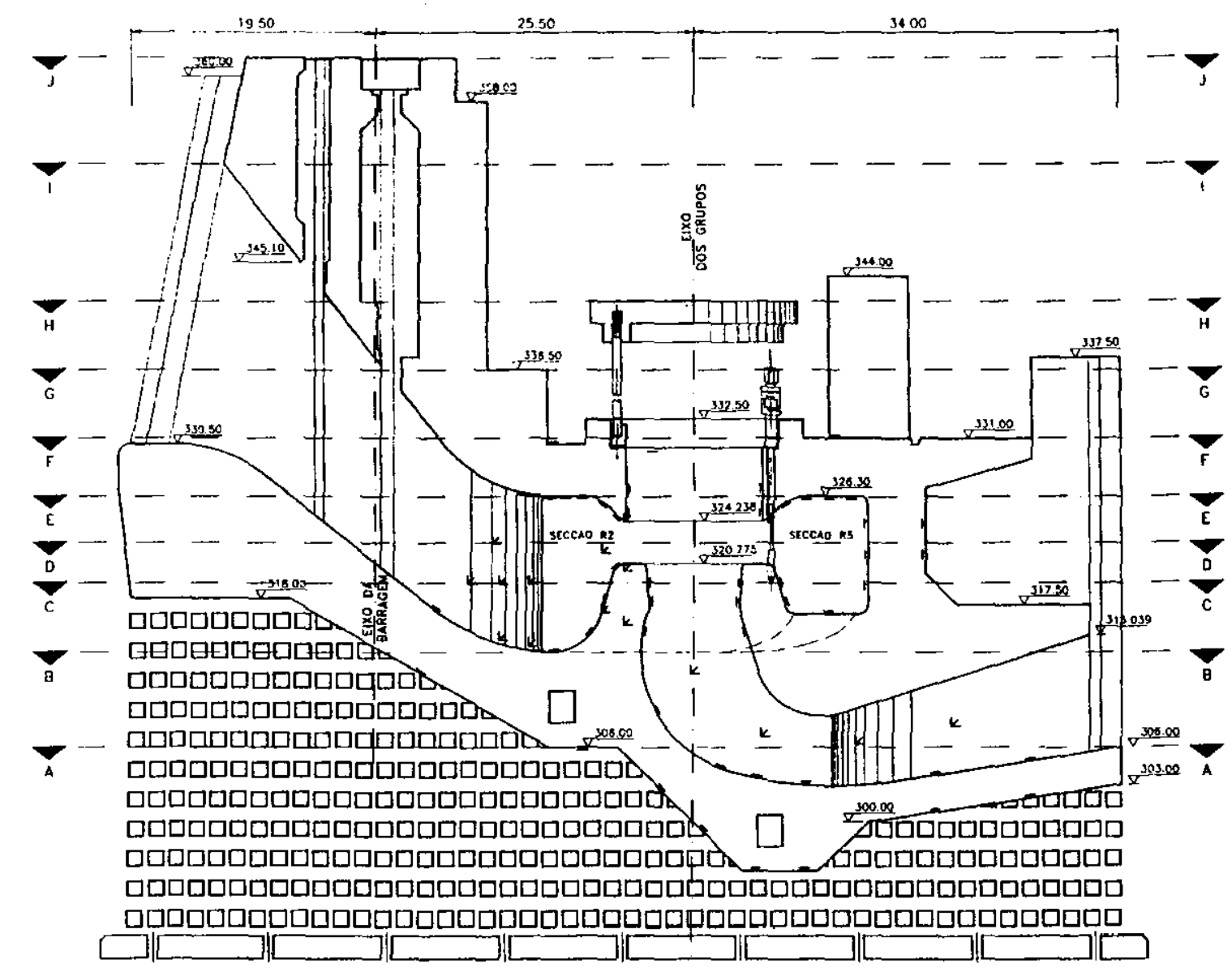

FIGURA 9 - Corte transversal do modelo físico reduzido, mostrando a tomada d'água, à esquerda; caixa espiral, ao centro; tubo de sucção e canal de fuga, abaixo e à direita, e rocha de fundação. (Fonte: CESP) 


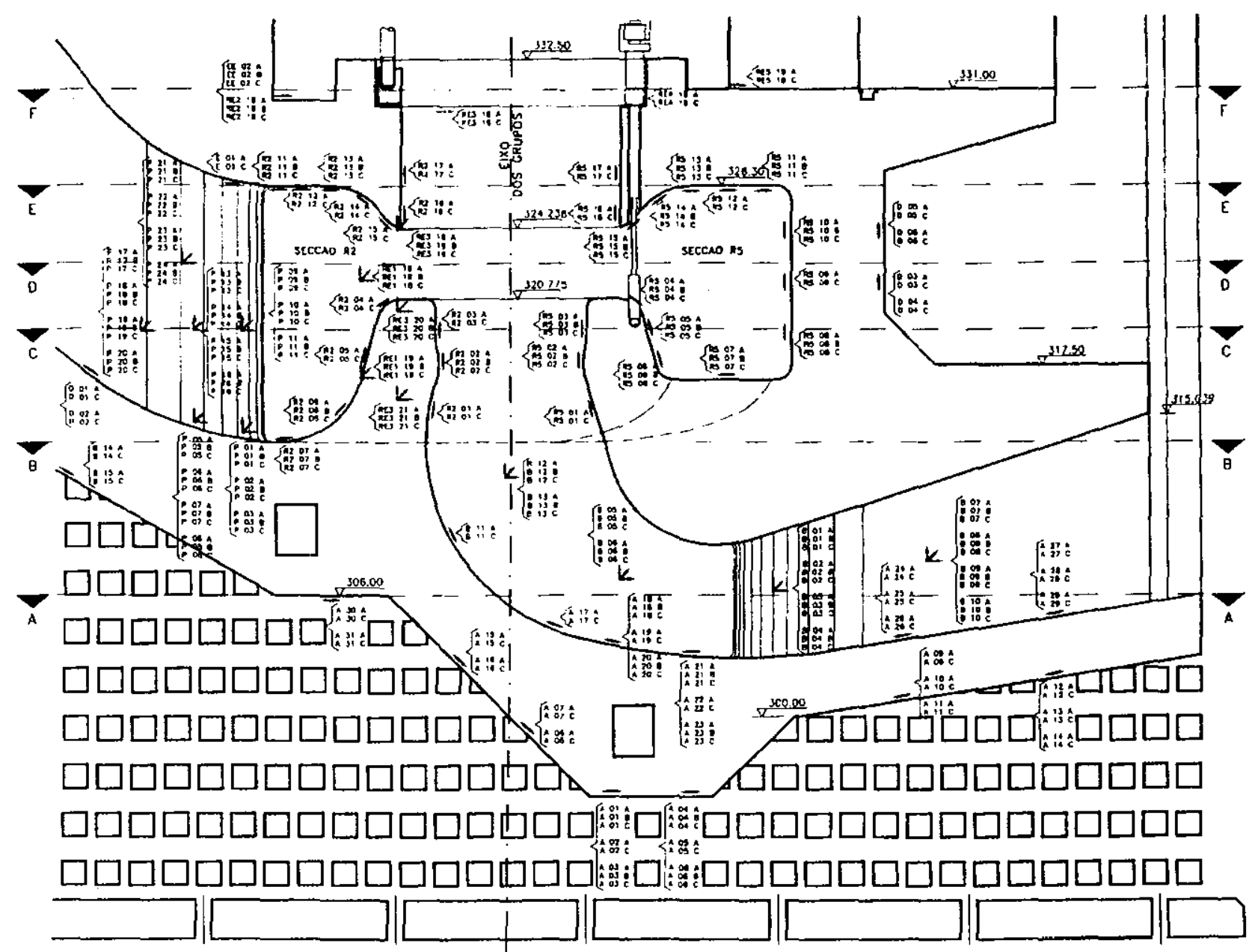

FIGURA 10 - Detalhes da instrumentação em corte transversal do modelo. (Fonte: CESP) 
em posições correspondentes, fixados em uma estrutura metálica especialmente montada para esse fim e considerada indeslocável, mostrada nas Figuras 11 e 12.

Na caixa espiral não foram medidos deslocamentos, os quais, por este motivo, não fazem parte do presente estudo.

A instalação dos extensômetros foi feita de acordo com a direção em que se desejava obter as medidas de deformações. É possível determinar experimentalmente as direções principais, que são sempre coincidentes para deformações e tensões, com a utilização de rosetas com três extensômetros posicionados convenientemente.

HETÉNYI (1950) observa que os extensômetros elétricos de resistência possuem sensibilidade às deformações na direção perpendicular ao seu eixo, chamada sensibilidade transversal, que pode provocar erro nas medidas.

Esse assunto também é abordado em boletim do MEASUREMENTS GROUP (1993) que, a exemplo de HETÉNYI (1950), sugere algumas fórmulas para correção.

HOSSDORF (1974), entretanto, afirma que este efeito corresponde à ordem de grandeza de cerca de $1 \%$ da deformação axial, ou longitudinal. Por ser de pequena magnitude, esse efeito não foi considerado.

Para medir as deformações, foram utilizados 401 extensômetros elétricos de resistência, com bases de $2 \mathrm{~mm}$ e $5 \mathrm{~mm}$, colados em 159 pontos sobre a superfície do modelo.

Em alguns desses pontos utilizaram-se rosetas em cruz com 2 extensômetros a 900, KFC-5-D16 e KFC-2-D16 e nos outros, rosetas retangulares com 3 extensômetros a $45^{\circ}$ e $90^{\circ}$, KFC-5-Di7 e KFC-2-D17, fabricados pela indústria KYOWA. As rosetas em cruz foram utilizadas nos pontos em que eram desejadas medidas de deformação e tensão em duas direções, A e C, não necessáriamente coincidentes com as principais. 


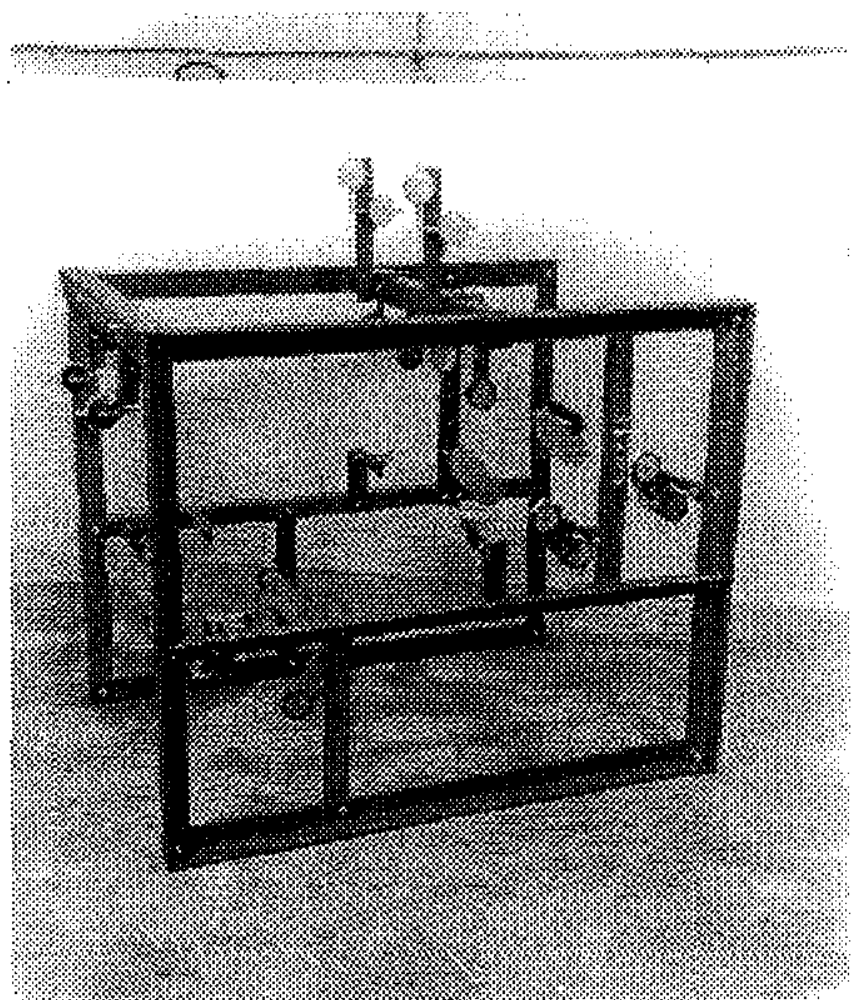

FIGURA 11 - Vista do dispositivo de montagem dos defletômetros, utilizados para as medidas dos deslocamentos. (Fonte: CESP)

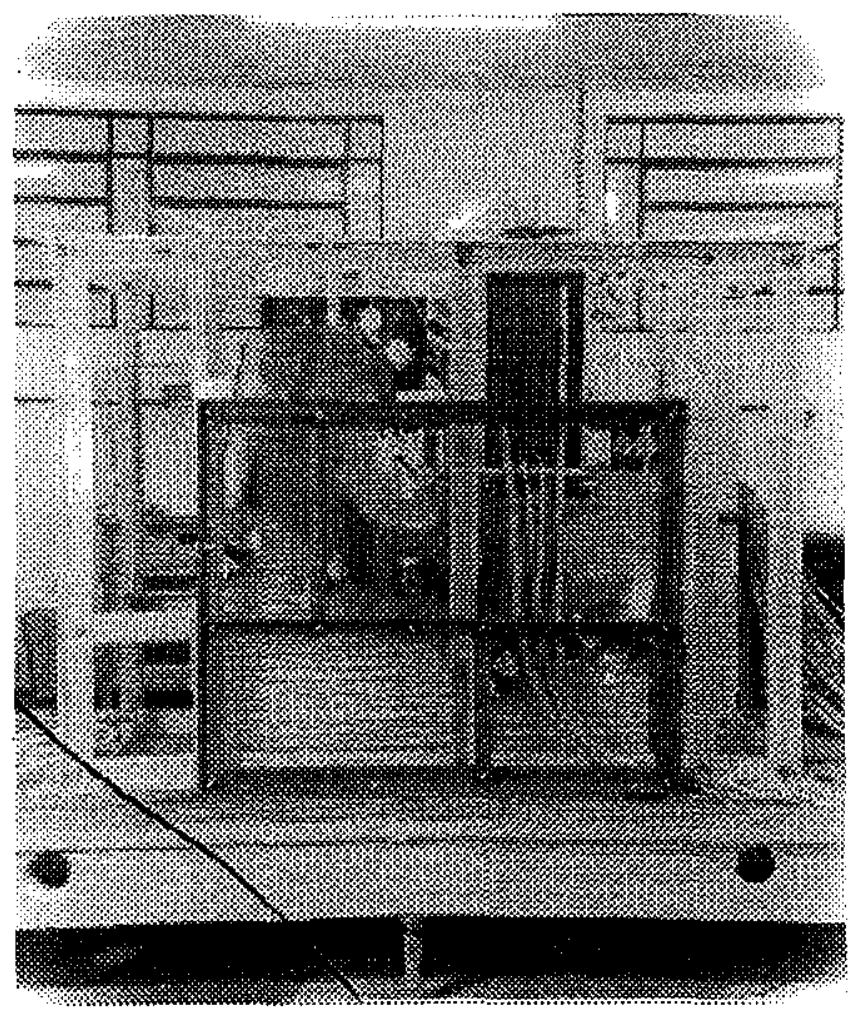

FIGURA 12 - Vista lateral do modelo montado sobre a base. Vê-se, já montada, a estrutura para suporte dos defletômetros. (Fonte: CESP) 
Nos pontos em que se desejava calcular as direções principais, 1 e 2, foram coladas rosetas retangulares, em direções chamadas A, B e C.

As forças de protensão nos pré-distribuidores foram medidas por meio de dinamômetros construídos com extensômetros elétricos.

A leitura das deformações indicadas pelos extensômetros elétricos de resistência e das forças nos pré-distribuidores, foi feita pelo sistema de aquisição de dados HP 2012-B, com capacidade de executar até 200 medidas de extensômetros diferentes em 20 segundos, como mostrado nas Figuras 13 e 14.

Devido à limitação do sistema em no máximo 200 extensômetros por vez, os ensaios foram divididos em 3 etapas e, em cada uma delas, foi lido um conjunto de extensômetros diferente.

A grande sensibilidade dos extensômetros levou a adoção de alguns cuidados para evitar que os efeitos da variação de temperatura interferissem nos resultados. Desta forma, os ensaios foram realizados em sala aclimatada, com instalações de ar condicionado e durante o período noturno, pois não foi possivel manter a temperatura ambiente constante durante o dia.

Além disso, ainda com a finalidade de compensar possiveis efeitos da variação da temperatura, foi colado num bloco do mesmo material do modelo um extensômetro compensador para cada extensômetro ativo no modelo.

No painel de entrada do sistema de aquisição de dados, foram instalados dois resistores para, com os extensômetros ativo e compensador, completar a ponte de Wheatstone usada para obtenção das medidas. As figuras 15 e 16 mostram o bloco compensador.

A identificação dos extensômetros se dá por meio de codificação alfanumérica. As letras iniciais indicam a região de localização, os números intermediários referem-se ao ponto instrumentado, e a letra final identifica o extensômetro. Exemplo: B-05-A, B-05-B e B-05-C são 3 extensômetros da roseta localizada no ponto B-05, na região do corte B-B. 


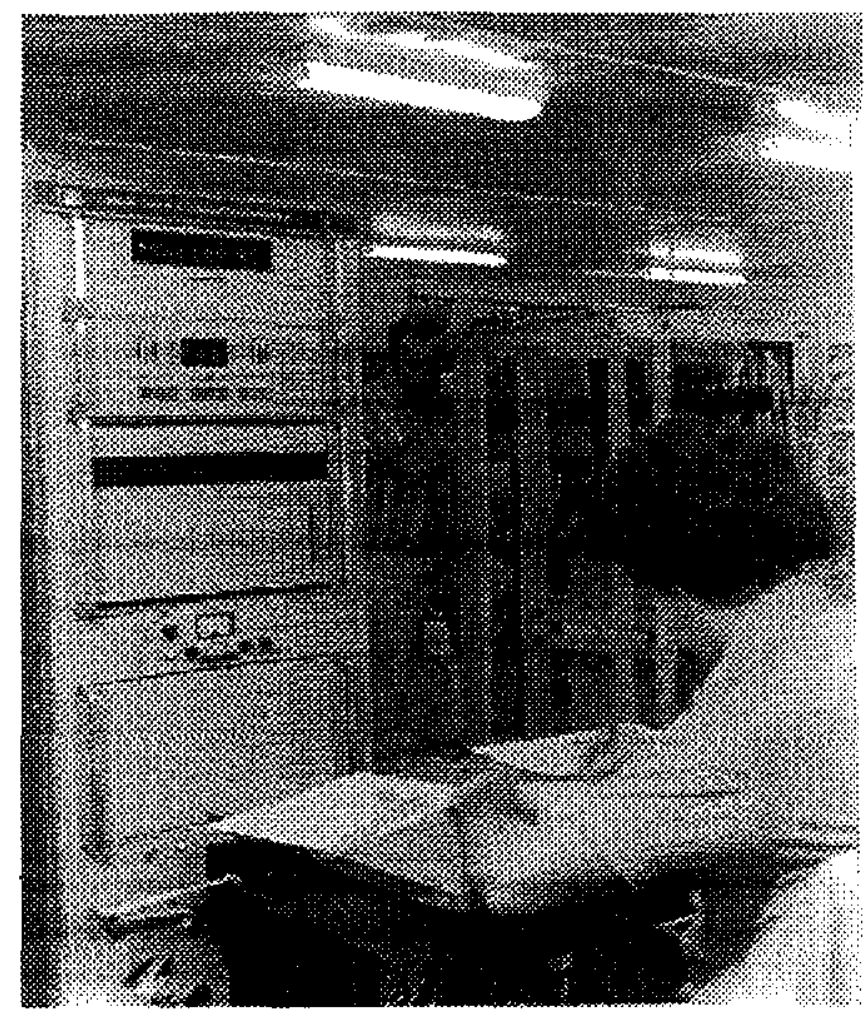

FIGURA 13 - Aquisição de dados. (Fonte: CESP)

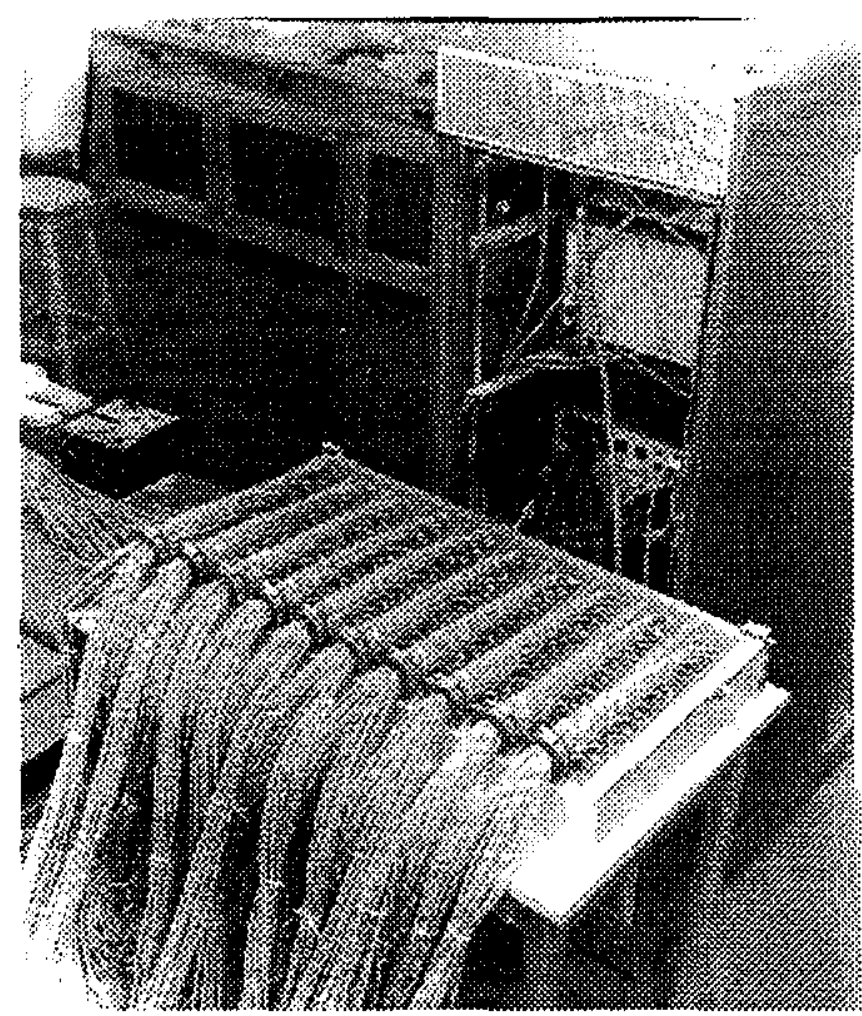

FIGURA 14 - Vista do painel de entrada para o sistema de aquisição de dados. (Fonte:CESP) 


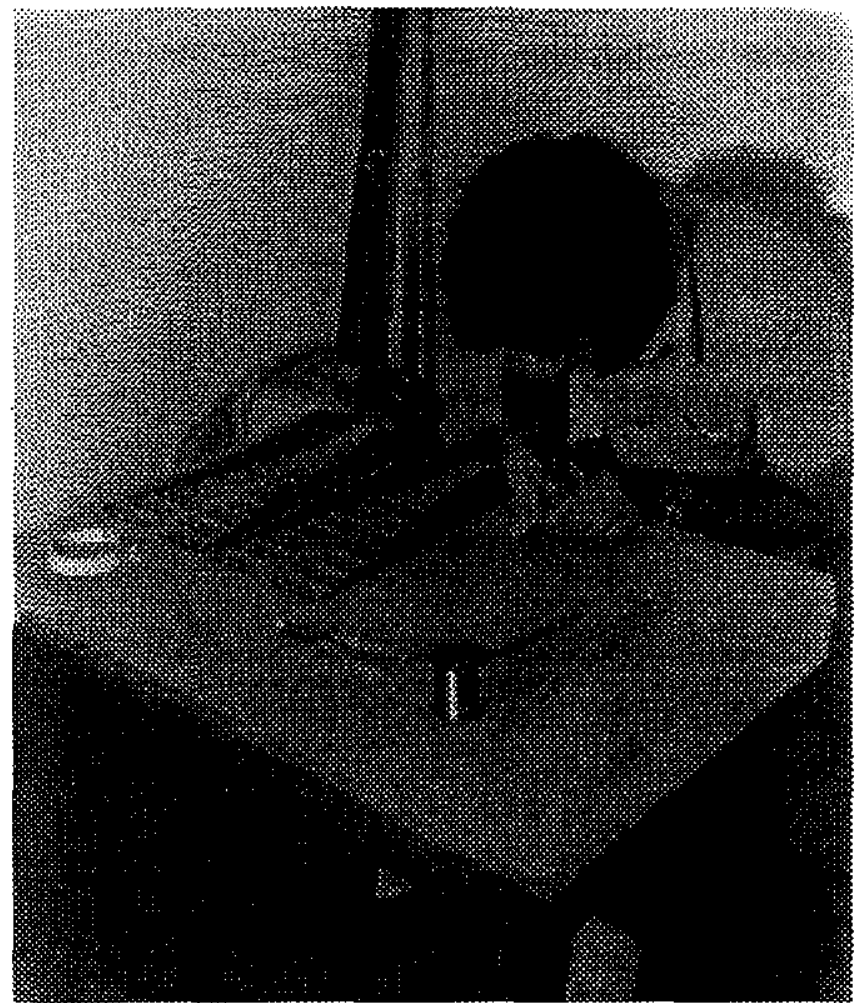

FIGURA 15 - Preparação do bloco compensador, onde são vistos os extensômetros colados e a fase de ligação dos fios de conexão. (Fonte: CESP)

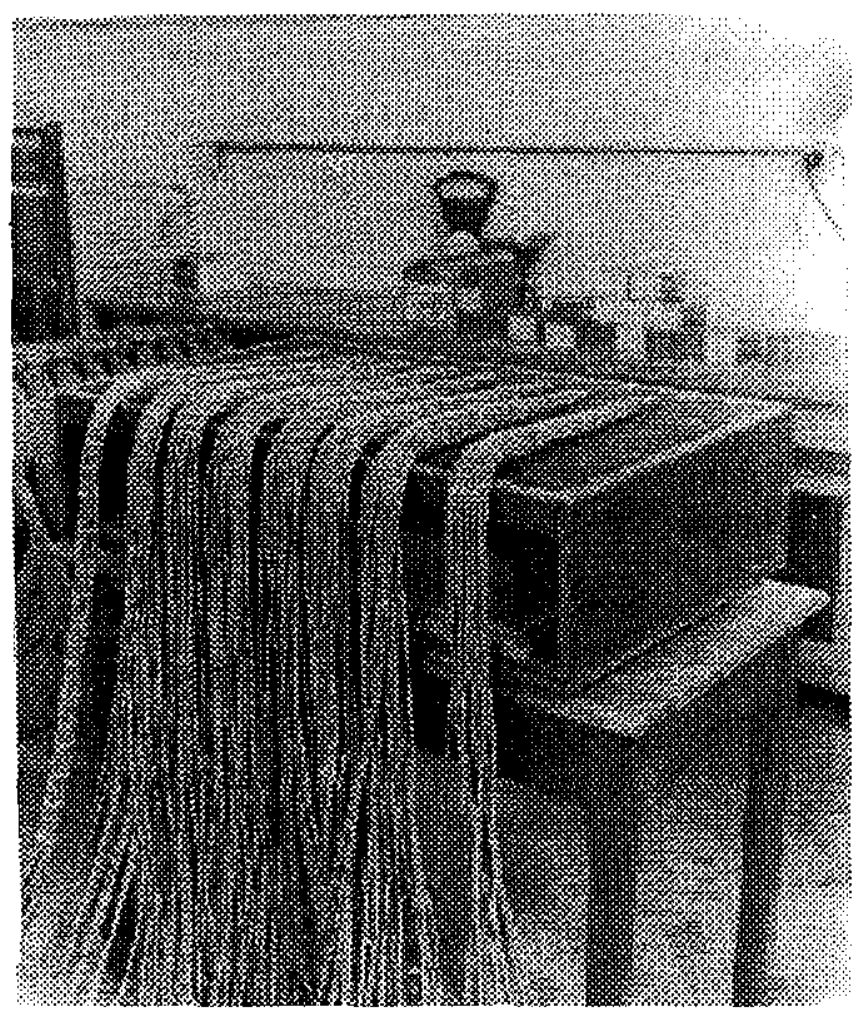

FIGURA 16 - Vista do bloco compensador já montado sobre um berço de espuma de plástico e os cabos de ligação. (Fonte: CESP) 
$\mathrm{Na}$ região situada abaixo do corte horizontal A-A há 31 pontos instrumentados numerados de A-01 até A-31. A Tabela 1 indica as posições dos pontos nas respectivas regiões.

TABELA 1 - Posições dos pontos nas respectivas regiões

\begin{tabular}{|c|l|}
\hline Região & Pontos \\
\hline A-A & A-01 até A-31 \\
\hline B-B & B-01 até B-15 \\
\hline D-D & D-01 até D-06 \\
\hline E-E & E-01 até E-02 \\
\hline R1 & R1-01 até R1-04 \\
& R1-13 até R1-15 \\
\hline R2 & R1-17 até R1-19 \\
\hline R3 & R2-01 até R2-07 \\
\hline R4 & R2-11 até R2-18 \\
\hline R5 & R3-01 até R3-21 \\
\hline & R4-01 atéR4-18 \\
\hline
\end{tabular}

Os pontos situados nas regiões R1, R2, R3, R4 e R5 têm maior importância para esse trabalho, pois essas regiões correspondem a seções transversai: da caixa espiral. Os pontos são numerados de modo crescente ao longo do perimetro 
da secção, no sentido anti-horário nas secções R1 e R2, e horário nas demais. A fim de manter correspondência entre as secções, as numerações apresentam alguns saltos.

As posições das seç̧ões e o detalhamento da instrumentação em cada uma delas são mostrados nas Figuras 17 a 23 e a instrumentação nas outras regiões é mostrada nas Figuras 24 a 32. 


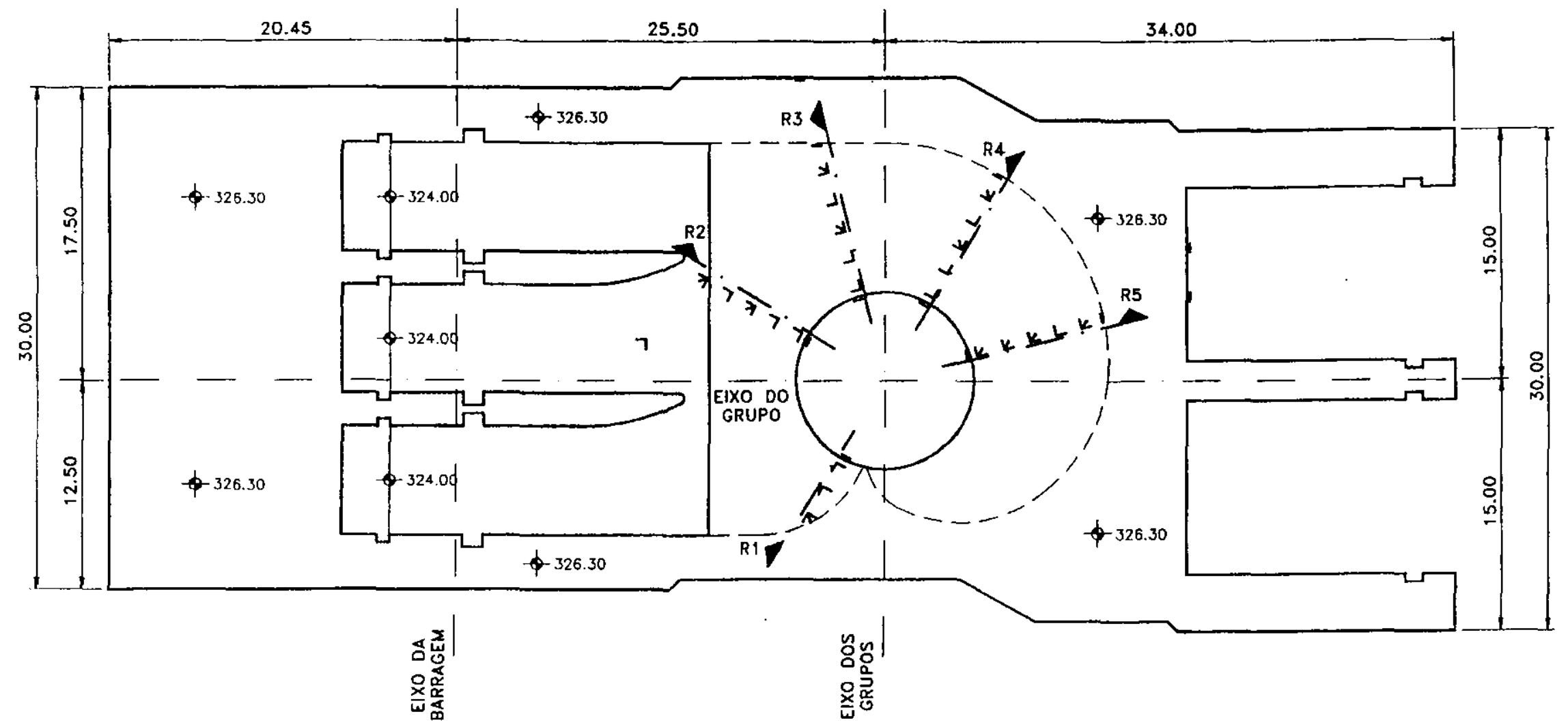

FIGURA 17 - Corte no nível EE do bloco Tomada d'Água/Casa de Força, mostrando as posições das secções R1 a R5 da Caixa Espiral. (Fonte: CESP) 


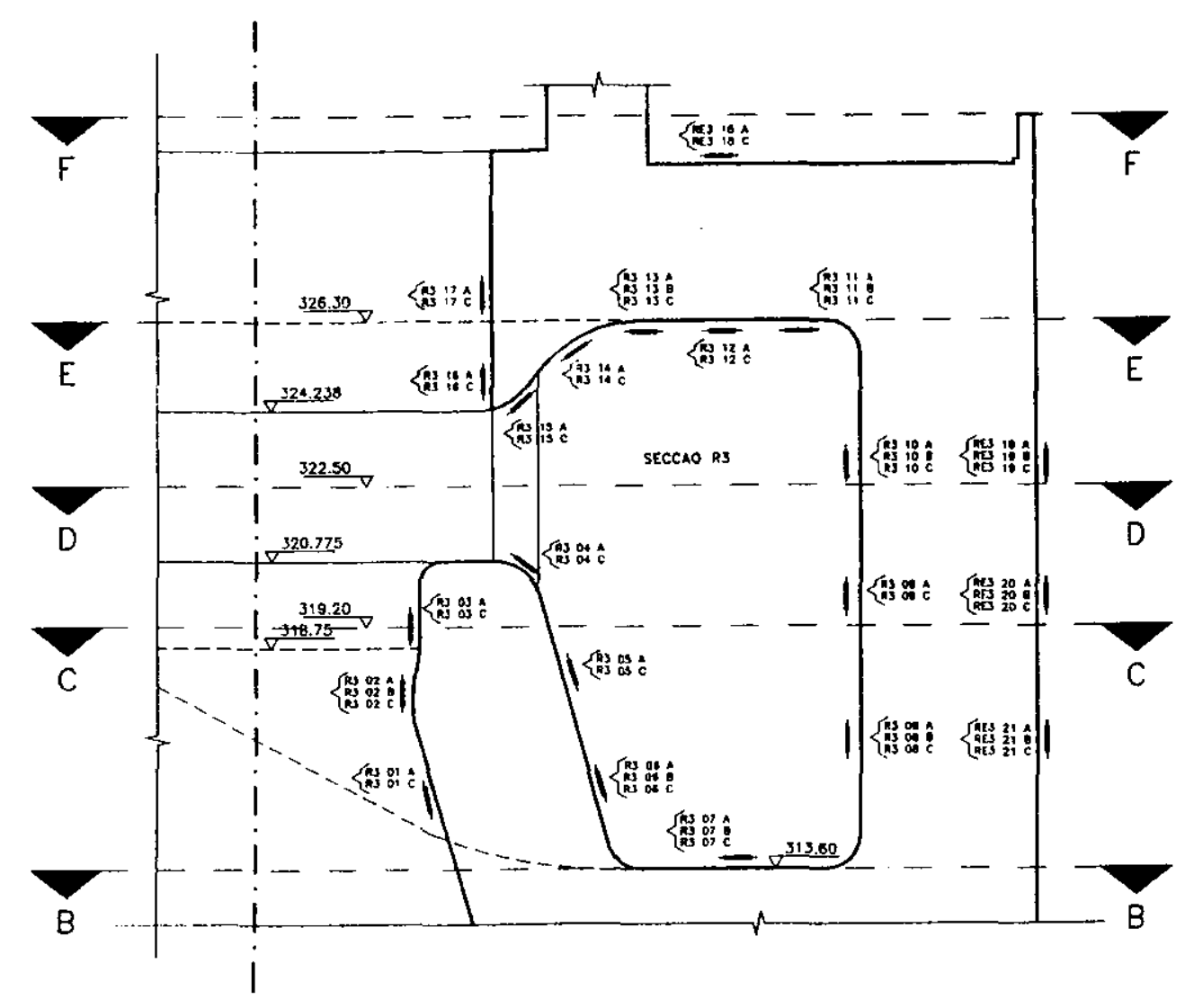

FIGURA 18 - Secção R3 da Caixa Espiral, mostrando detalhes da instrumentação do modelo. (Fonte: CESP) 


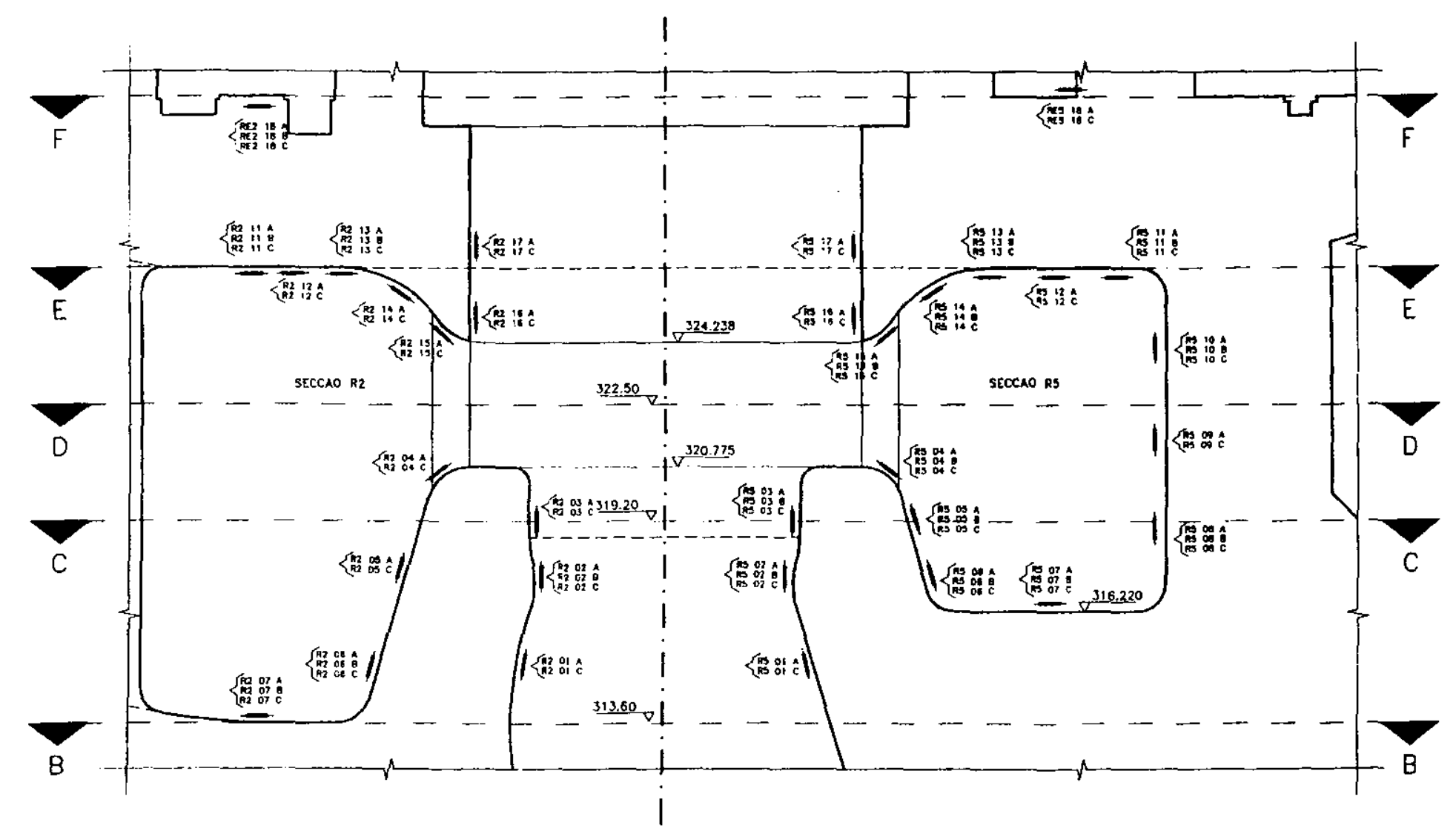

FIGURA 19 - Secções R2 e R5 da Caixa Espiral, mostrando detalhes da instrumentação do modelo. (Fonte: CESP) 


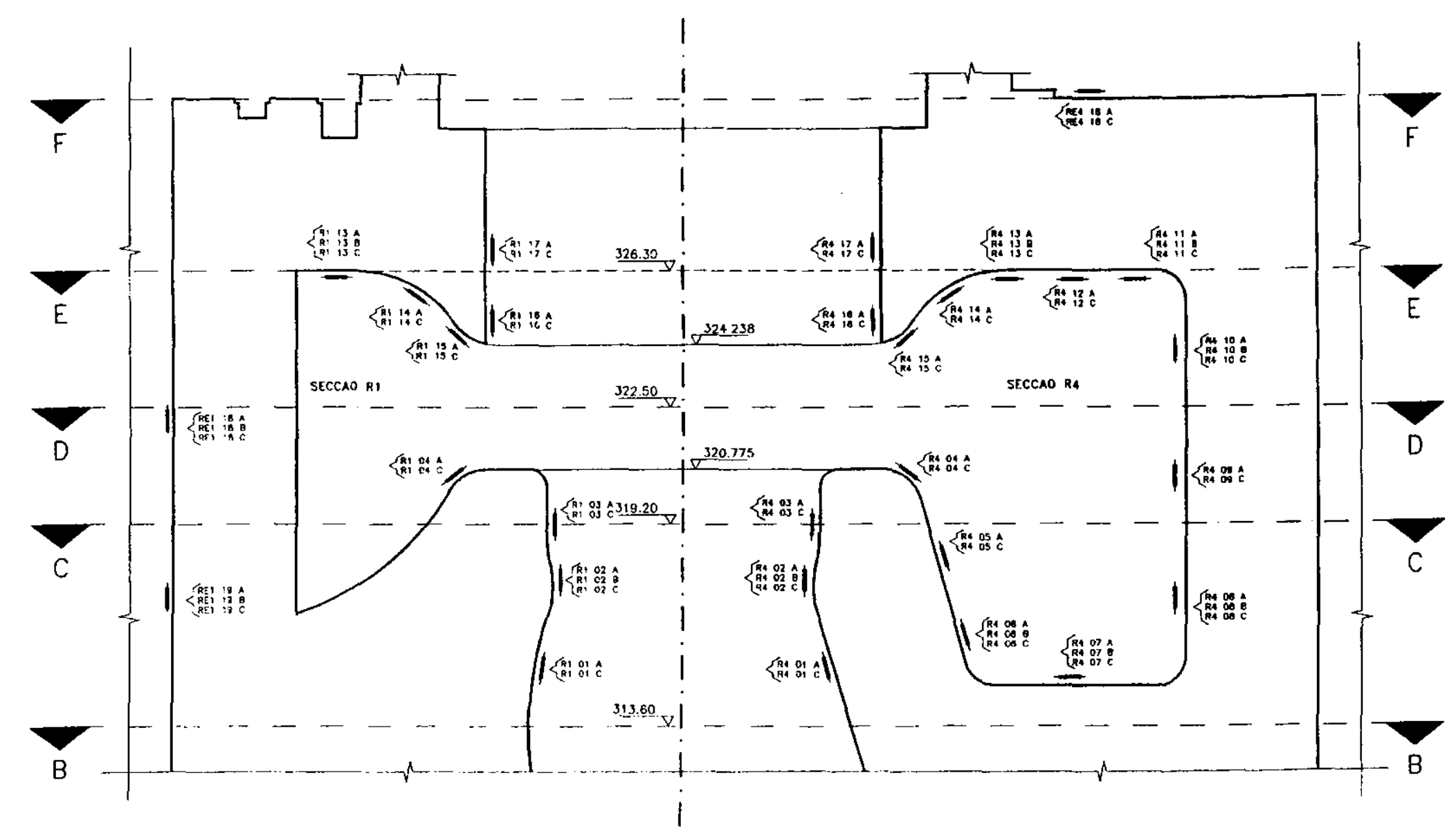

FIGURA 20 - Secções R1 e R4 da Caxa Espiral, mostrando detalhes da instrumentação do modelo. (Fonte: CESP) 


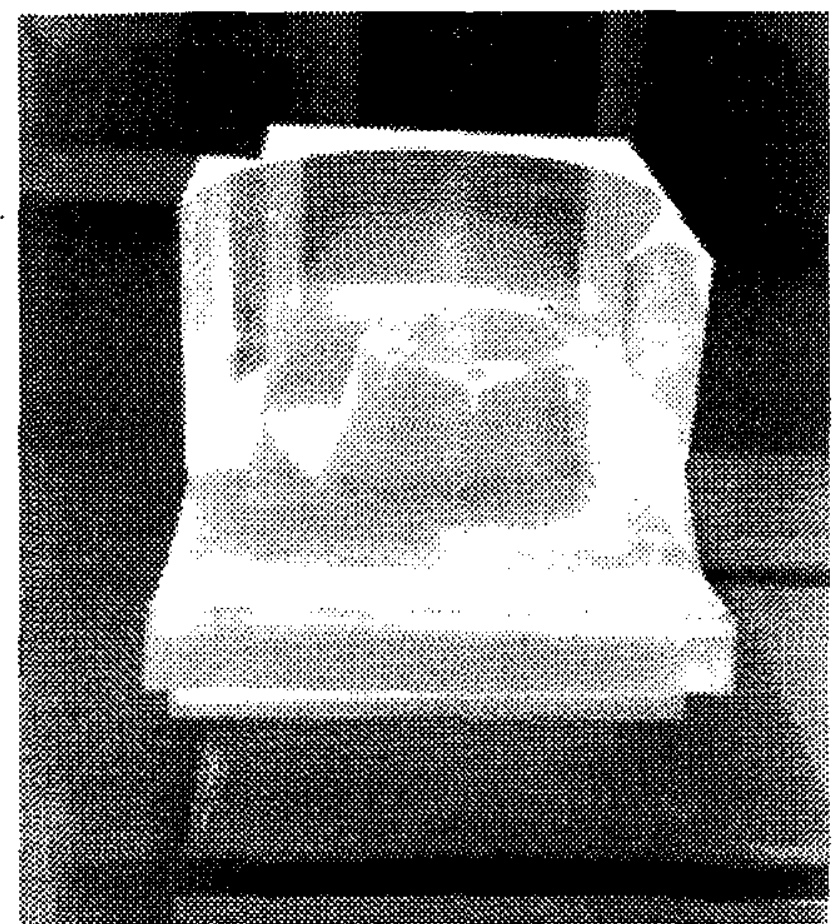

FIGURA 21 - Bloco da Caixa Espiral e Canal de Fuga já usinado.(Fonte: CESP)

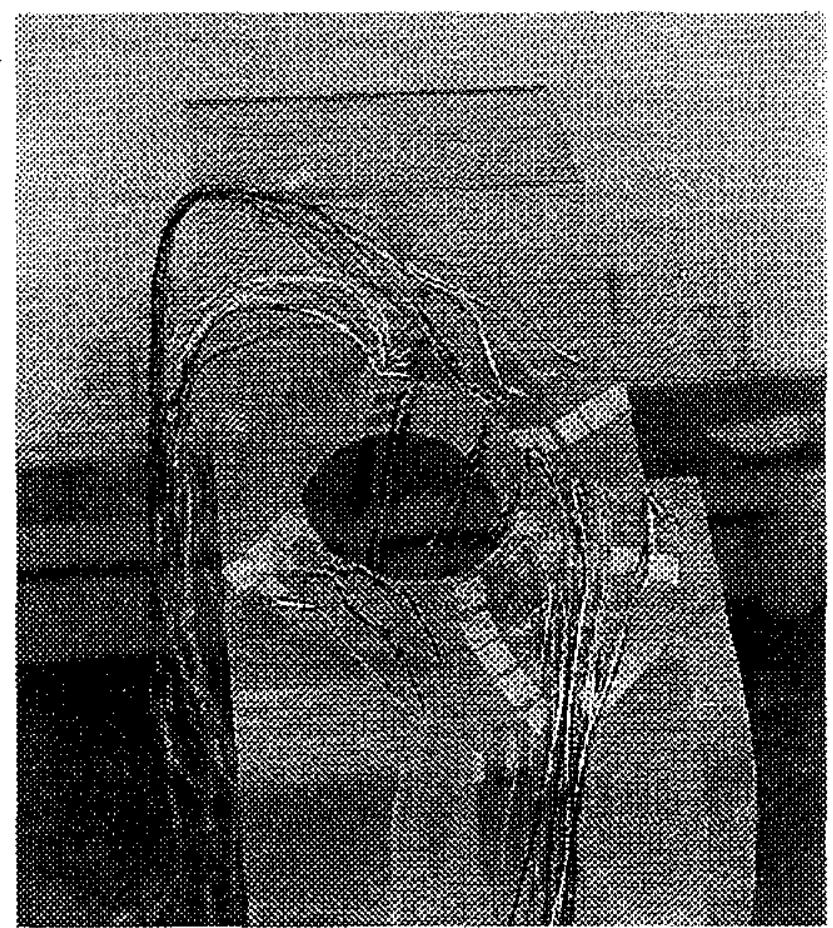

FIGURA 22 - Vista da instrumentação com extensômetros elétricos de resistência instalada no teto da Caixa Espiral. (Fonte: CESP) 


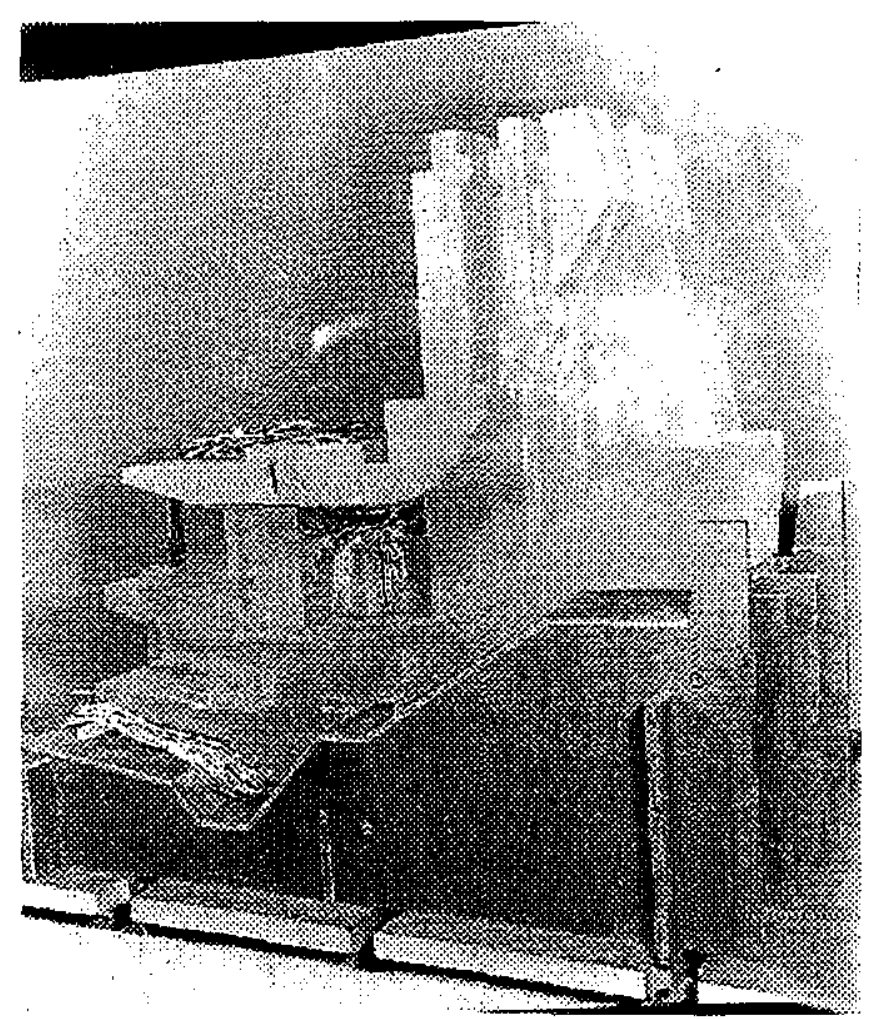

FIGURA 23 - Fase de instrumentação e montagem, vista do interior da Caixa Espiral. (Fonte: CESP) 


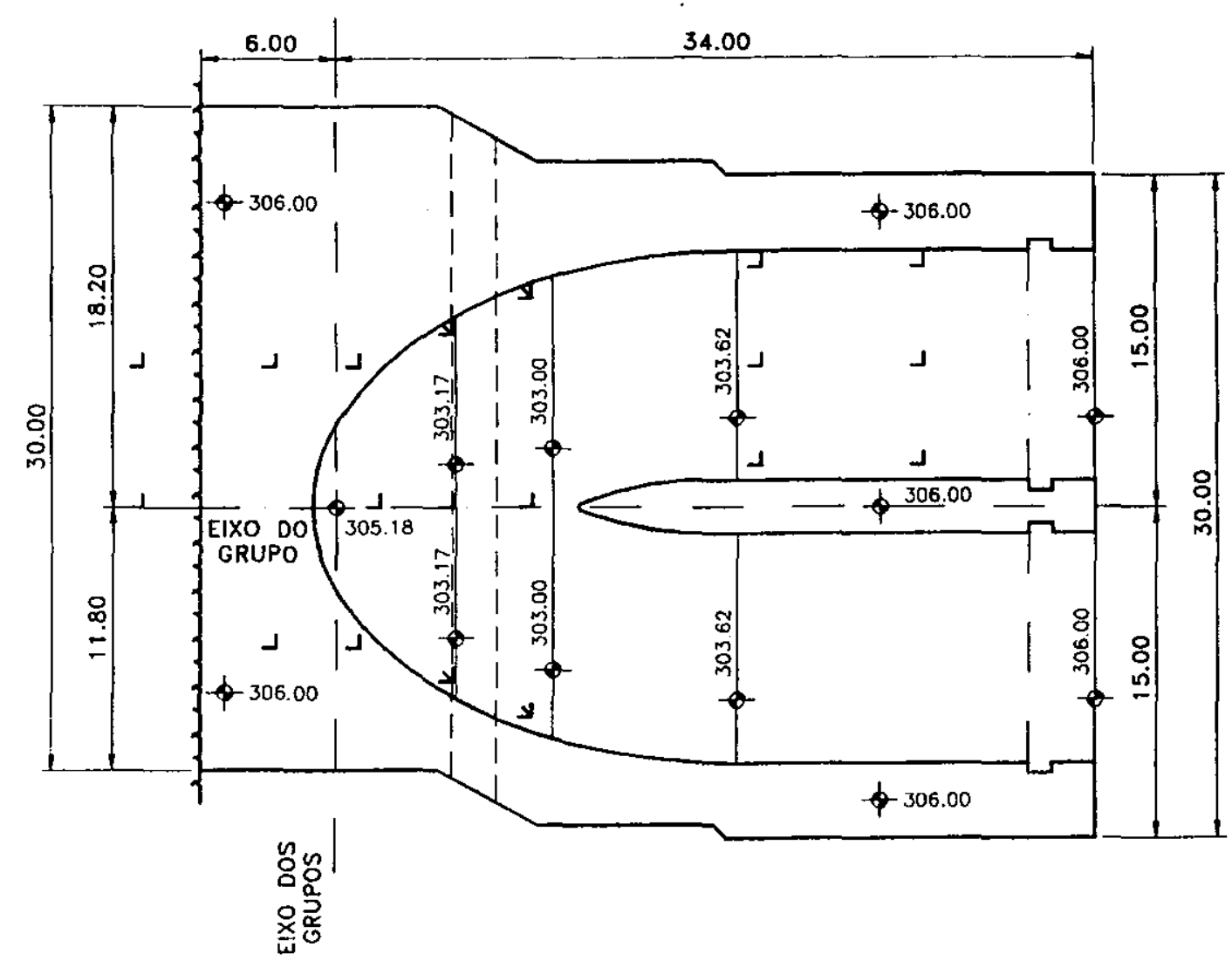

FIGURA 24 - Corte no nível AA do modelo fisico reduzido. (Fonte: CESP) 


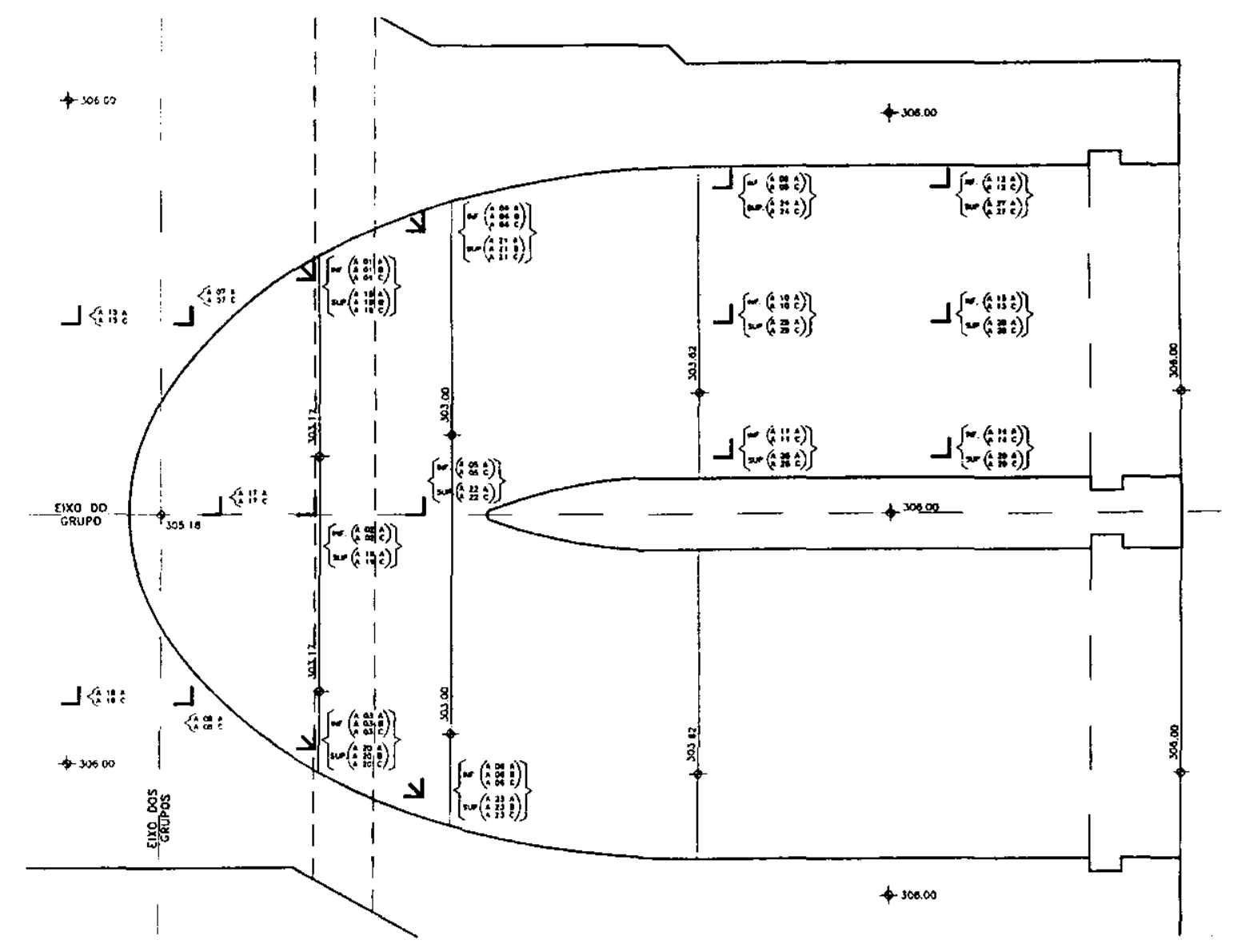

FIGURA 25 - Detalhes da instrumentação do contato estrutura-fundação do modelo no nível AA. (Fonte: CESP) 


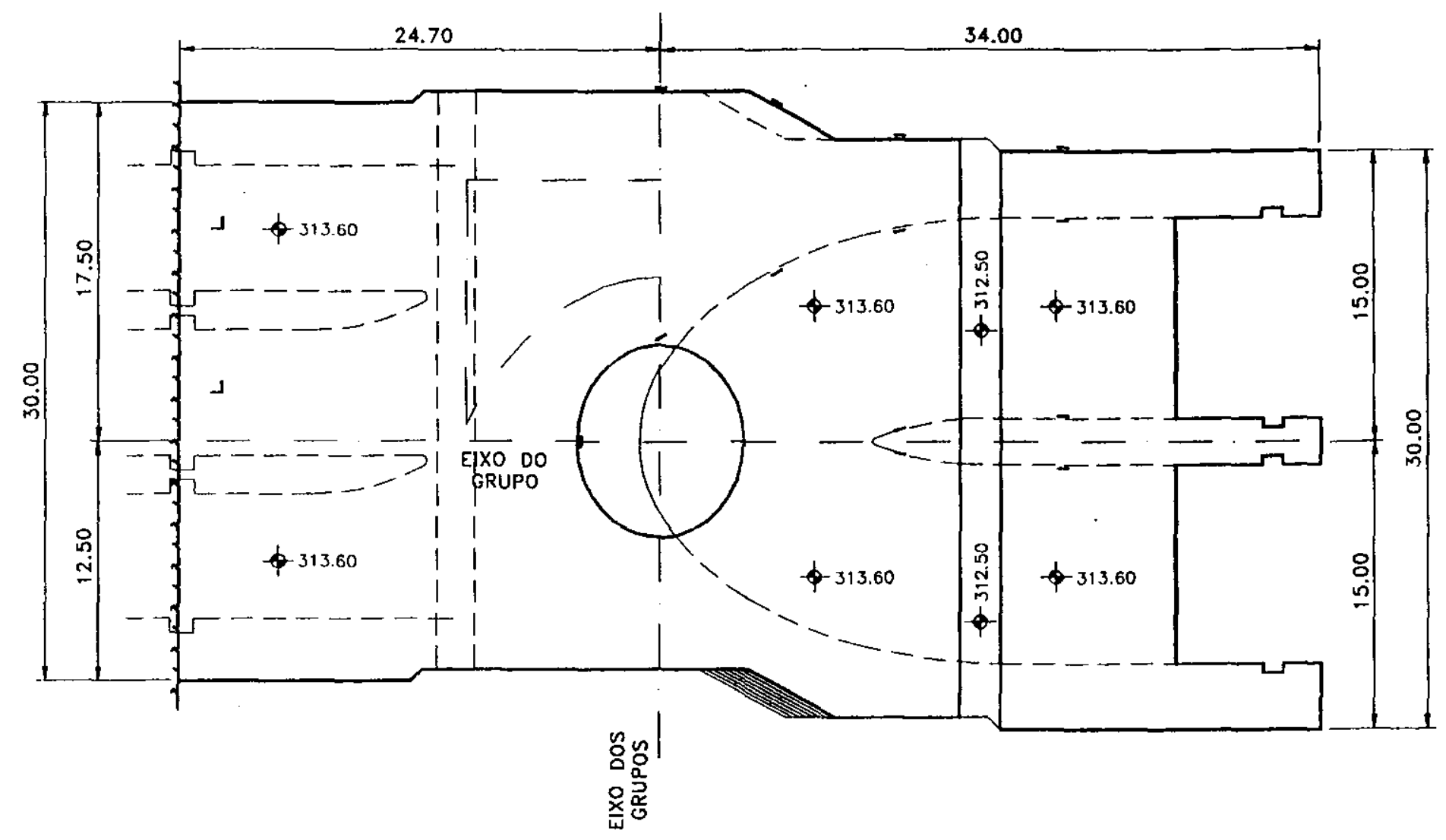

FIGURA 26 - Corte no nível BB do modelo físico reduzido. (Fonte: CESP) 

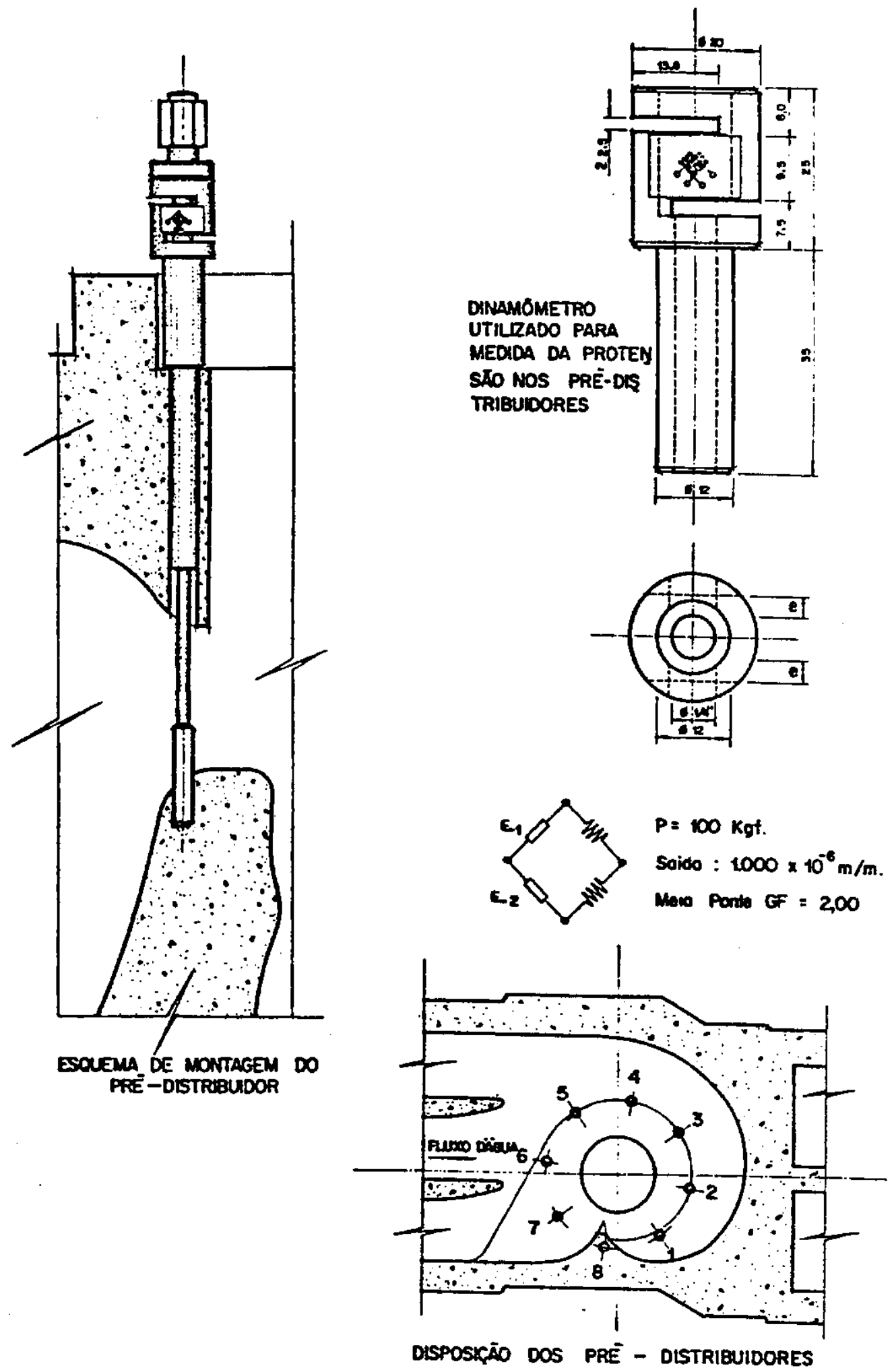

FIGURA 27 - Detalhes do dinamômetro para medida da força de protensão nos prédistribuidores do modelo (Fonte: CESP) 


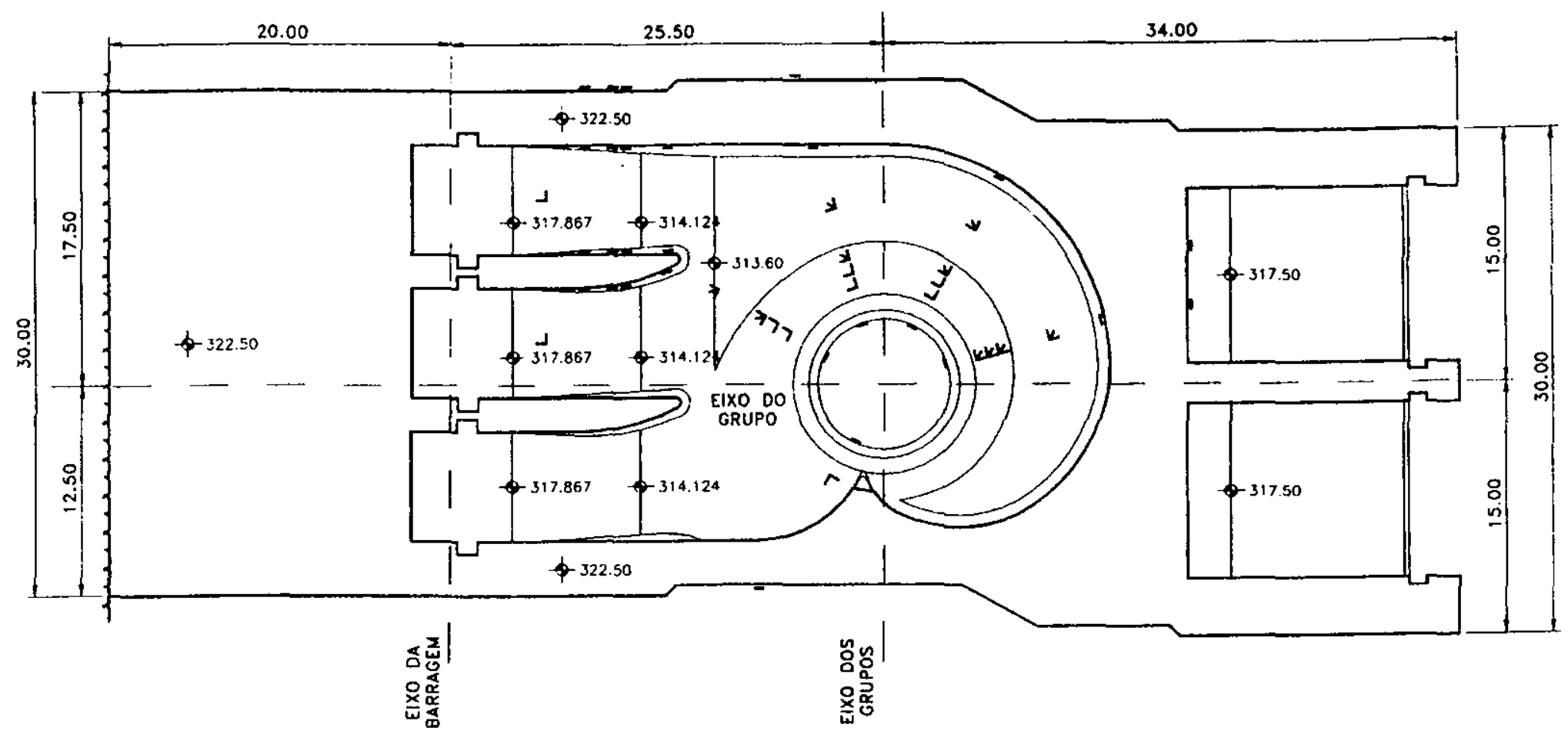

FIGURA 28 - Corte no nível DD do modelo físico reduzido. (Fonte: CESP) 


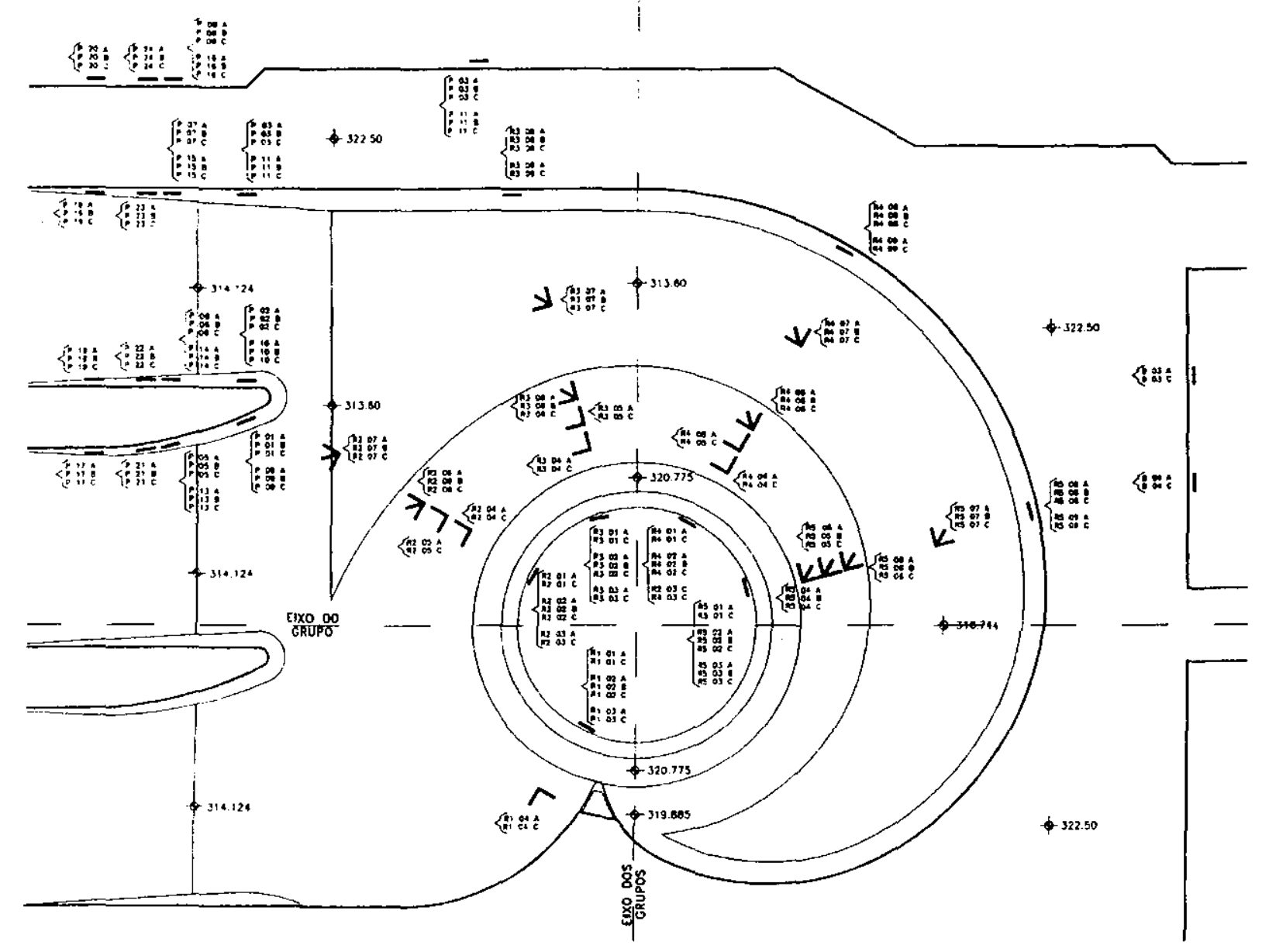

FIGURA 29 - Detalhes da instrumentação da Caixa Espiral do modelo no nível DD. (Fonte: CESP) 


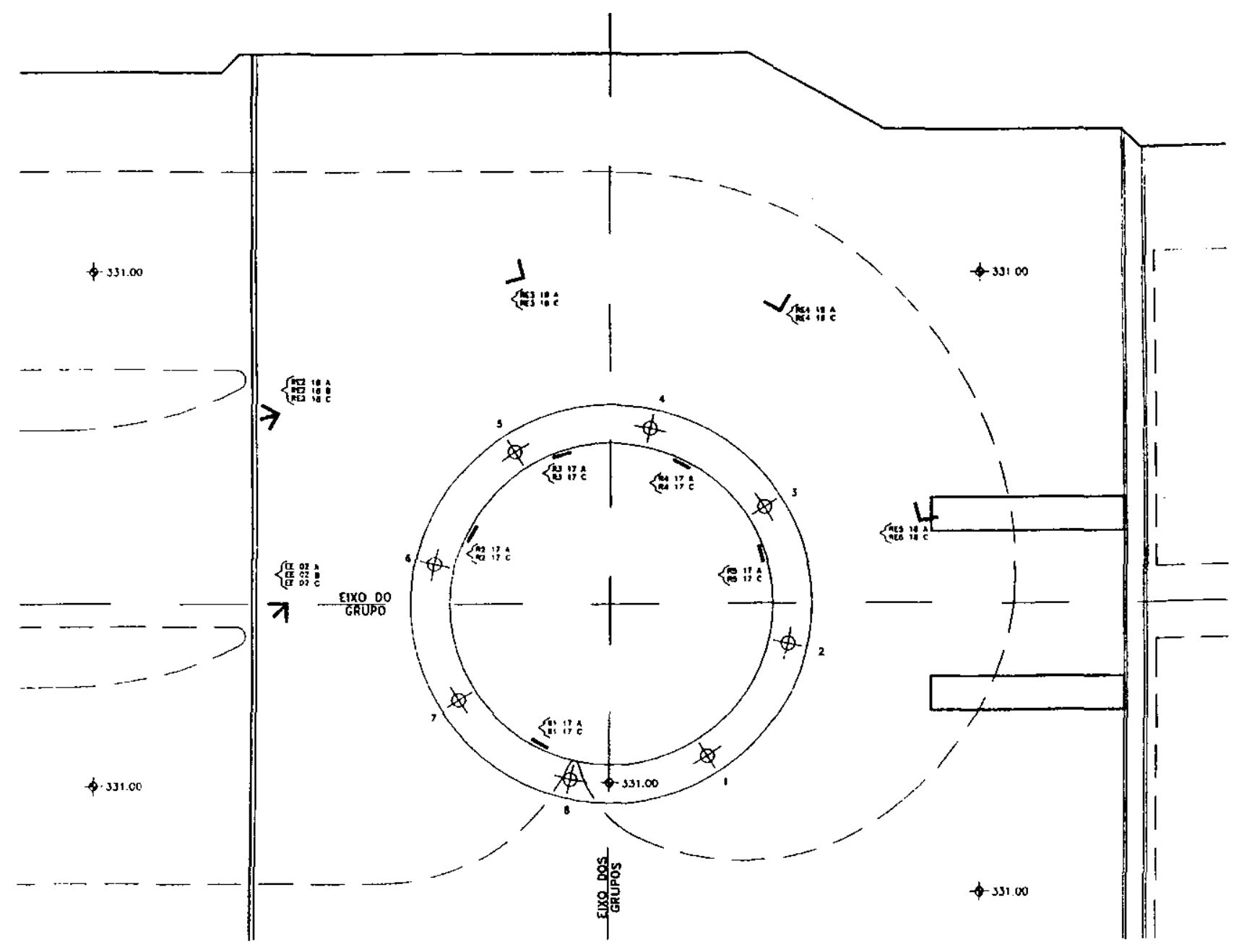

FIGURA 30 - Detalhes da instrumentação da Caixa Espiral do modelo no nível EE. (Fonte: CESP) 


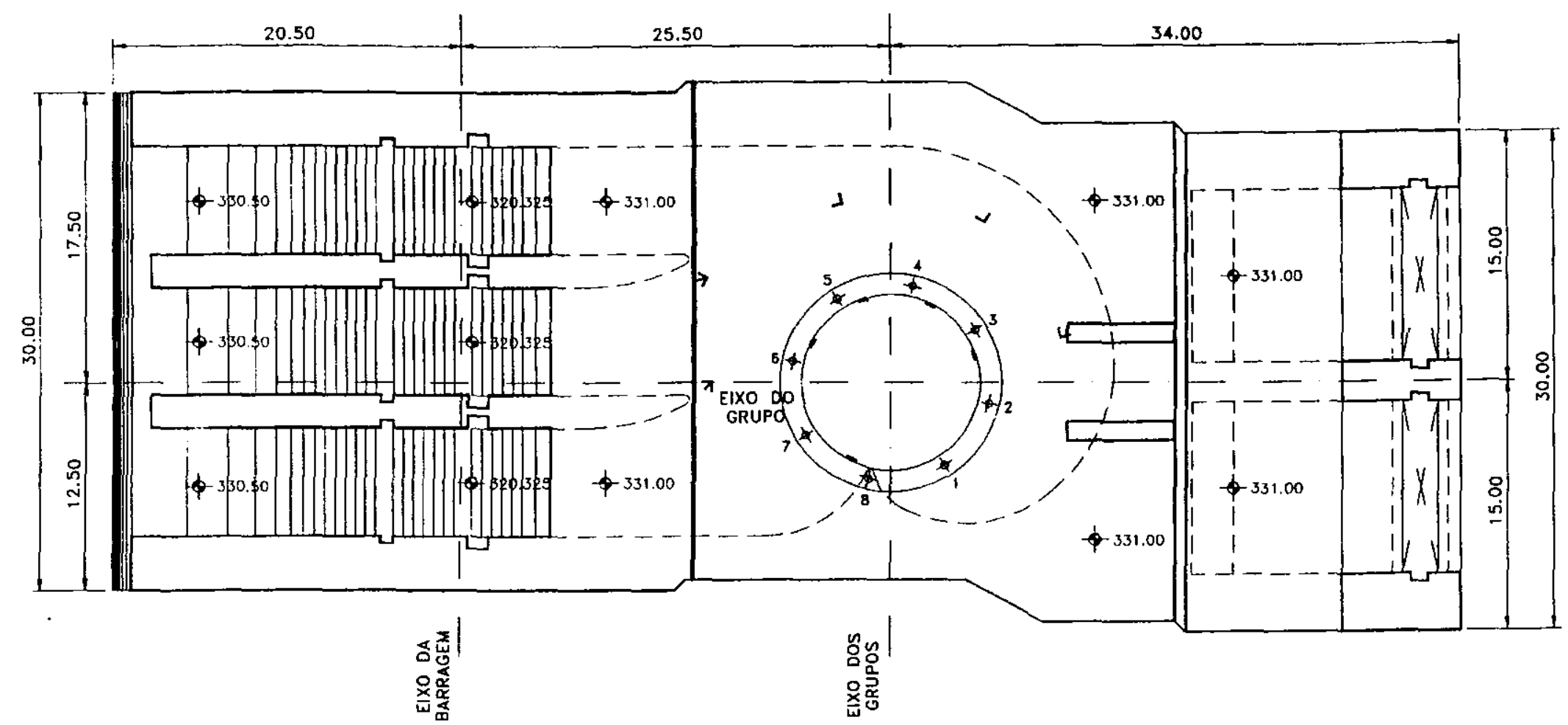

FIGURA 31 - Corte no nível FF do modelo físico reduzido. (Fonte: CESP) 


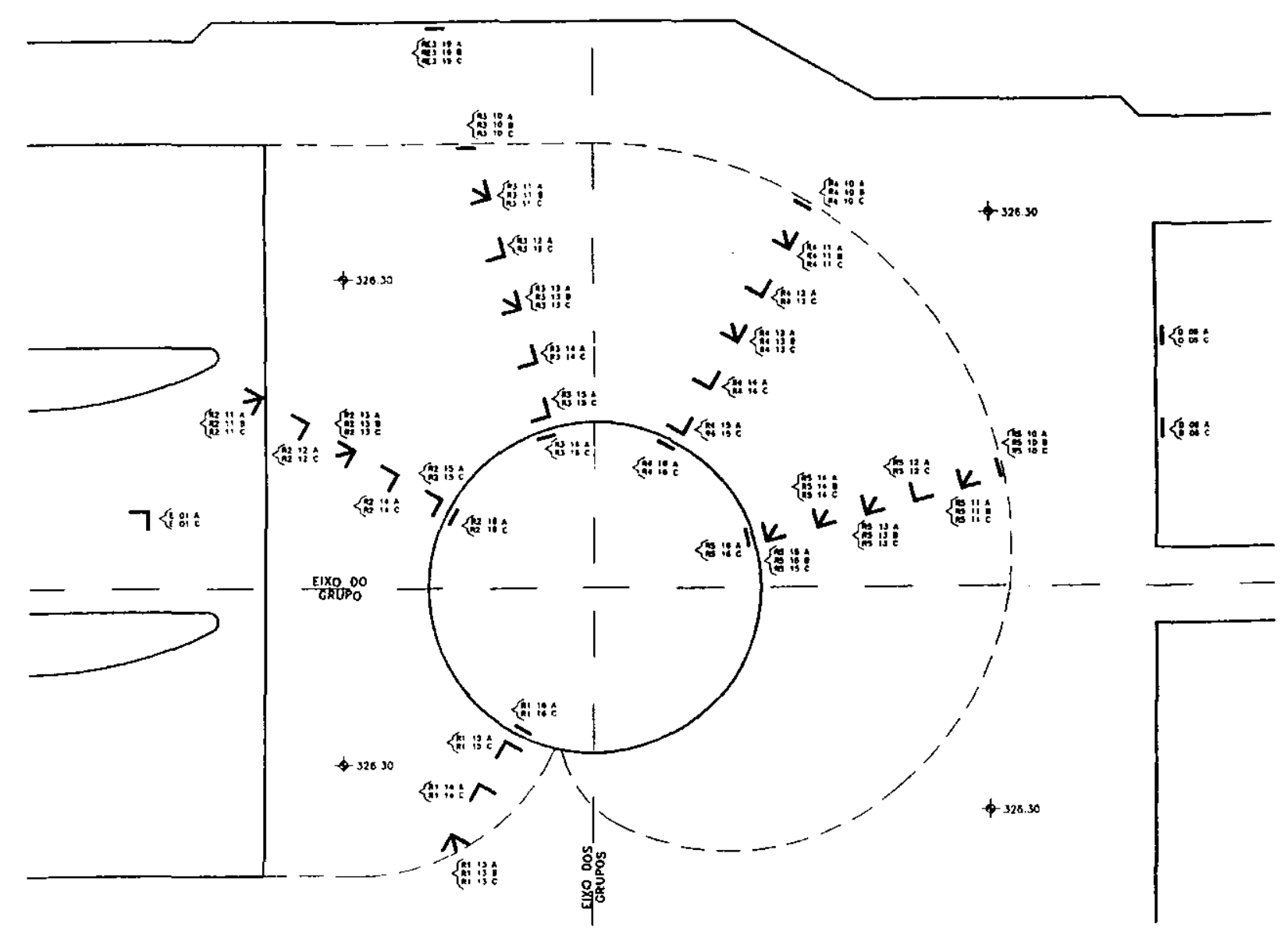

FIGUR\ 32 - Detalhes da instrumentação da Caixa Espiral do modelo no nível FF. (Fonte: CESP) 


\subsection{ENSAIOS REALIZADOS}

Foram realizados ensaios considerando-se três diferentes condições de carregamento:

1) protensão dos pré-distribuidores e carga distribuída uniformemente no perimetro do assento da máquina,

2) carga hidrostática nos paramentos de montante da tomada d'água a partir do N.A. $358,50 \mathrm{~m} \mathrm{e}$

3) carga hidrostática interna com pressão a montante e a jusante.

Para cada uma delas foram realizadas três repetições dos ensaios, sempre alternando-se os extensômetros ligados ao sistema de aquisição de dados, que toma três leituras por vez.

Durante um ensaio o modelo era carregado e descarregado 6 ou 8 vezes, gerando, respectivamente, 18 ou 24 leituras de deformações.

Na primeira condição de carregamento, aplicou-se inicialmente uma força de $100 \mathrm{~N}$ em cada pré-distribuidor, o que equivale a uma força de $5625 \mathrm{kN}$ no protótipo, considerando o fator de escala $\mathrm{Sp}=56.250$. Este valor está acima dos valores reais, mas foi adotado com o objetivo de obter medidas amplificadas.

Em seguida foi aplicada uma força de $800 \mathrm{~N}$ distribuida uniformemente na circunferência de diâmetro $11,80 \mathrm{~m}$ do assento da máquina. No protótipo esta força corresponde a $45.000 \mathrm{kN}$.

O pré-distribuidor consiste de uma haste de latão engastada na sua extremidade inferior, atravessando a parte superior da estrutura livremente, tendo um dinamômetro inserido antes da extremidade superior, onde existe uma porca que permite efetuar a protensão. Os 8 pré-distribuidores estão colocados na mesma circunferência do assento da máquina.

A simulação da carga hidrostática referente à segunda condição de carregamento, foi feita a partir da discretização do carregamento de distribuição 
triangular em 6 carregamentos uniformemente distribuídos, através do dispositivo mostrado na Figura 33.

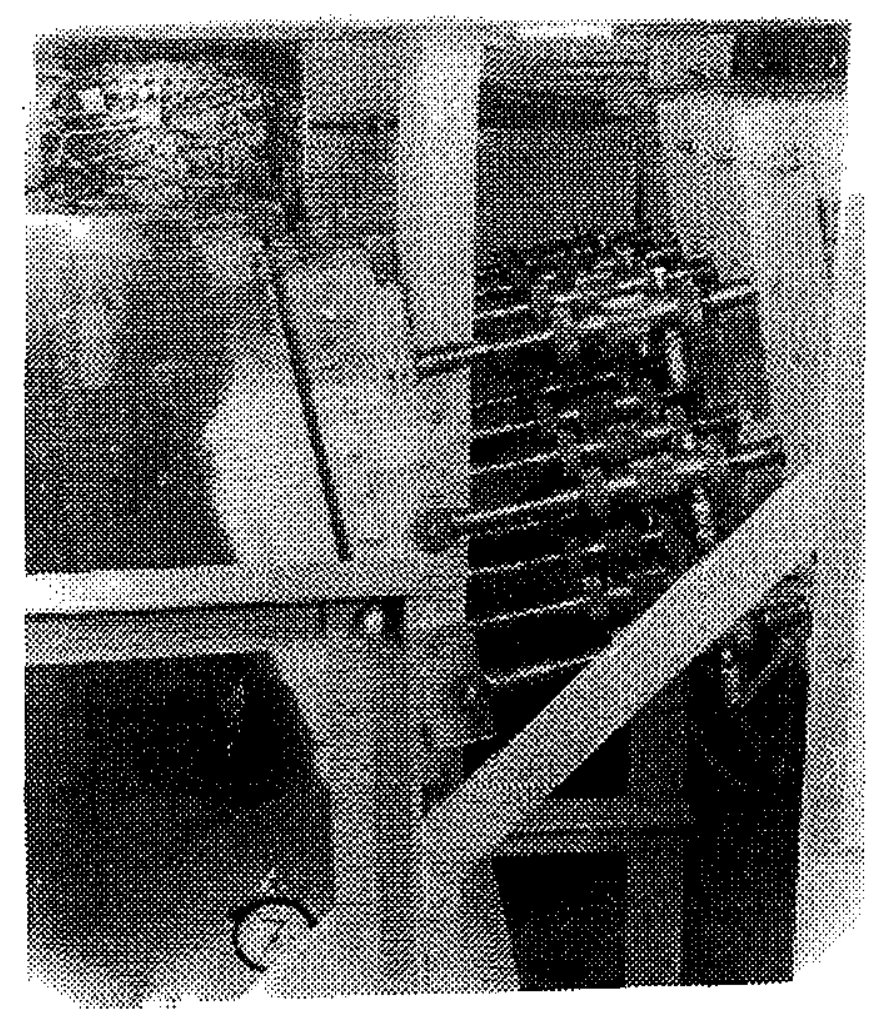

FIGURA 33 - Vista do dispositivo de aplicação de carga hidrostática nos paramentos de montante. (Fonte: CESP)

$\mathrm{Na}$ terceira condição de carregamento a aplicação da carga hidrostática interna com pressão foi realizada utilizando-se mercúrio. Para isso, o modelo foi dividido em dois circuitos hidráulicos distintos: o primeiro a montante, na tomada d'água e caixa espiral, e o segundo a jusante, no tubo de sucção e canal de fuga.

A utilização de mercúrio exigiu a proteção dos extensômetros com uma camada de silicone, como ilustrado pela Figura 34. 


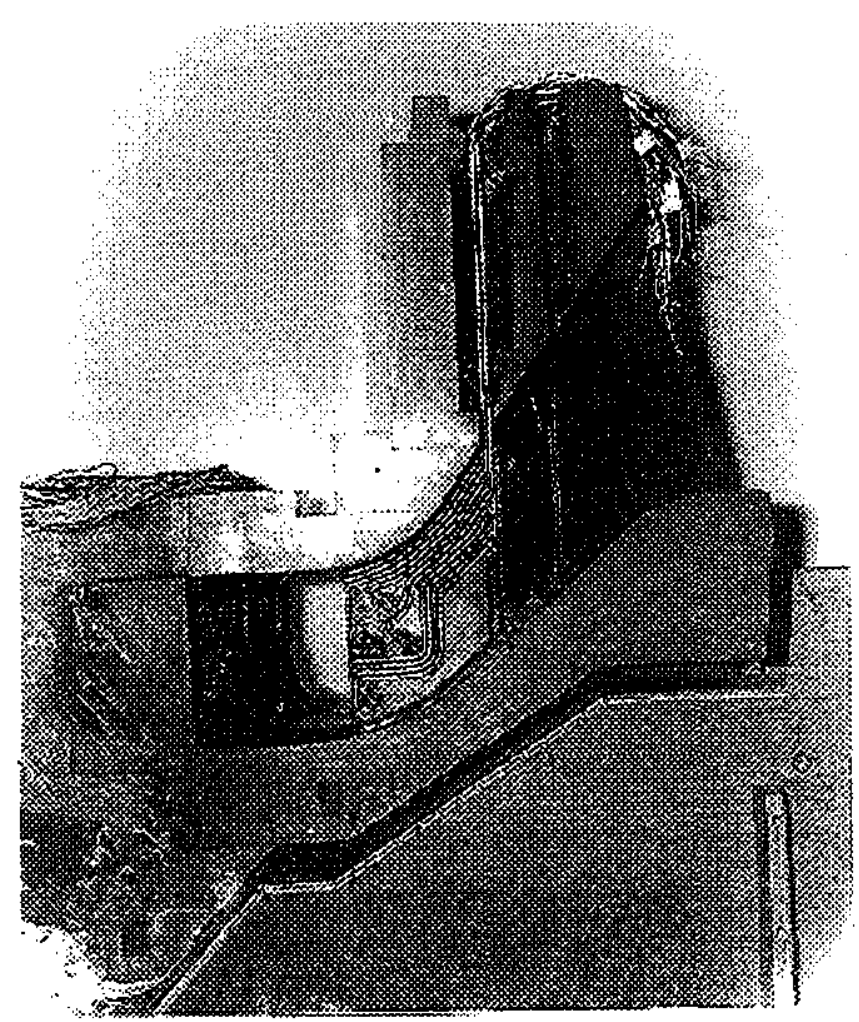

FIGURA 34 - Fase de montagem e proteção da instrumentação com uma camada de silicone (SYL-GARD $170 \mathrm{~A} / \mathrm{B}$ ) para preenchimento com mercúrio do carregamento hidráulico. (Fonte: CESP)

$O$ fator de escala de peso específico é 1/7,5. Isso significa que o líquido utilizado no carregamento do modelo deveria ter peso específico 7,5 vezes maior que a água, que carrega o protótipo e tem $\rho a=10^{4} \mathrm{~N} / \mathrm{m}^{3}$. No entanto, o mercúrio apresenta $\rho \mathrm{Hg}=1,36 \times 10^{5} \mathrm{~N} / \mathrm{m}^{3}$.

A fim de compensar a diferença provocada pela utilização de mercúrio, a carga hidrostática nos paramentos de montante, que tem valor máximo de $0,285 \mathrm{MPa}$ a uma profundidade de $28,5 \mathrm{~m}$ no protótipo, foi considerada igual a:

$$
\mathrm{p}=0,285 \times \rho_{\mathrm{Hg}} \times \mathrm{S}_{\rho}=0,285 \times 1,36 \times 10^{5} \times \frac{1}{7,5}=5,17 \times 10^{-3} \mathrm{MPa}
$$


Utilizando-se a lei de semelhança com fator de escala $S p=10$, chega-se ao valor da carga hidrostática máxima aplicada aos paramentos do modelo:

$$
\mathrm{q} 1=5,17 \times 10^{-4} \mathrm{MPa}
$$

Além destes ensaios foram realizados outros, auxiliares, com o objetivo de determinar as características do acrílico empregado no modelo: módulo de elasticidade e coeficiente de Poison.

Para a determinação da deformabilidade da grelha tridimensional que representa a fundação do modelo, foram feitos ensaios de compressão simples em três direções ortogonais em um corpo de prova cúbico, mostrado na Figura 35.

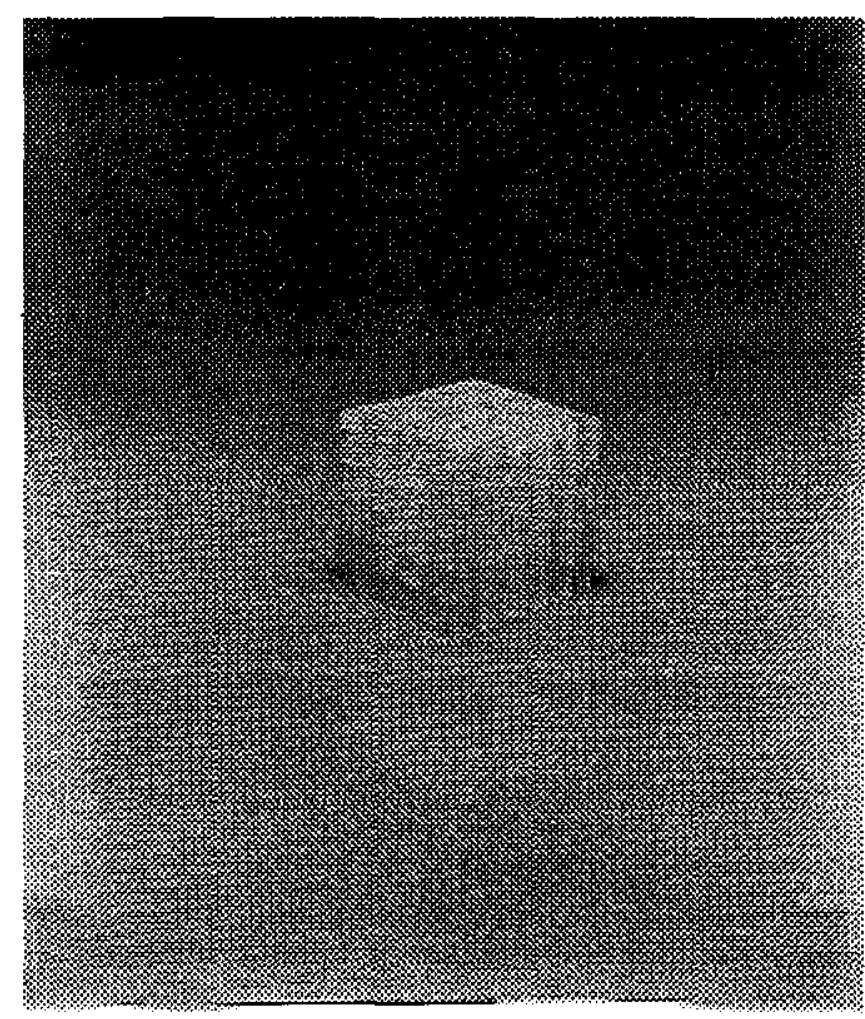

FIGURA 35 - Vista do corpo de prova do material de fundação, para determinação das propriedades elásticas. (Fonte: CESP) 
O conjunto de ensaio, devidamente montado e pronto para receber os carregamentos e possibilitar as leituras é mostrado na Figura 36.

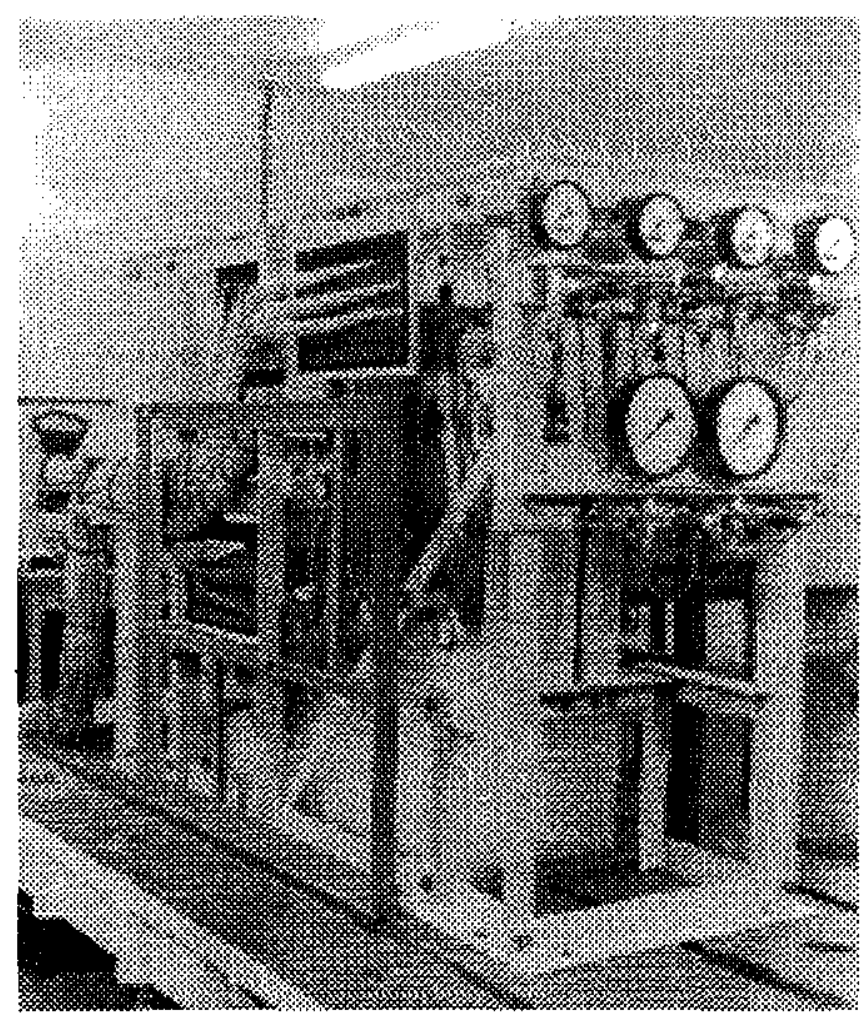

FIGURA 36 - Vista do conjunto de ensaio, mostrando-se o cabeamento, o dispositivo de fixação dos defletômetros e os demais dispositivos. (Fonte: CESP)

\subsection{RESULTADOS OBTIDOS}

Os resultados de ensaio do modelo apresentavam dispersão e alguns valores expúrios, exigindo a utilização de um processo de depuração. Dentre os vários existentes, VIOLANTE (1980) aplicou o processo baseado no critério de Chauvenet, conforme descrito por HETÉNYI (1950), para depurar resultados obtidos no ensaio sob cargas hidrostáticas internas. No presente trabalho foi utilizado o mesmo processo para os resultados dos outros casos de carregamento 
O critério consiste na fixação de uma tabela com a relação "x/s", entre a semi-largura da faixa de valores representativos e o desvio padrão do conjunto, para um conjunto de $\mathrm{n}$ valores medidos.

Multiplicando-se " $\mathrm{x} / \mathrm{s}$ " pelo desvio padrão "s", calculado de todas as medidas, resulta o valor " $\mathrm{x}$ " que, somado e subtraído da média das mesmas, define os limites superior e inferior, respectivamente, do intervalo que deverá conter todas as medidas representativas.

Se algum valor ficar fora do intervalo obtido, deve ser eliminado, sendo esse processo repetido iterativamente, até que todos os valores não representativos sejam expurgados. A totalidade dos valores pode ser representada pela média do conjunto resultante da depuração.

O sistema de aquisição HP 2012-B, lendo medidas de 200 extensômetros, em cada uma das 3 repetições em que eram feitas, em média, 20 observações, forneceu 12.000 valores por caso de carregamento, ou seja, um total geral aproximado de 36.000 dados.

Esse universo de medidas foi digitado em 9 planilhas, cada uma com 4.000 medidas de grupos de 200 extensômetros, através do software EXCEL, que efetuou a depuração automaticamente.

Com as deformações assim obtidas, tornou-se possível calcular as tensões nas mesmas direções.

Nos pontos onde foram instaladas rosetas retangulares, com 3 extensômetros, nas direções A, B e C (A e C perpendiculares entre sí e B a $45^{\circ}$ de ambas), havia a possibilidade de determinar as deformações, tensões e direções principais.

Como não era possível calcular os valores principais para todos os pontos, já que alguns foram instrumentados com rosetas em cruz, que não dispõem dos extensômetros na direção $B$, foram consideradas as tensões somente na direção A. 
Os cálculos das tensões a partir das deformações também foram realizados com o software EXCEL, programado com a formulação da Lei de Hooke, assumindo módulo de elasticidade $\mathrm{E}$ e coeficiente de Poison $v$ iguais a $3.000 \mathrm{MPa}$ e 0,36 respectivamente.

Os resultados das tensões calculadas são apresentados no capitulo 5. 


\section{CAPÍTULO 3}

\section{AUSCULTAÇÃO DO PROTÓTIPO}

\subsection{ASPECTOS GERAIS}

Segundo PEDRO \& FLORENTINO (1989), além de atender ao objetivo fundamental de controlar a segurança, a auscultação do protótipo, ou seja da estrutura real, em escala natural, dá importantes contribuições para a verificação dos critérios de projeto e para o progresso dos conhecimentos, permitindo o aperfeiçoamento da qualidade e economia das obras.

São utilizados instrumentos de medição para as mais variadas grandezas fisicas, como tensões, deformações, temperaturas, deslocamentos, vazões e outras.

Os custos de instrumentação são consideráveis e o investimento inicial ainda é seguido por despesas adicionais, com a observação contínua e análise dos dados (CORNS et al., 1988).

De modo geral, a instrumentação é compensatória para barragens de grande porte, de acordo com AMERICAN SOCIETY OF CIVIL ENGINEERS; UNITED STATES COMITTEE ON LARGE DAMS (1967). Entretanto, existe a tendência de que, com a redução dos custos, torne-se viável sua instalação em obras cada vez menores.

O artigo OS PERCALÇOS da instrumentação de obras (1987) conta que, no Brasil, a instrumentação nasceu no Instituto de Pesquisas Tecnológicas do Estado de São Paulo (IPT), por volta de 1935, graças ao trabalho pioneiro de vários 
profissionais, entre eles Telêmaco Van Langendonck e Milton Vargas. A técnica brasileira evoluiu principalmente a partir dos anos 60, com as grandes barragens,sendo Ilha Solteira a primeira totalmente instrumentada.

O COMITÊ BRASILEIRO DE GRANDES BARRAGENS (1986) confeccionou um manual com recomendações para a formulação e verificação de critérios e procedimentos sobre segurança de barragens nas fases de projeto, construção, operação e abandono das obras.

Distingüi-se, em função da localização na obra, a instrumentação geotécnica da utilizada para estruturas de concreto, devido às diferentes características dos materiais e das grandezas fisicas a serem medidas.

A instrumentação deve estar protegida contra danos durante a construção, ser instalada em seções representativas dos trechos auscultados, mas sem afetar a integridade estrutural nem alterar as características físicas das seções, possibilitando sua observação.

As leituras são feitas desde o início da obra, para testar o seu funcionamento e garantir um máximo de informações, visando controlar o comportamento dos blocos e estruturas durante as diversas fases da obra, particularmente as mais críticas, como a de enchimento do lago.

Periodicamente a instrumentação é inspecionada a fim de se verificar sua confiabilidade.

Nas estruturas de concreto, objetiva-se controlar a ocortência de vazamentos, desalinhamentos, deterioração material, recalques diferenciais, abertura excessiva de juntas de contração e o aparecimento de trincas. As áreas expostas a elevadas velocidades de água são inspecionadas quanto a sinais de erosão ou cavitação.

Se a estrutura vier a ser abandonada, mas parte dela permanecer, o manual alerta que o monitoramento deve prosseguir até a remoção completa dos componentes estruturais. 


\subsection{O SISTEMA SEGURANÇA DE BARRAGENS}

O controle sobre o comportamento estrutural das 21 usinas da CESP é realizado no Laboratório Central de Engenharia Civil, para onde são encaminhadas as leituras realizadas nas usinas.

No laboratório é feita a compilação e são confeccionados gráficos, que juntamente com dados das inspeções visuais e subaquáticas, vão compor relatórios sobre a situação das estruturas.

Conforme CARPENTER et al. (1988), SAINI (1988), WALZ (1989), e SILVEIRA (1994), a automação no gerenciamento desses dados corresponde a uma tendência internacional.

Nos Estados Unidos, por exemplo, foram implantados dois grandes sistemas computadorizados, um do US Army Corps of Engineers, que mantém 557 barragens, e outro do Bureau of Reciamation.

De acordo com relatório da CESP (1988) esse conjunto de atividades passou a ser informatizado na empresa através do Sistema Segurança de Barragens (SSB), desenvolvido a partir de convênio com a Fundação para o Desenvolvimento Tecnológico da Engenharia (FDTE).

No SSB toda a atividade de compilação, que inclui a verificação da consistência, cálculos, elaboração de tabelas e gráficos, além do arquivamento dos dados históricos, é executada por uma rede de microcomputadores padrão IBM-PC nas usinas, interligada com o computador central ou "Mainframe", IBM-3090, e com outros microcomputadores instalados nas áreas responsáveis pela análise.

O sistema é composto por três unidades: Unidade de Manutenção (UM), Unidades de Registro (UR) e Unidades Centrais (UC)

A UM efetua o cadastramento dos dados básicos dos instrumentos, arquivando essas informações no "Mainframe". 
As UR's retiram do "Mainframe" os dados atualizados de cadastro, recebem as leituras digitadas, efetuam consistência, transformam essas leituras em grandezas de interesse, emitem relatórios de observações e arquivam os dados no "Mainframe".

As UC's retiram do "Mainframe" os dados de cadastro e arquivos históricos de medidas calculadas, emitem tabelas e os gráficos correspondentes, facilitando a tarefa de análise.

\subsection{AUSCULTAÇÃO DA BARRAGEM NOVA AVANHANDAVA}

O término das obras da Barragem Nova Avanhandava deu-se em 1982, quando ocorreu o enchimento do lago. A primeira unidade geradora de eletricidade começou a operar no mesmo ano e a última, em 1985, completando o carregamento da estrutura.

No entanto, a partir de setembro de 1980 já iniciavam-se as primeiras leituras nos instrumentos de auscultação, de acordo com a CESP (1981a).

As estruturas de concreto do aproveitamento contam com dispositivos de auscuitação com finalidades específicas, para observação de deslocamentos absolutos e relativos; e tensões e deformações nos diversos tipos de material.

Segundo a CESP (1992), a empresa utiliza, na confecção de seus instrumentos, princípios de funcionamento mecânicos, elétricos, pneumáticos, magnéticos, hidráulicos e óticos.

Para observar os deslocamentos absolutos há os Marcos de Referência, Pêndulos Invertidos e Cadeias Clinométricas. Pêndulos Diretos e Medidores de Junta (mecânicos e elétricos) medem os deslocamentos relativos. 
Nas zonas de concreto simples estão instalados Extensômetros para Concreto (EC), para a medição de deformações e Tensômetros para Concreto (TC), para tensões. A medição de tensões no concreto armado se dá através de Tensômetros para Concreto Armado (RC), que anteriormente recebiam a denominação Tensômetros para Armadura (TA).

Além desses instrumentos, ainda são utilizados Células de Carga para forças de protensão da Viga Munhão, Termômetros para o concreto e para a água, Drenos e Piezômetros para observação das subpressões, Medidores de Vazão para as galerias de drenagem, e os instrumentos geotécnicos, como Medidores de Nível d'Água, Piezômetros, Medidores de Recalque, Células de Tensão Total, Extensômetros de Hastes e Extensômetros de Grande Base.

\subsection{INSTRUMENTAÇÃO PARA TENSÕES NAS ESTRUTURAS DE CONCRETO DE NOVA AVANHANDAVA}

A instrumentação da Barragem Nova Avanhandava conta com Tensômetros para Concreto Armado (RC) e Tensômetros para Concreto (TC) para a auscultação das tensões nas estruturas de concreto, instalados nas zonas consideradas mais convenientes, com o objetivo de verificar a configuração geral do fluxo de tensões e o controle dos valores máximos correspondentes às diversas fases de carregamento.

De acordo com INTERNACIONAL DE ENGENHARIA (1983a), os Tensômetros para Concreto Armado são do tipo LCEC, produzidos nos laboratórios da CESP, utilizando extensômetros colados em barras de armadura protegidos contra a umidade por meio de materiais sintéticos. Foram instalados em substituição aos medidores norte-americanos, de fabricação Carlson. Ilustração com uma secção do instrumento é mostrada na Figura 37. 


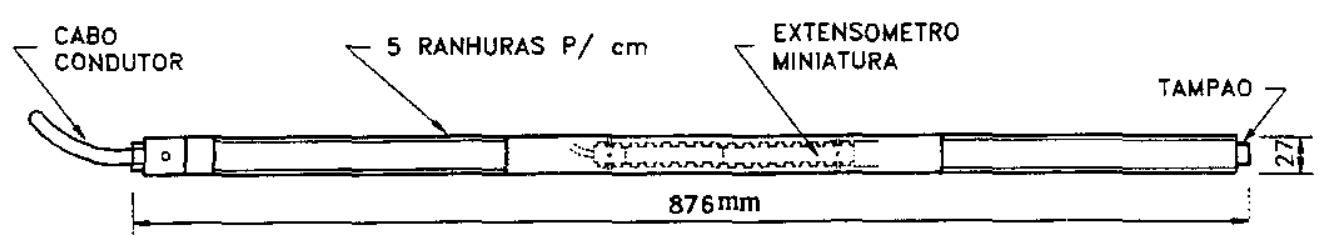

FIGURA 37 - Secção do tensômetro para concreto armado (RC). (Fonte: CESP)

No total existem 38 aparelhos deste tipo nas estruturas de concreto do aproveitamento, numerados de RC-301 até RC-338, sendo que, destes, 11 situam-se no conjunto TA/CF-02, os numerados de RC-317 a RC-327.

Para a observação de tensões de compressão no concreto, foram instalados 14 Tensômetros para Concreto, dos quais 7 se encontram no conjunto TA/CF-02 (COMPANHIA ENERGÉTICA DE SÃO PAULO, 1981b).

Conforme INTERNACIONAL DE ENGENHARIA (1983a), são aparelhos do tipo "Stress-Meters", de fabricação Carlson, constituídos basicamente de um disco de $18,5 \mathrm{~cm}$ de diâmetro e $1,30 \mathrm{~cm}$ de espessura, contendo em seu interior um filme de mercúrio, formando uma "almofada".

O esforço de compressão do concreto é transmitido à almofada e conseqüentemente ao mercúrio nela contido. A pressão a que fica submetido o mercúrio é medida através da deformação de um diafragma metálico, situado no centro da placa superior da almofada, relacionando-a com a variação da relação de resistências ocorrida em meia ponte de Wheatstone. A Figura 38 apresenta um esquema do instrumento.

Esse tipo de instrumento apresenta uma sensibilidade de aproximadamente $0,035 \mathrm{MPa}$ para as tensões lidas. Para sua instalação, segundo um plano transversal ao eixo da barragem, em grupos de três, posicionados na vertical, horizontal e inclinado a $45^{\circ}$, é necessária a construção de um recesso, de acordo com o esquema descrito na Figura 39. 


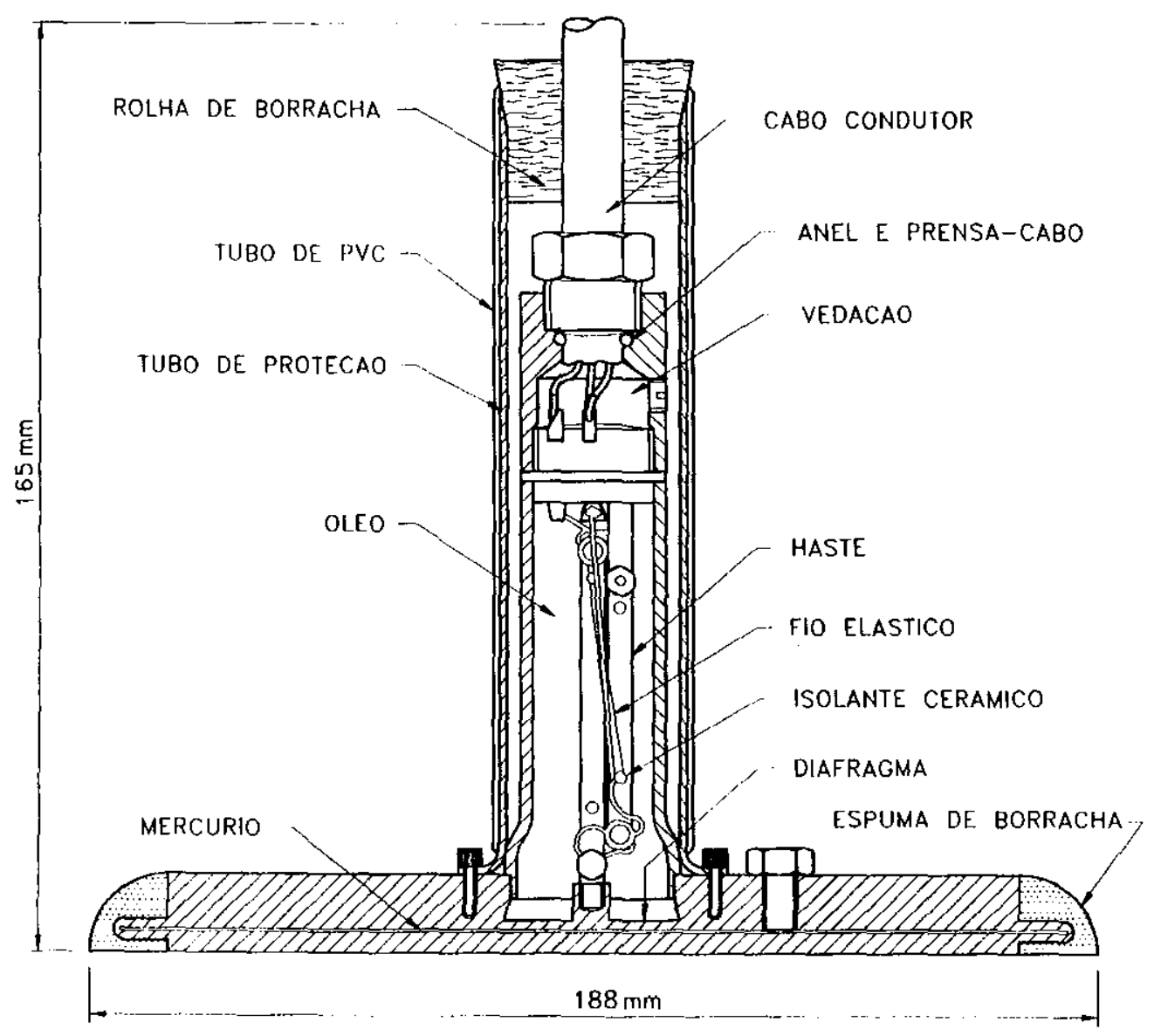

FIGURA 38 - Secção do tensômetro para concreto. (Fonte: CESP) 


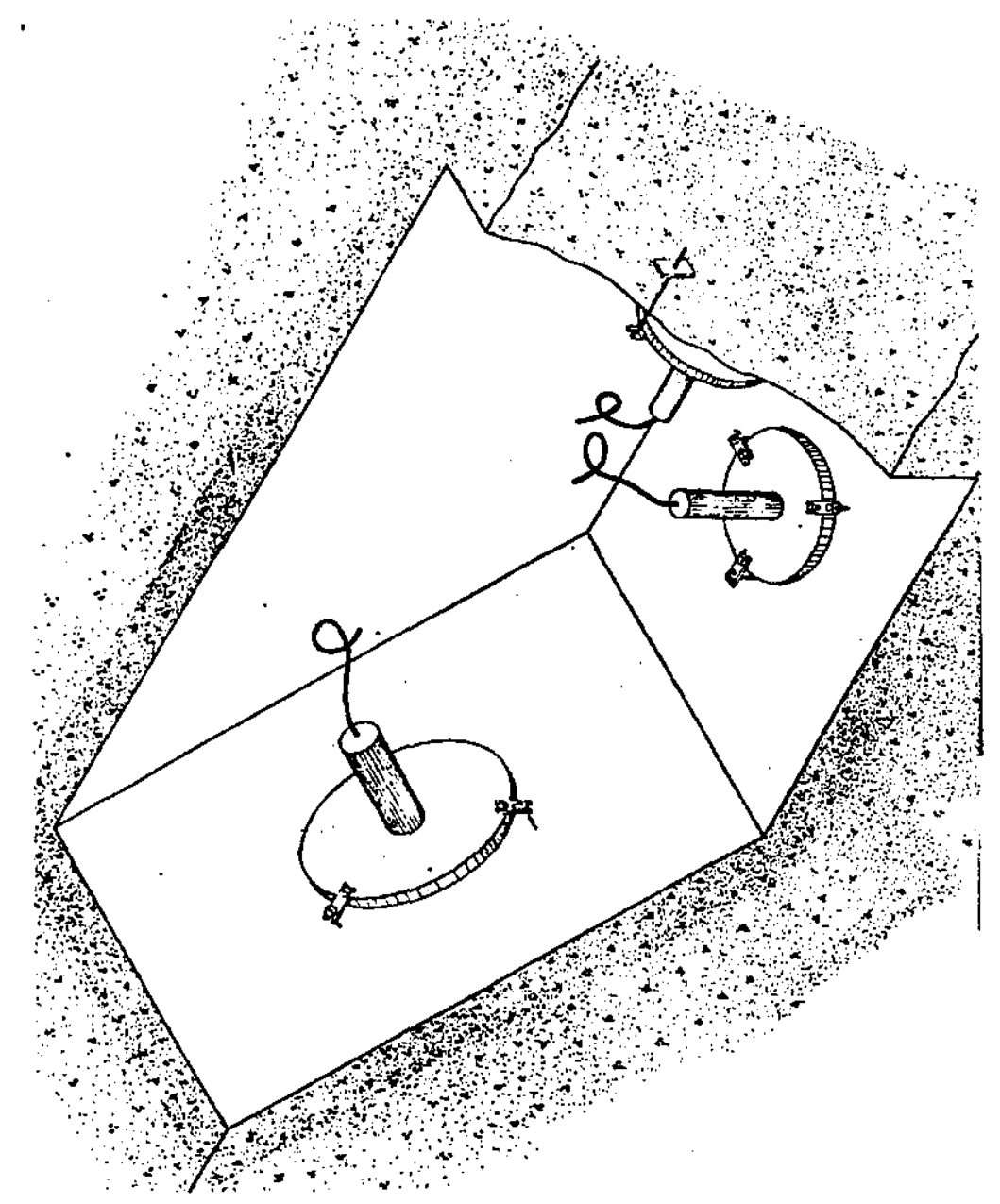

FIGURA 39 - Perspectiva do recesso para instalação dos Tensômetros para Concreto. (Fonte: CESP)

\subsection{PONTOS INSTRUMENTADOS}

Os instrumentos para medição de tensões no conjunto TA/CF-2 somam 7 Tensômetros para Concreto (TC), instalados em 3 pontos, e 11 Tensômetros para Concreto Armado (RC), situados em 11 pontos, totalizando 18 instrumentos em 14 pontos. 
Deste conjunto de pontos instrumentados, serão de interesse para o presente trabalho somente os 3 pontos com Tensômetros para Concreto, uma vez que os demais apresentam resultados de tensão na armadura, não sendo possível, portanto, a comparação desses resultados com os da análise pelo Método dos Elementos Finitos, tendo em vista que este último baseia-se nas hipóteses da Teoria da Elasticidade, entre elas, a de homogeneidade do material.

As disposições dos Tensômetros para Concreto no conjunto Tomada d'Água/Casa de Força 2 encontram-se representadas nas Figuras 40, 41 e 42 . Em cada um dos 3 pontos instrumentados foi construído um recesso, de modo que no primeiro instalou-se apenas um instrumento, o TC-304; no segundo foram instalados os medidores TC-305, TC-306 e TC-307; e no último, TC-312, TC-313 e TC-314. Os resultados das leituras são apresentados no capítulo 5.

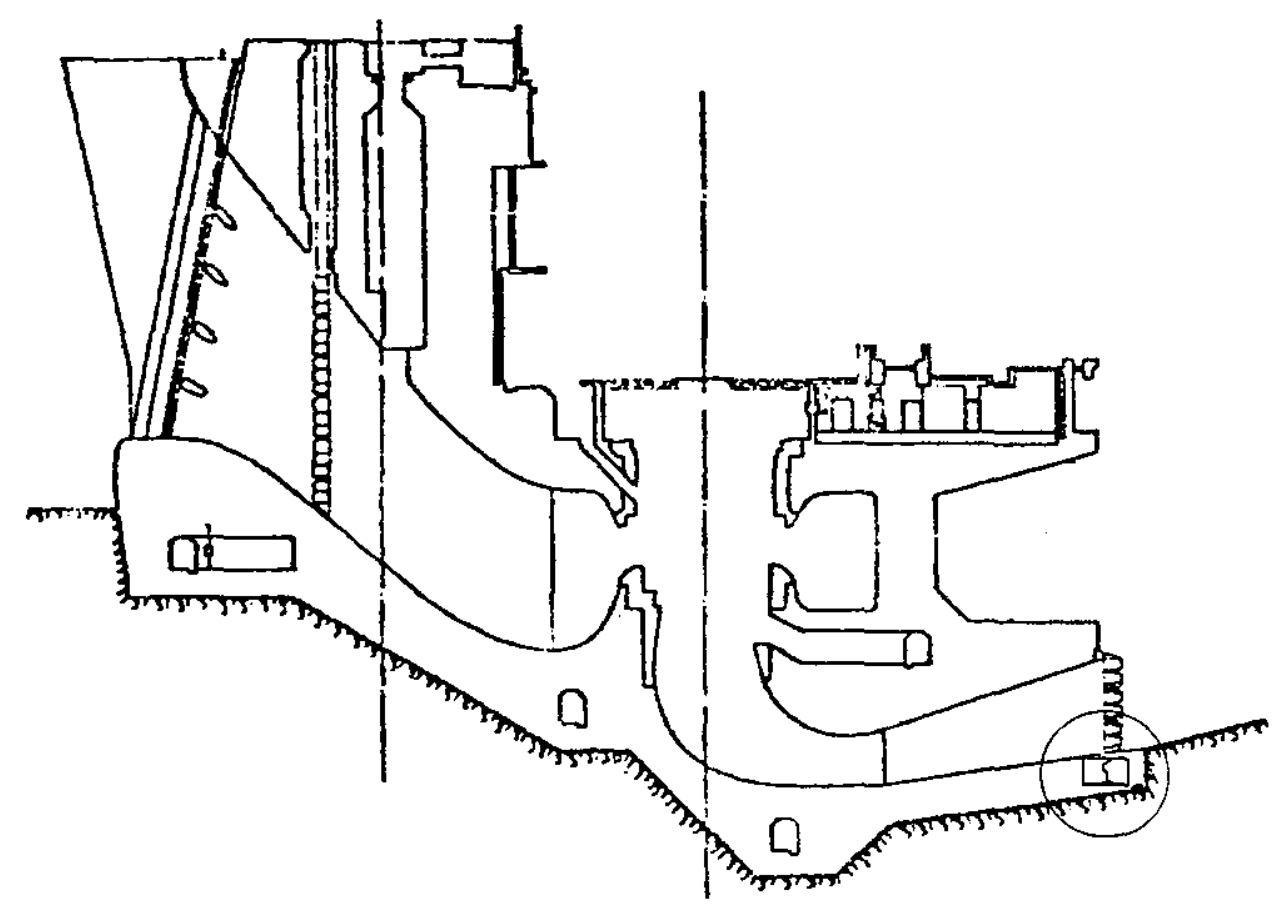

FIGURA 40 - Localização do TC-304. (Fonte: CESP) 


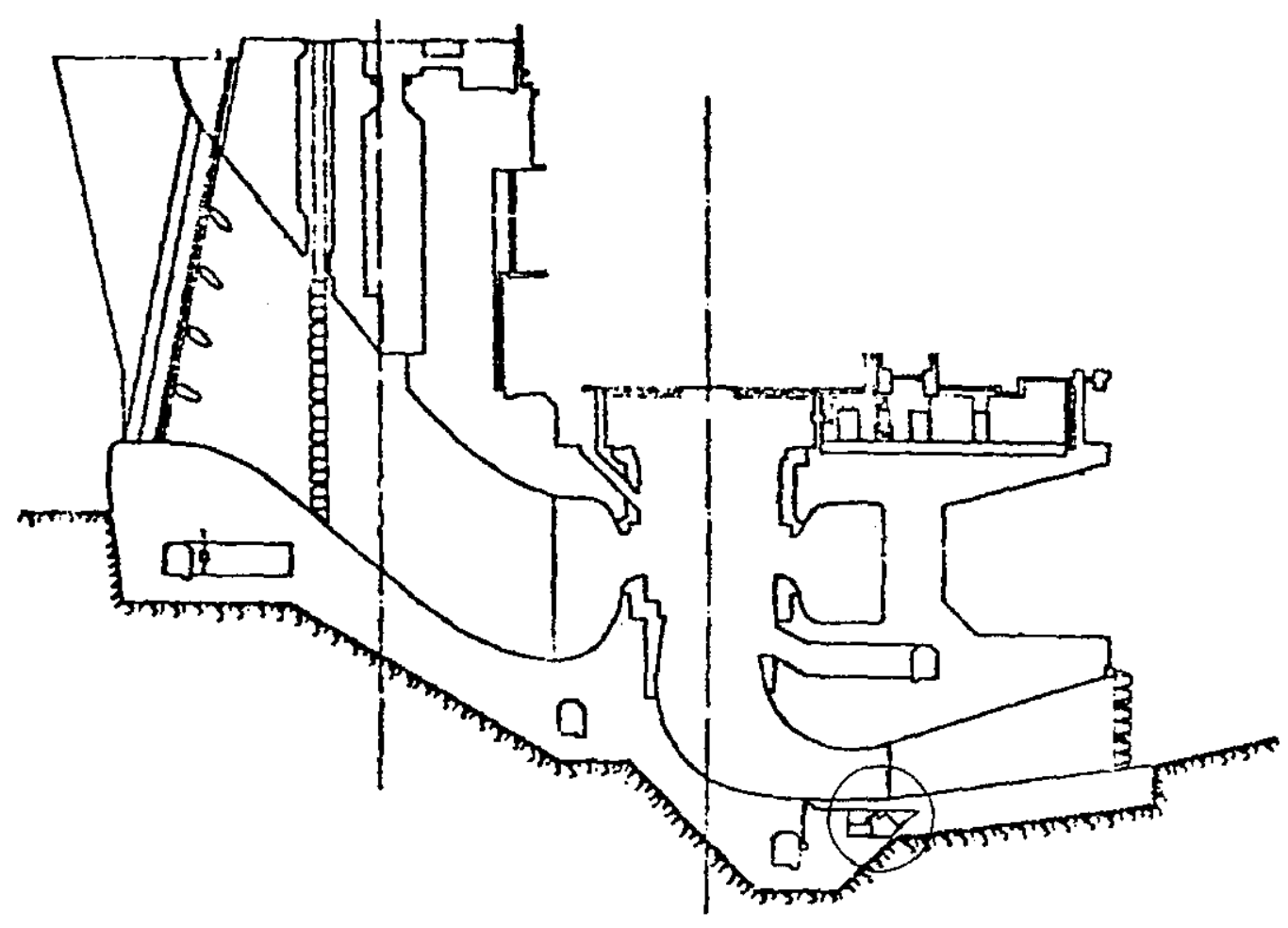

FIGURA 41 - Localização dos TC-305, TC-306 e TC-307. (Fonte: CESP)

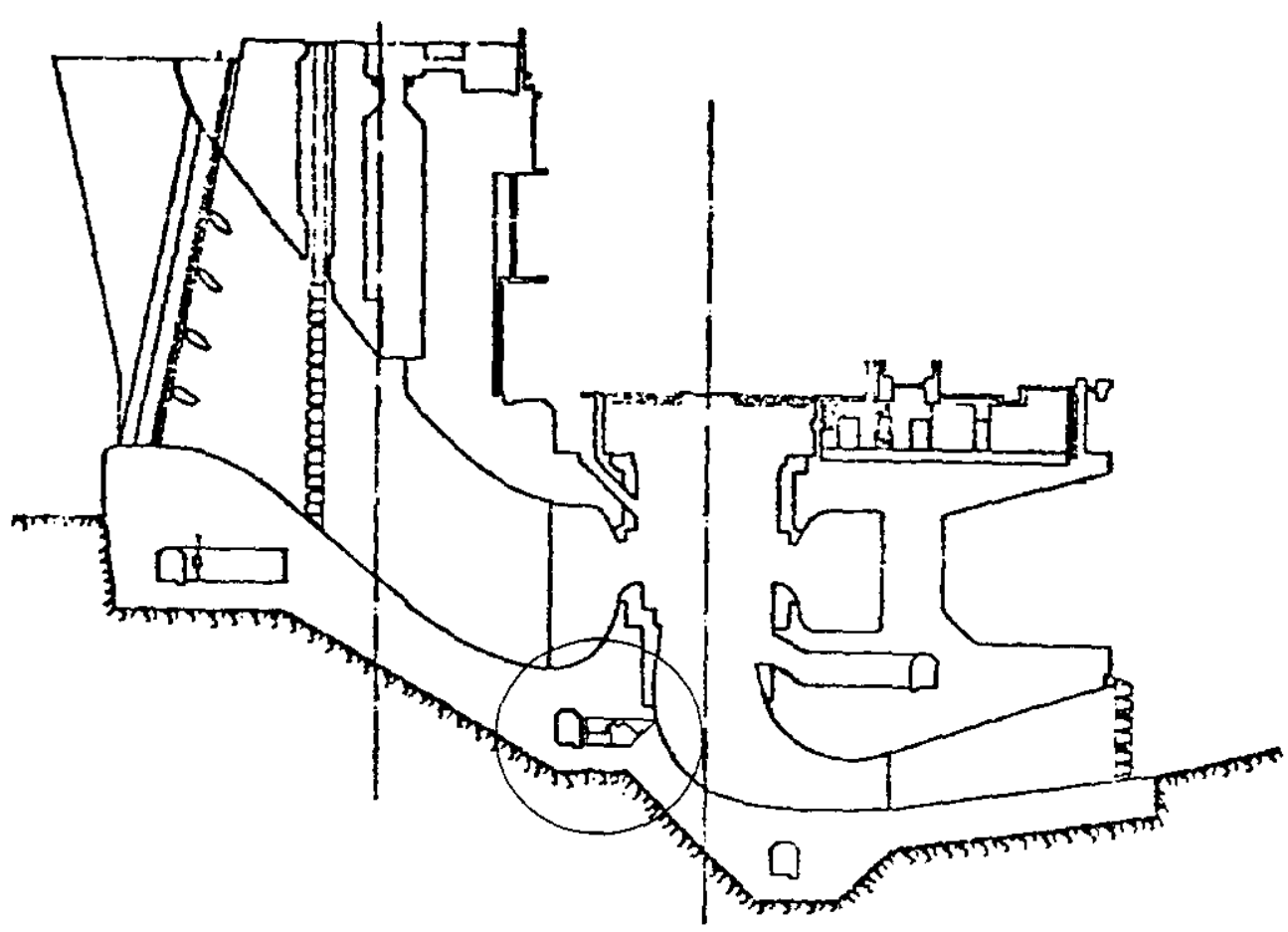

FIGURA 42 - Localização dos TC-312, TC-313 e TC-314. (Fonte: CESP) 


\section{CAPÍTULO 4}

\section{MODELAGEM POR ELEMENTOS FINITOS}

A análise pelo método dos elementos finitos foi realizada através do software SAP-90, desenvolvido pela Computers and Structures Incorporation, dos Estados Unidos, por tratar-se de programa utilizado com sucesso em vários países.

O programa possibilita a utilização de quatro diferentes tipos de elementos finitos: Frame, Shell, Asolid e Solid.

O elemento tipo "Frame" é utilizado para a simulação das estruturas compostas de barras.

O elemento tipo "Shell" é utilizado para as estruturas bidimensionais, como as membranas, placas e cascas.

Os outros dois tipos de elementos são utilizados para estruturas tridimensionais. $\mathrm{O}$ "Asolid" para a resolução de equilíbrios axissimétricos em sólidos de revolução submetidos a estado plano de tensão ou deformação e o "Solid" para modelagem de equilíbrios tridimensionais em geral.

No presente trabalho foram utilizados o "Solid", que é um elemento tipo "brick" de formulação isoparamétrica com 8 nós, e "Asolid", bidimensional com 9 nós.

BARBOSA et al. (1994) discutem métodos de análise estrutural de caixa espiral de uma turbina tipo Francis com elementos bidimensionais e tridimensionais, 
concluindo que os resultados se aproximam satisfatoriamente, quando os carregamentos permitem uma modelagem axissimétrica.

Conclusão semelhante foi tirada por ZIENKIEWICZ et al. (1975) do estudo comparativo entre resultados analíticos e experimentais no projeto de uma barragem tipo gravidade aliviada, a barragem Carrapatelo. Os resultados da análise bidimensional se aproximaram dos da análise tridimensional.

O modelo físico de Nova Avanhandava foi ensaiado sob cargas que não estavam contidas nos planos das seções transversais da caixa espiral, como as cargas hidrostáticas sobre os paramentos de montante, fato que torna impossivel a simulação desse caso de carregamento através de análise bidimensional, obrigando à consideração somente dos outros casos através desse tipo de análise.

A seç̧ão R3 da Caixa Espiral é geométricamente semelhante às demais, apresentando maiores dimensões. Além disso, no ensaio do modelo físico essa região foi a que proporcionou maior número de leituras, pois no rodízio imposto pela limitação do sistema de aquisição de dados, seus extensômetros sempre permaneciam conectados.

Por esses motivos, esta secção foi tomada como representativa das demais, e o modelo numérico bidimensional simulou apenas o seu comportamento.

Os elementos sólidos tridimensionais foram utilizados, apesar da dificuldade em relação aos bidimensionais, com vistas a possibilitar a verificação da influência de todas as cargas.

As montagens dos modelos bi e tridimensional permitiram o estabelecimento de comparações entre esses dois procedimentos de análise.

\subsection{MODELAGEM TRIDIMENSIONAL}

O primeiro passo para uma análise numérica é a discretização da estrutura. $\mathrm{Na}$ modelagem tridimensional, a discretização levou a elementos com 
arestas de comprimento médio aproximado de $4 \mathrm{~m}$, em escala natural, chegando a $0,5 \mathrm{~m}$ na região central da caixa espiral, objeto deste estudo, e a mais de $30 \mathrm{~m}$ nas fundações. $O$ processamento se deu na escala $1 / 75$, a partir de conversão feita pelo próprio SAP-90.

A entrada de dados no software é feita via arquivo-texto, segundo sintaxe própria, no qual as informações são organizadas em blocos que definem informações de controle do sistema, dados dos nós do modelo com suas respectivas coordenadas, vinculações, carregamentos, características dos elementos, inclusive propriedades dos materiais de que se compõe e outros.

Foram utilizados os geradores automáticos de nós linear, circunferencial e frontal, mas a falta de um gerador tridimensional na versão do programa utilizada levou a um consumo estimado de 1.000 horas de trabalho para a geração da malha.

Adotou-se um sistema de coordenadas global composto por um eixo vertical coincidente com o eixo do grupo gerador (eixo $\mathrm{Z}$ ), com sentido de baixo para cima; outro, horizontal, paralelo ao eixo do conjunto dos grupos geradores (eixo Y), com sentido da ombreira direita da barragem para a esquerda; e o terceiro no sentido do fluxo do rio (eixo X).

A rocha de fundação e o corpo da barragem foram divididos em 18 camadas horizontais sobrepostas, a maioria delas com 200 nós, em média, cada uma, totalizando cerca de 3.500 nós e 2.200 elementos.

Segundo WILSON \& HABIBULLAH (1989), a capacidade do software é de 4.000 nós ou 10.000 equações, e o número de equações depende do número de nós, do número de graus de liberdade de cada nó e das condições de vinculação da estrutura.

Cada nó foi gerado com 3 graus de liberdade, correspondentes às 3 translações, exceto os 200 nós da camada inferior, totalmente fixos. Com isso, formou-se um sistema composto por 9.870 equações.

A adoção de um eixo do sistema de coordenadas global, coincidindo com o eixo da caixa espiral, e o posicionamento da origem no Nivel do Mar, referencial de 
todas as cotas constantes nas pranchas fornecidas pela projetista, facilitou o trabalho de geração da malha de nós, que se deu a partir das dimensões do protótipo, em metros. Utilizou-se o recurso do SAP-90 que permite adotar um fator de escala, no caso $s=1 / 75$, incluído na primeira linha do bloco de dados referentes aos nós.

A numeração dos nós foi feita com números compostos de 4 dígitos, de modo que os primeiros indicam a camada a que o nó pertence e os últimos, a posição do nó na camada.

Numerou-se os nós de cada camada a partir do tubo ao redor do eixo $Z$, em circunferências concêntricas, de forma crescente até os limites da Caixa Espiral, no sentido horário para quem observa de cima para baixo.

Os nós da região do Canal de Fuga foram numerados a partir da região mais próxima à Caixa Espiral, em linhas paralelas ao eixo $\mathrm{Y}$, mas crescendo no sentido inverso.

Na região da Tomada d'Água a numeração dos nós foi feita a partir da região mais próxima da Caixa Espiral, em linhas paralelas ao eixo $\mathrm{Y}$, crescente no mesmo sentido, da direita para a esquerda da barragem.

Os números dos nós crescem de cima para baixo, com passo $300 \mathrm{de}$ camada para camada, de modo que os nós 1.623 e 1.923 , por exemplo, ocupam posições correspondentes em camadas subseqüentes, tendo o primeiro cota maior.

As características elásticas dos materiais foram tomadas com os mesmos valores do modelo físico reduzido, medidos em ensaios.

Assumiu-se as seguintes condições de carregamento:

1) Peso da máquina;

2) Protensão dos 8 pré-distribuidores;

3) Carga hidrostática nos paramentos de montante; e

4) Carga hidrostática interna a montante com nível d'água $358,50 \mathrm{~m}$ e a jusante, com nível d'água $328,00 \mathrm{~m}$. 
O processamento em um microcomputador 486 de $66 \mathrm{MHz}$, demorou cerca de 6 horas e foram ocupados mais de 150 megabytes em disco rígido para armazenar os arquivos temporários gerados pelo software. Foram obtidos 21 arquivos de saída, alguns com até 8 megabytes, como o que armazena a matriz de rigidez.

As tensões resultantes desta análise têm as direções $\mathrm{X}, \mathrm{Y}$ e $\mathrm{Z}$ e as direções principais em cada ponto. Foi necessário um pós-processamento em que, a partir das matrizes de cossenos diretores, foi rotacionado o tensor de modo a obter as tensões nas direções dos extensômetros do modelo físico, apresentadas no capítulo 5.

As Figuras 43 a 48 mostram o modelo numérico tridimensional nas posições indeformada e deformadas sob o efeito dos diversos casos de carregamento. As Figuras 49 a 61 mostram detalhes da secção R3, com as geometrias indeformada e deformadas e as curvas de isotensões, também para os diversos casos de carregamento.

\subsection{MODELO NUMÉRICO BIDIMENSIONAL}

O modelo matemático em duas dimensões objetivou analisar o comportamento estrutural da secção R3 da Caixa Espiral, considerada como um sólido de revolução em equilíbrio axissimétrico.

Foram utilizados 615 nós e 180 elementos, 68 elementos de 4 nós e 112 elementos de 9 nós, todos com espessura unitária.

As coordenadas lançadas no arquivo de entrada se referem às do protótipo, sendo multiplicadas pelo fator de escala $1 / 75$ pelo próprio SAP-90, como no modelo numérico tridimensional. $O$ plano adotado foi $0 \quad \mathrm{Y}-\mathrm{Z}$. 


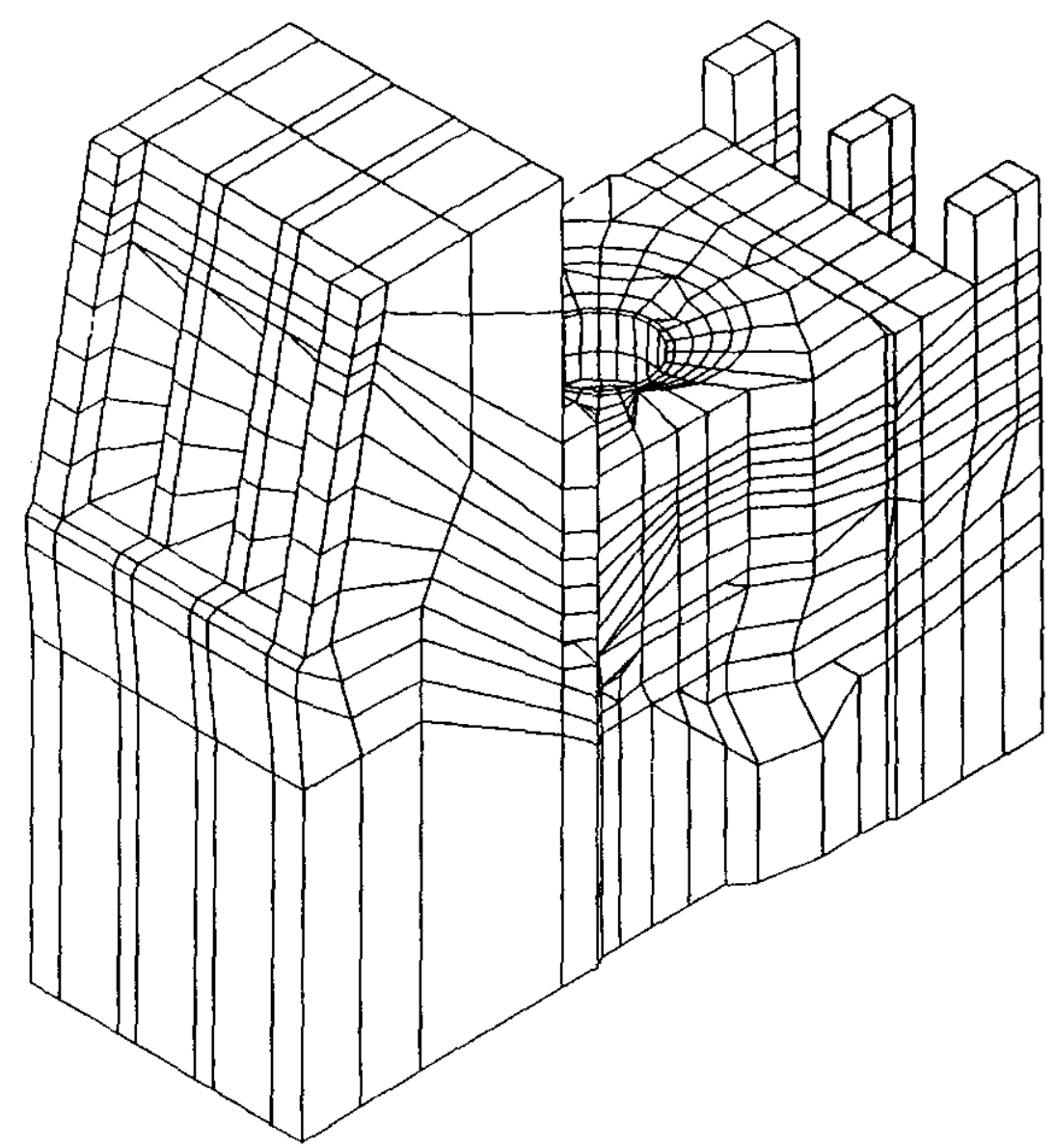

FIGURA 43 - Vista geral do modelo numérico tridimensional indeformado. 


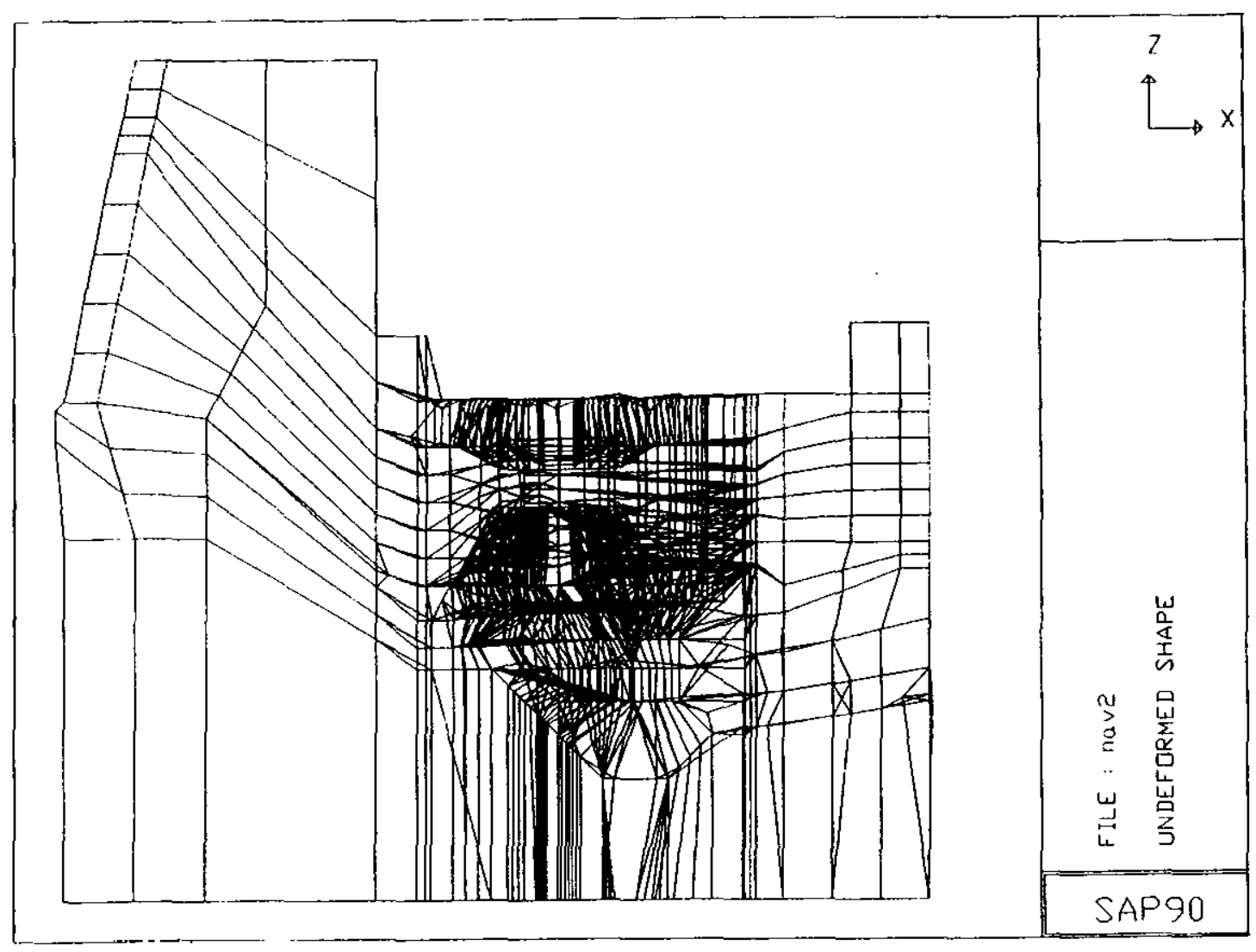

FIGURA 44 - Vista lateral do modelo numérico tridimensional indeformado. 


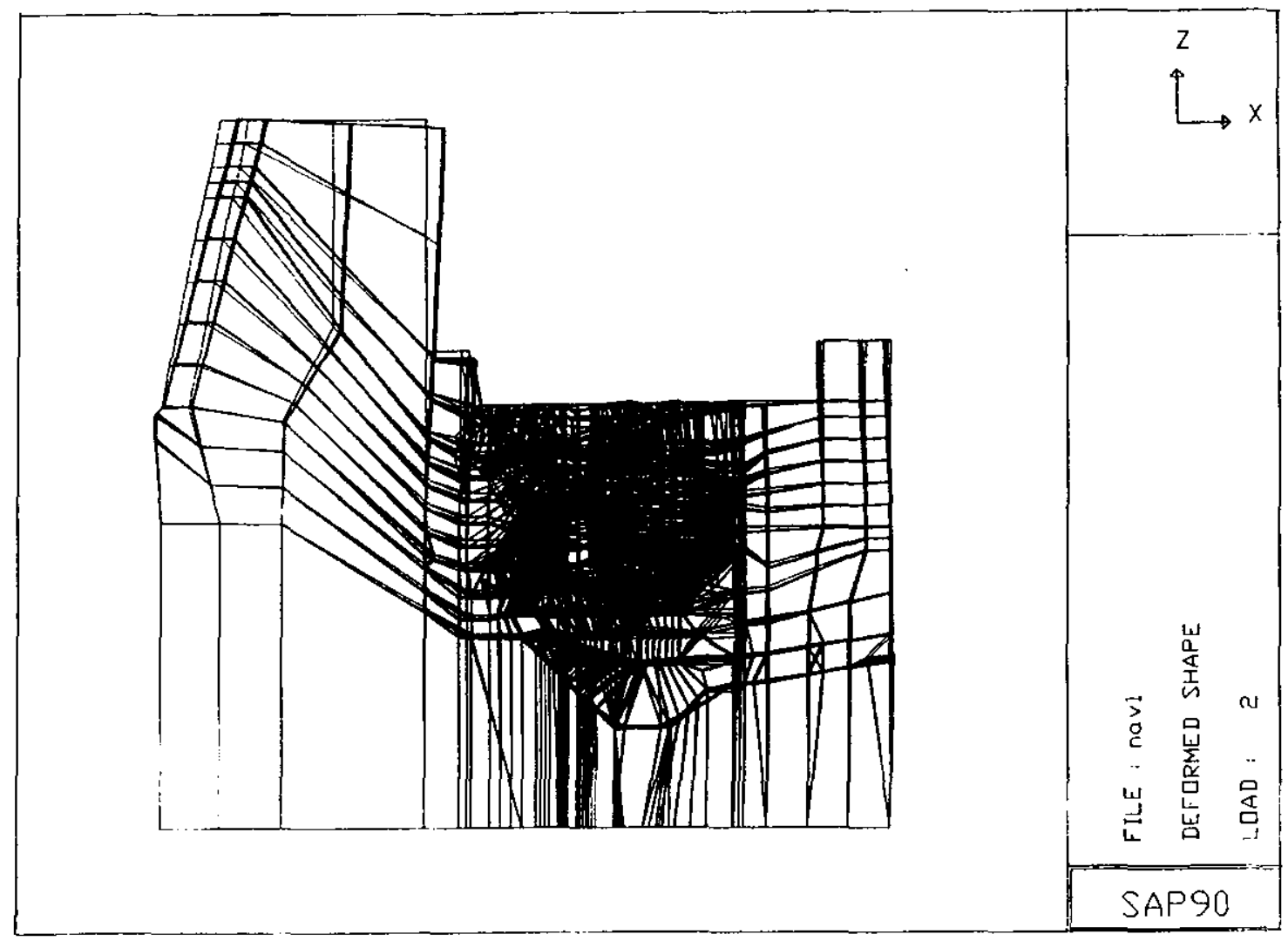

FIGURA 45 - Modelo numérico tridimensional deformado sob a ação do peso da máquina. 


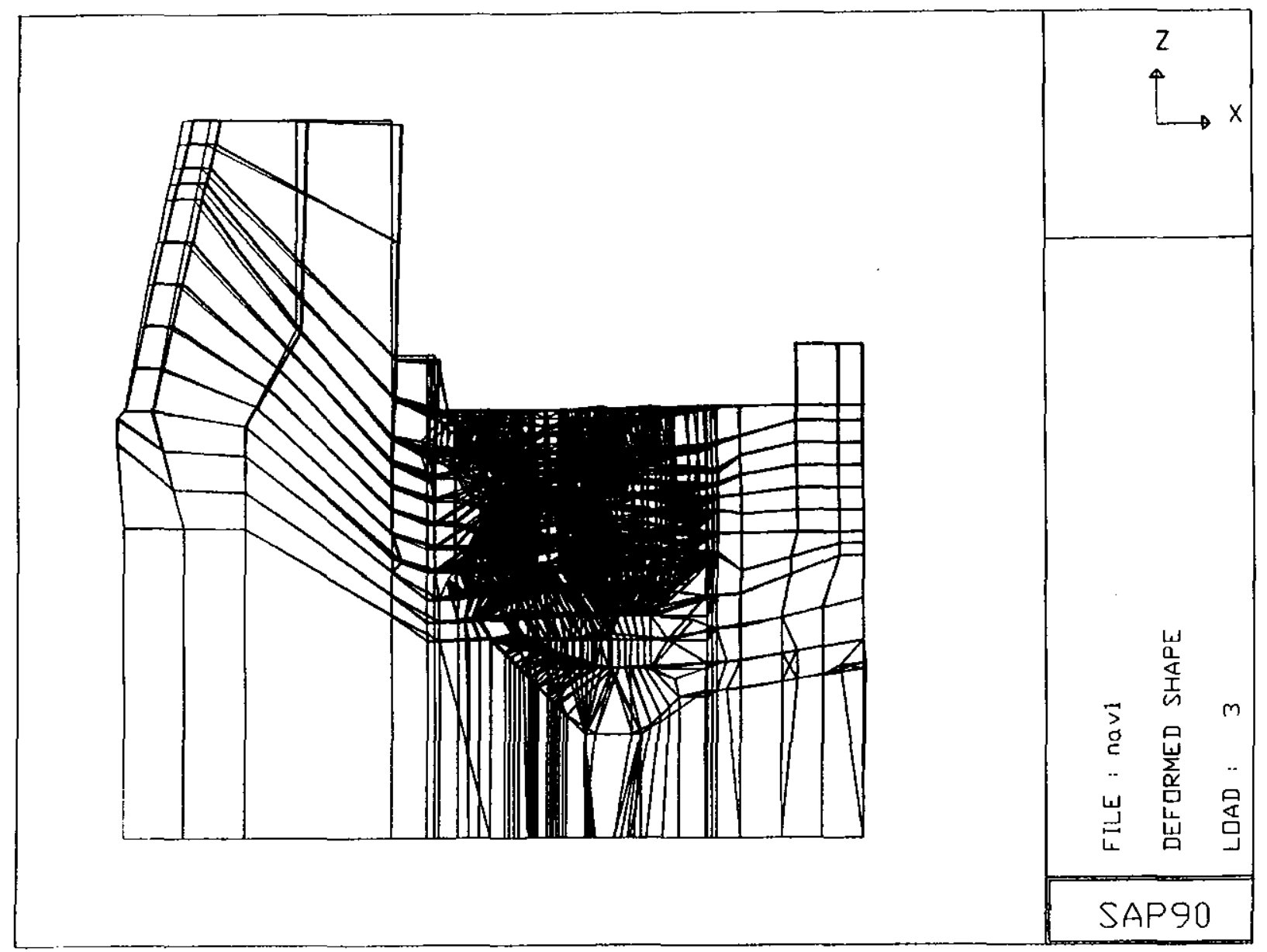

FIGURA 46 - Modelo numérico tridimensional deformado sob a ação da protensão dos pré-distribuidores. 


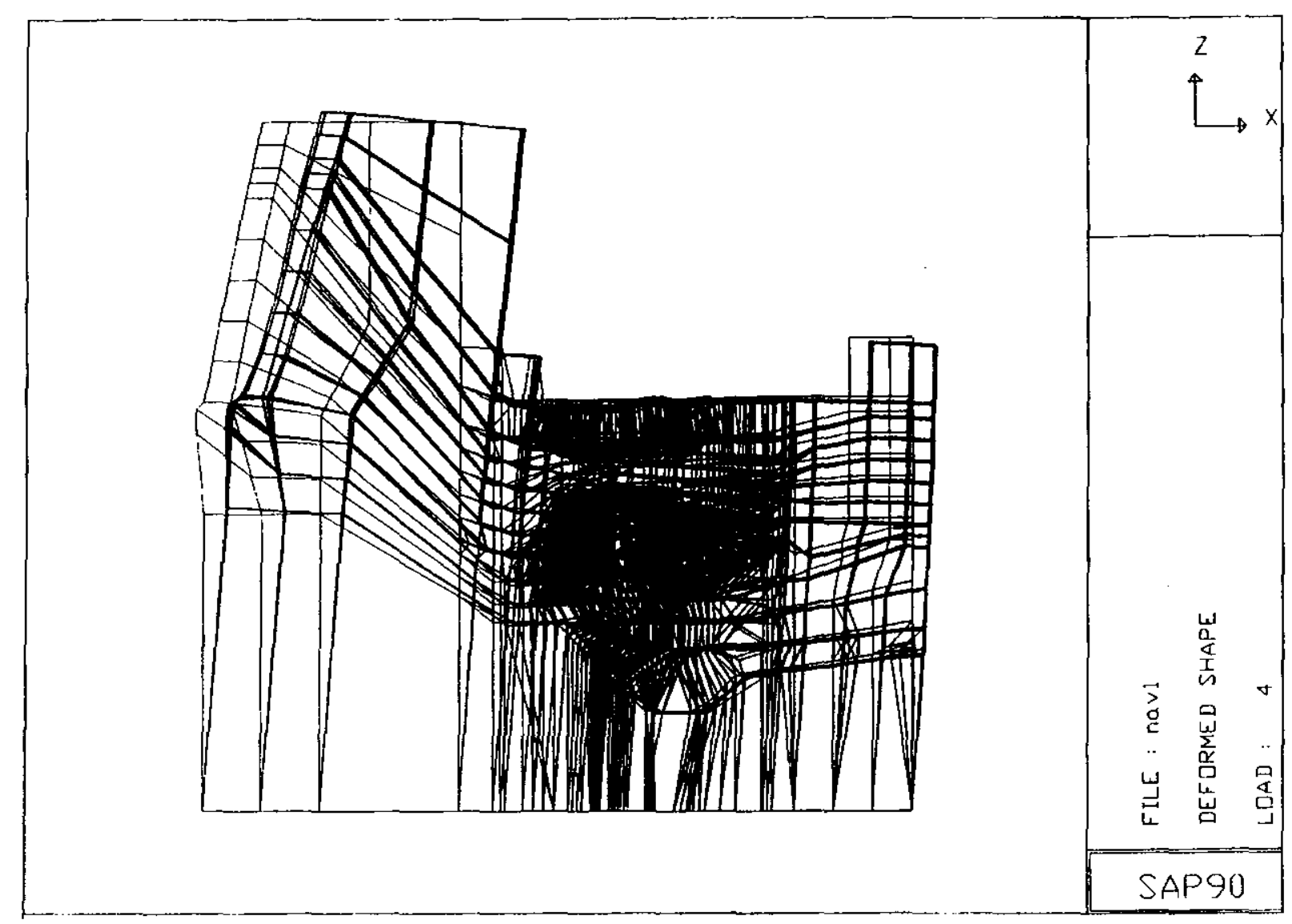

FIGURA 47 - Modelo numérico tridimensional deformado sob ação da carga hidrostática nos paramentos de montante. 


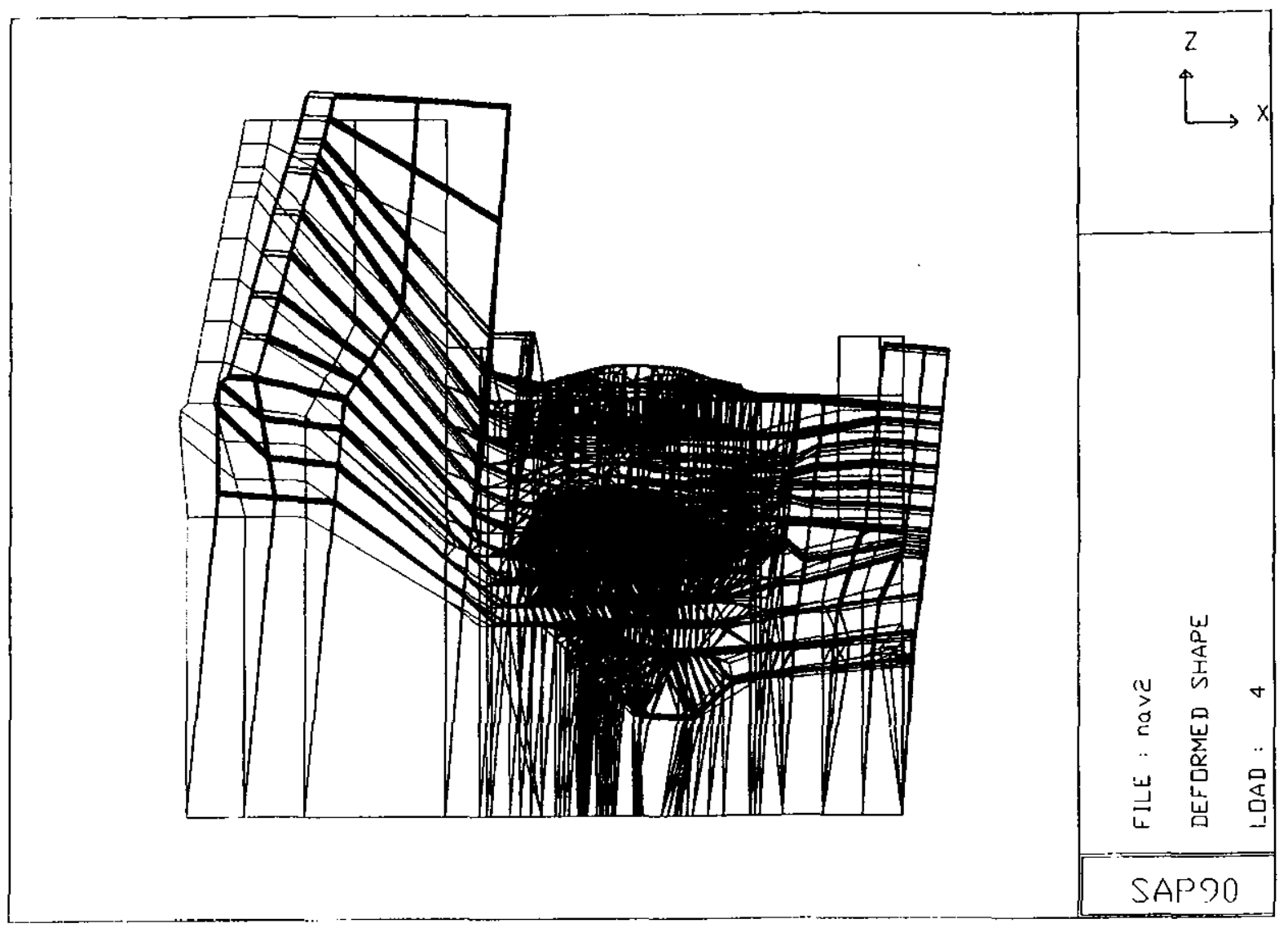




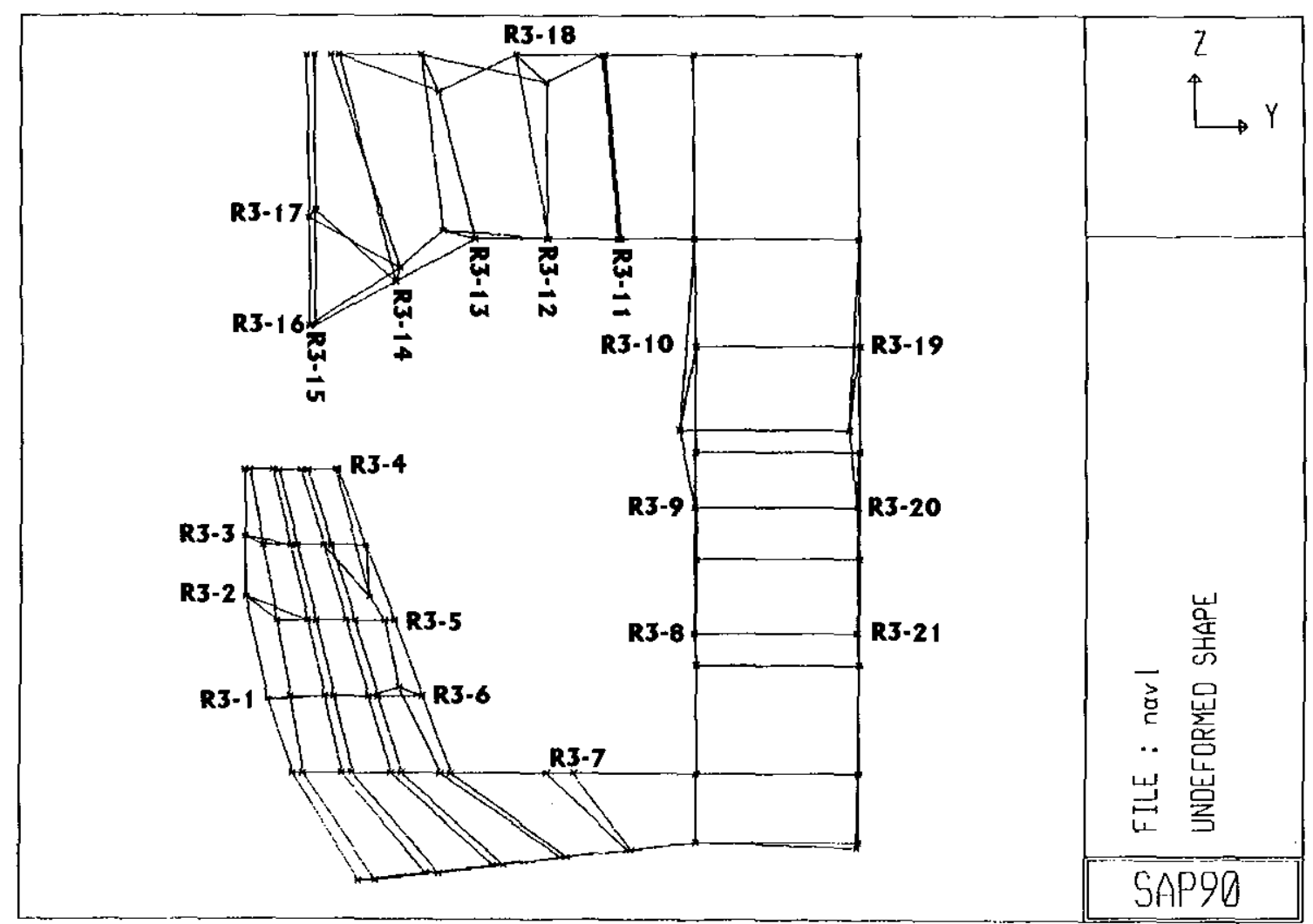

FIGURA 49 - Modelo numérico tridimensional da seç̧ão R3 indeformada. 


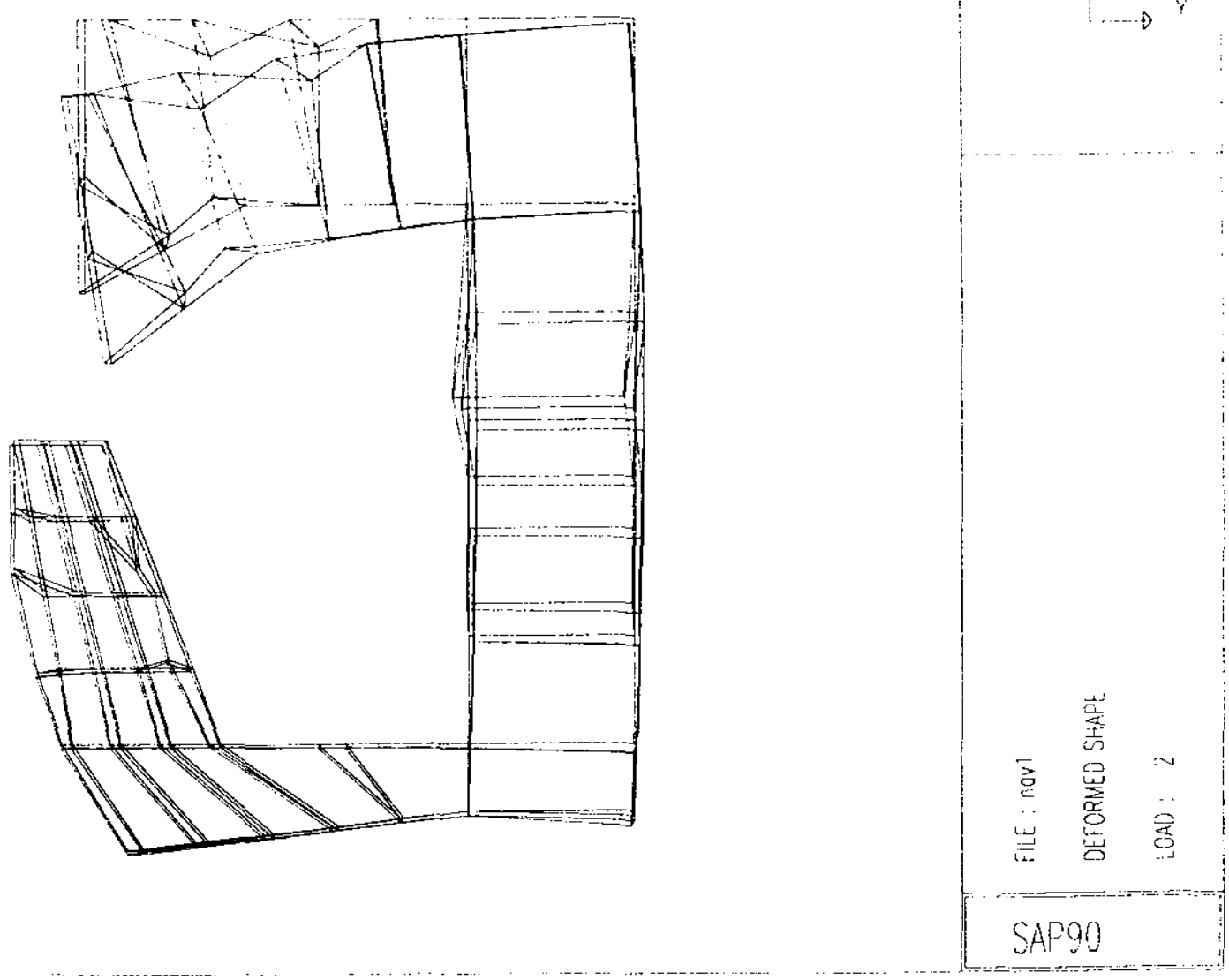

FIGURA 50 - Modelo numérico tridimensional da secção R3 deformada sob a ação do peso da máquina. 


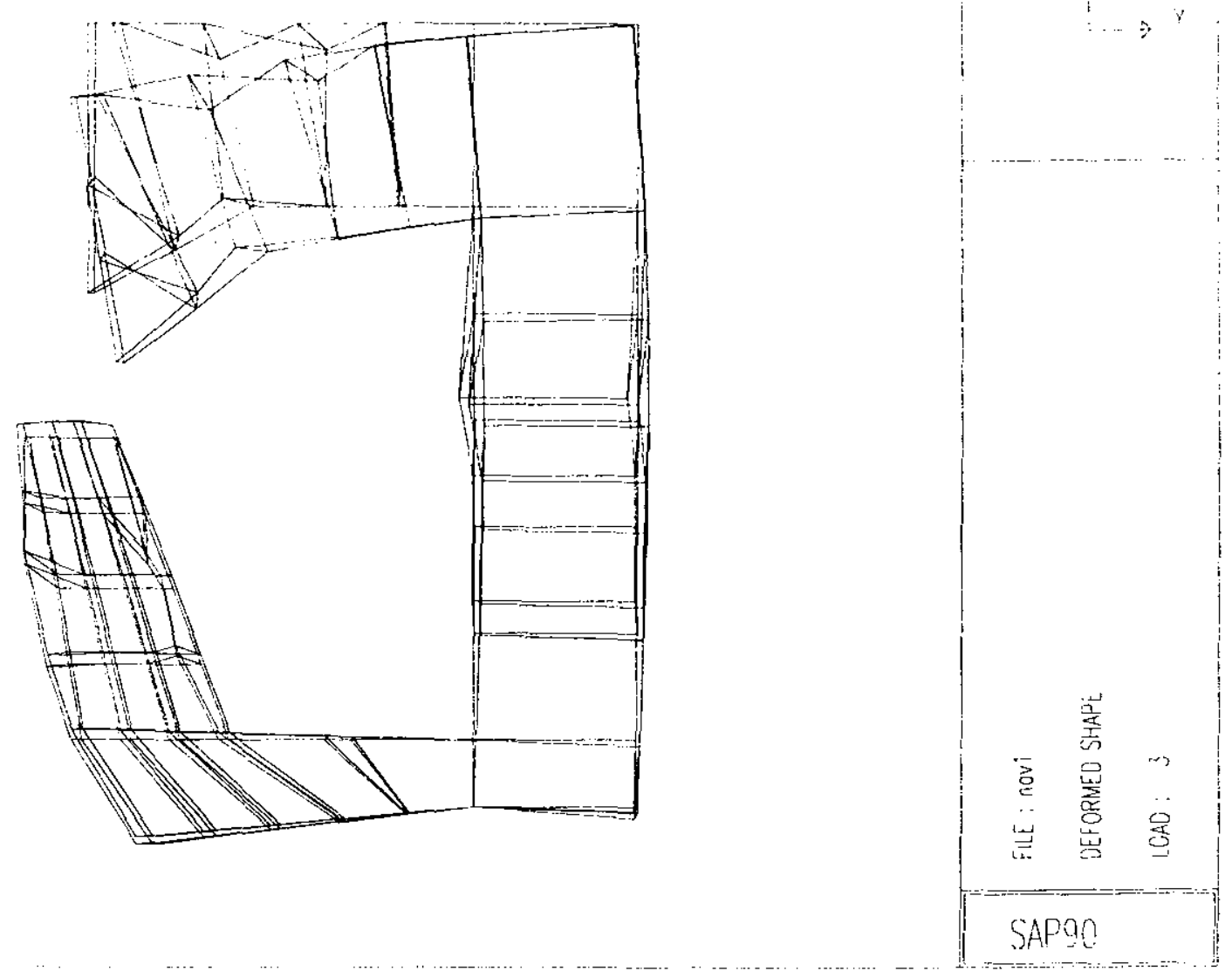

FIGURA 51 - Modelo numérico tridimensional da seç̧ão R3 deformada sob a ação da protensão dos pré-distribuidores. 

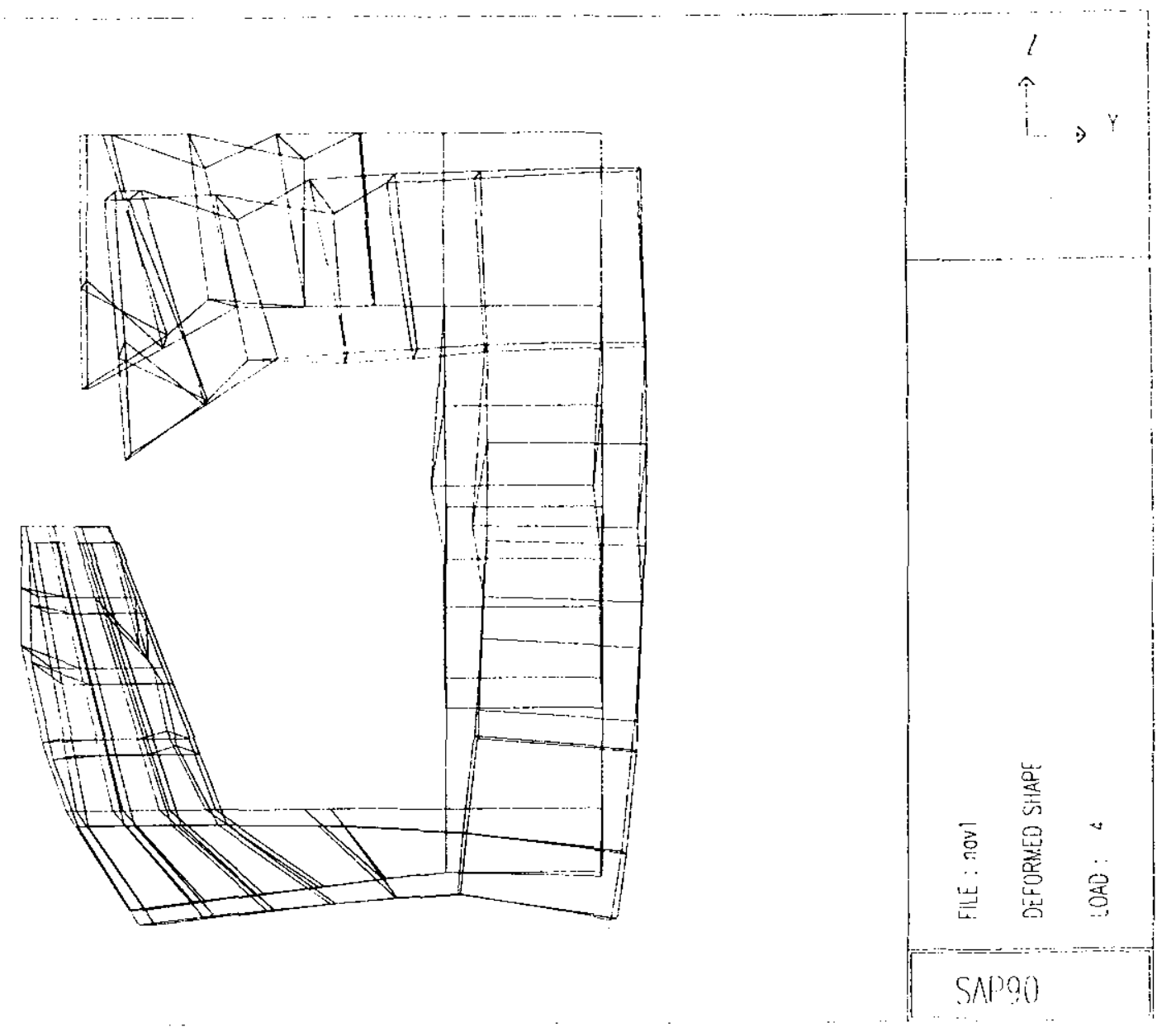

FIGURA 52 - Modelo numérico tridimensional da seç̧ão R3 deformada sob a ação da carga hidrostática nos paramentos de montante. 


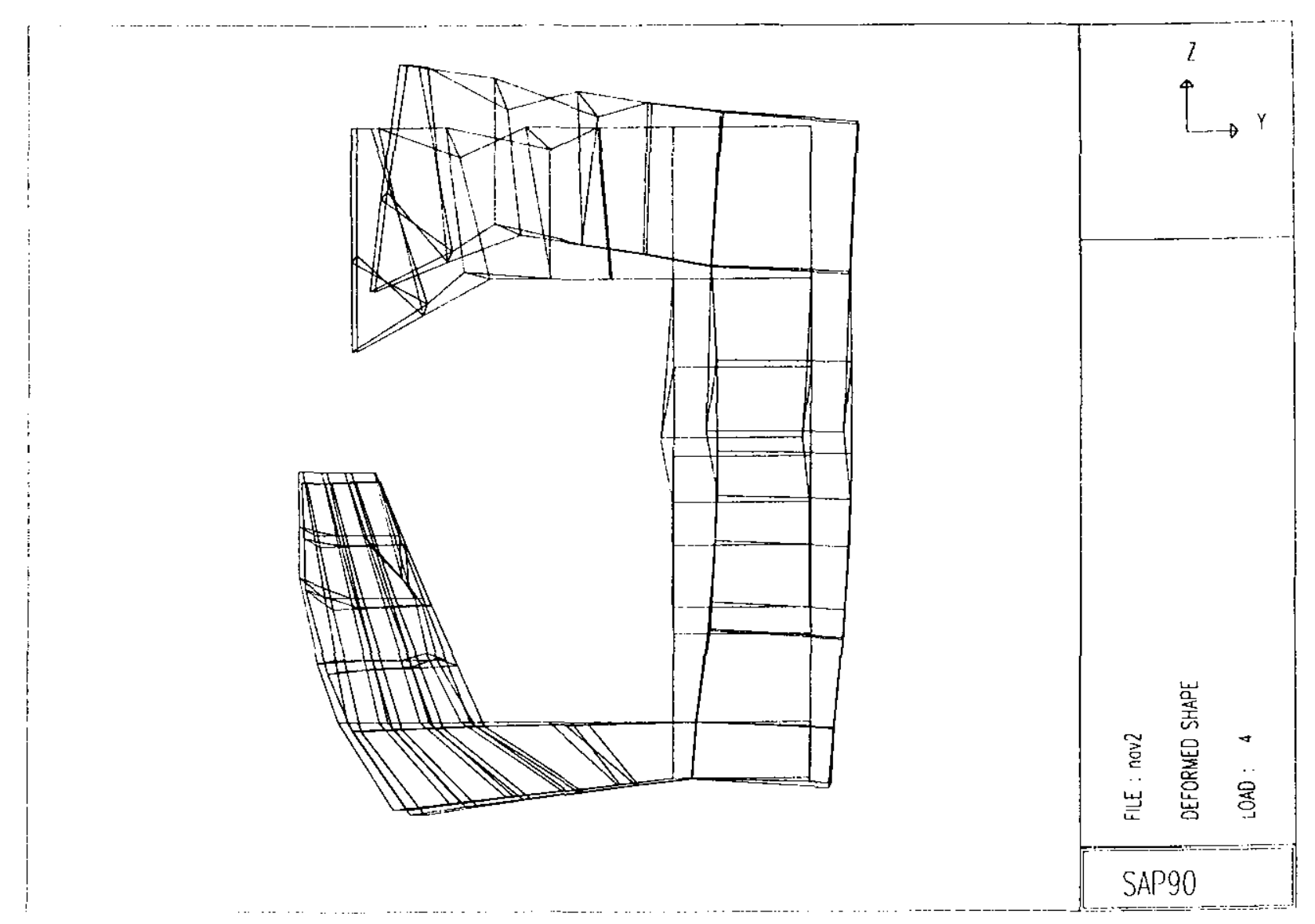

FIGURA 53 - Modelo numérico tridimensional da secção R3 deformada sob a ação da pressão hidrostática interna a montante e a jusante. 


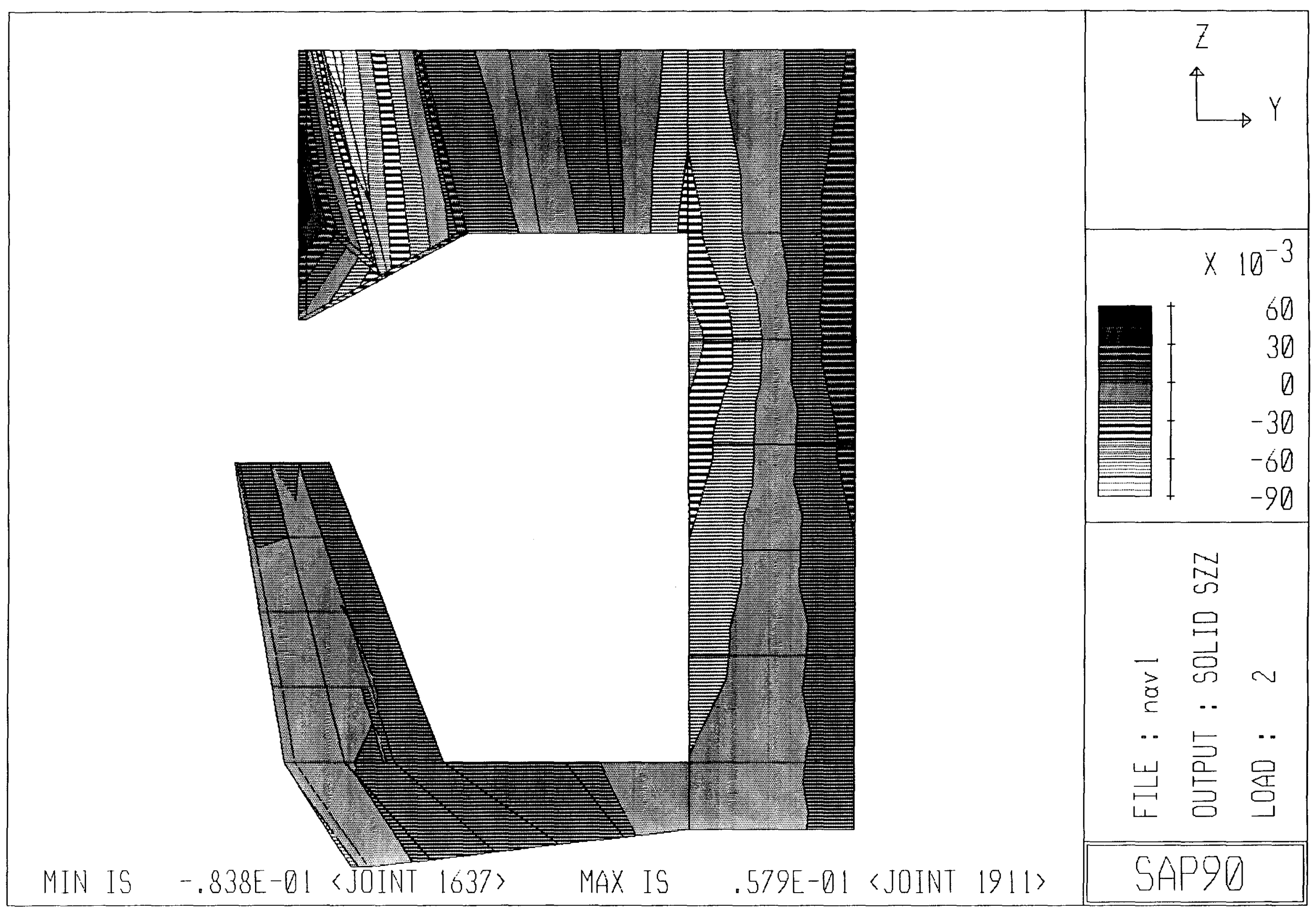


FIGURA 54 - Modelo numérico tridimensional da seç̧ão R3 mostrando as isotensões para tensão normal na direção $\mathrm{Z}$ sob a ação do peso da máquina. 


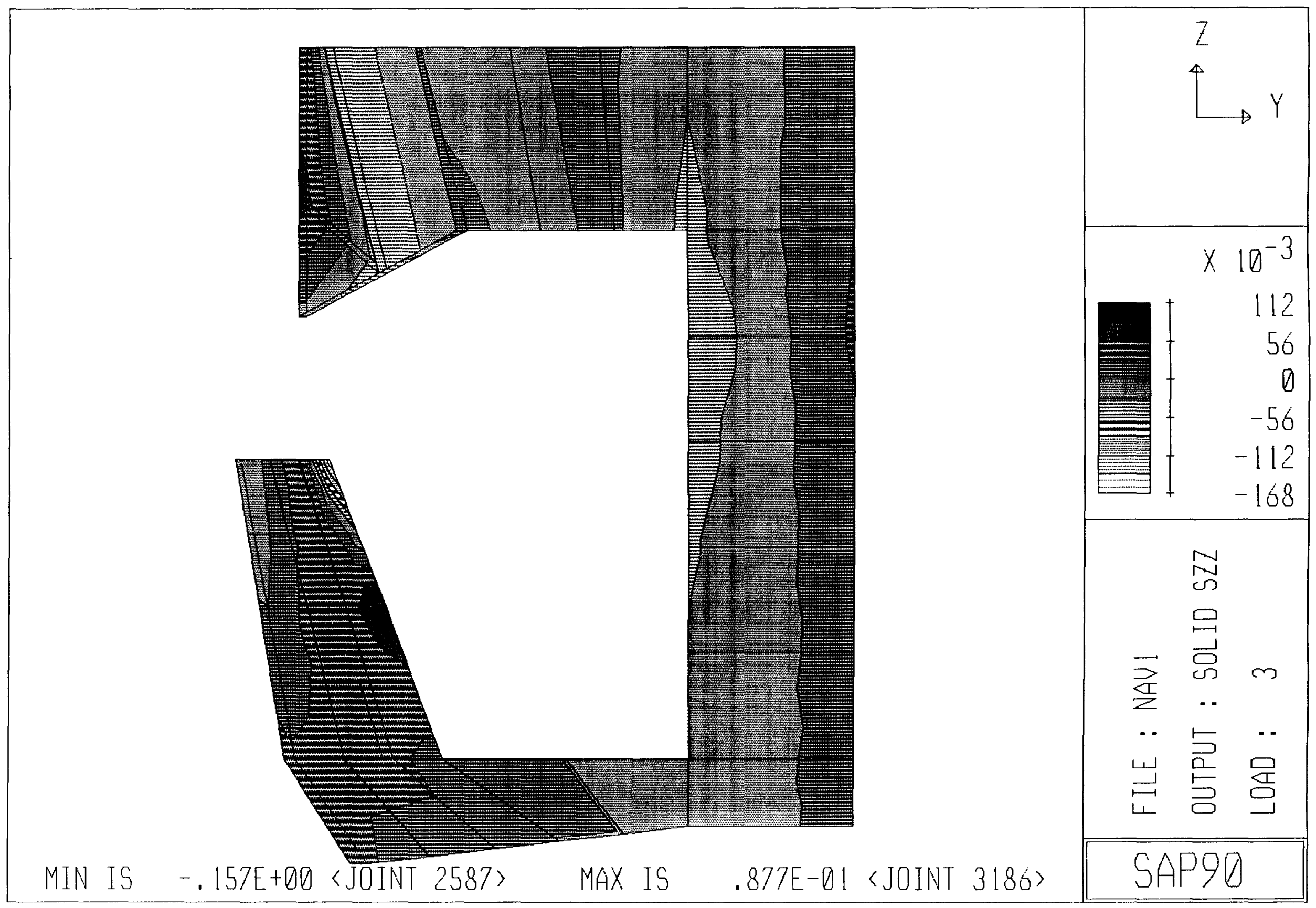


FIGURA 55 - Modelo numérico tridimensional da secção R3 mostrando as isotensões para tensão normal na direção $Z$ sob a ação da protensão dos pré-distribuidores. 


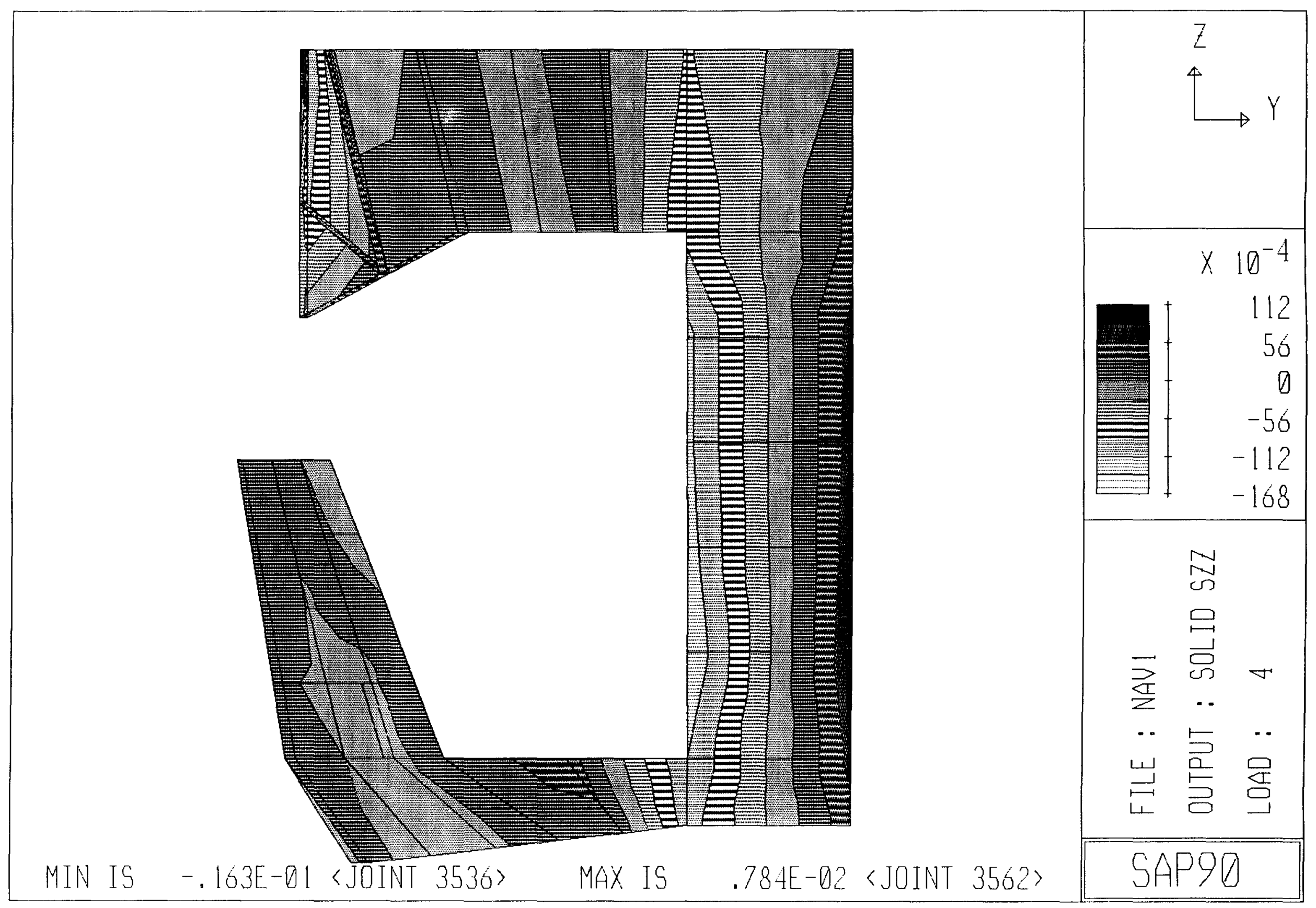


FIGURA 56 - Modelo numérico tridimensional da secção R3 mostrando as isotensões para tensão normal na direção $Z$ sob a ação da carga hidrostática nos paramentos de montante. 


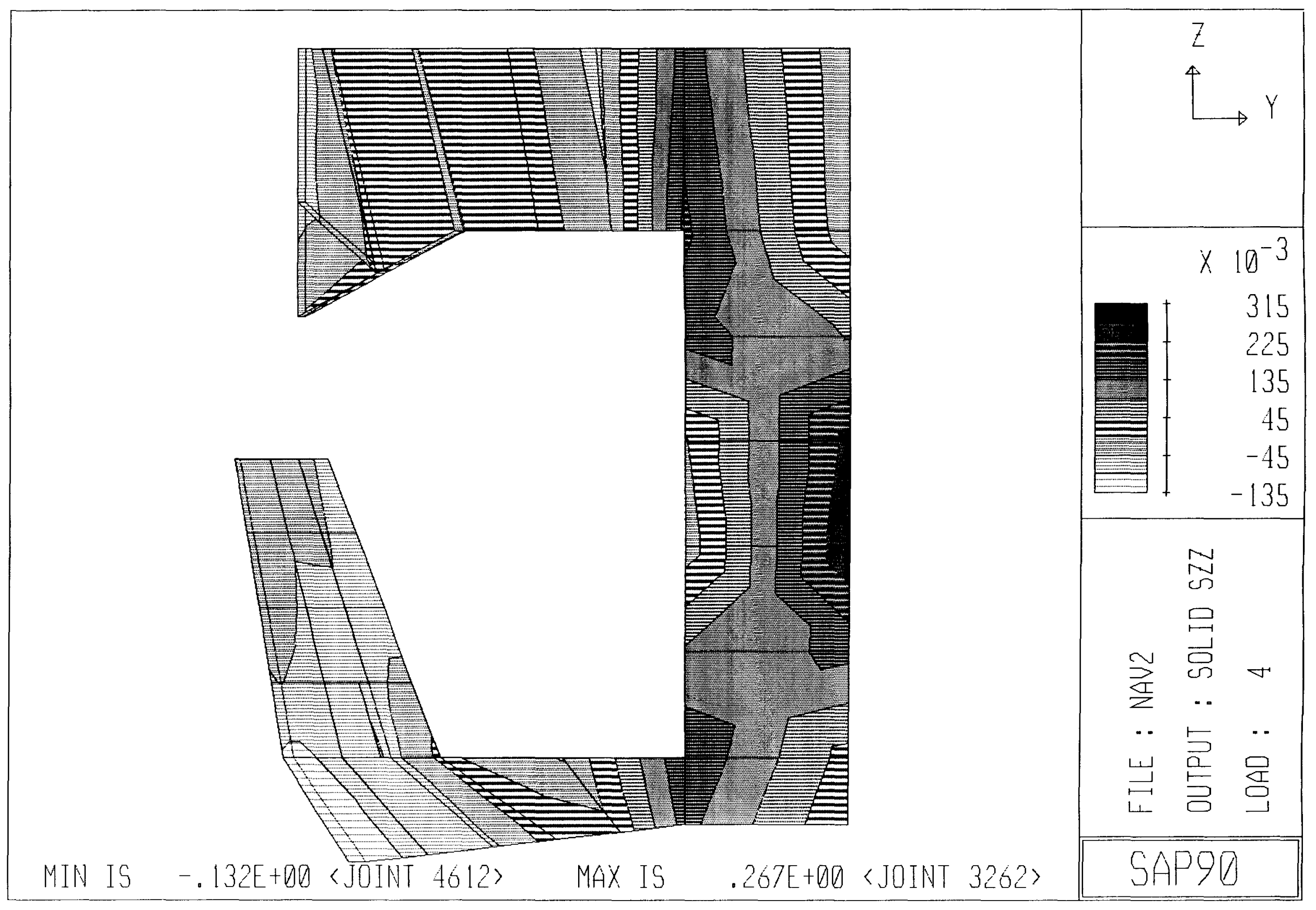


FIGURA 57 - Modelo numérico tridimensional da secção R3 mostrando as isotensões para tensão normal na direção $Z$ sob a ação da pressão hidrostática interna a montante e a jusante. 


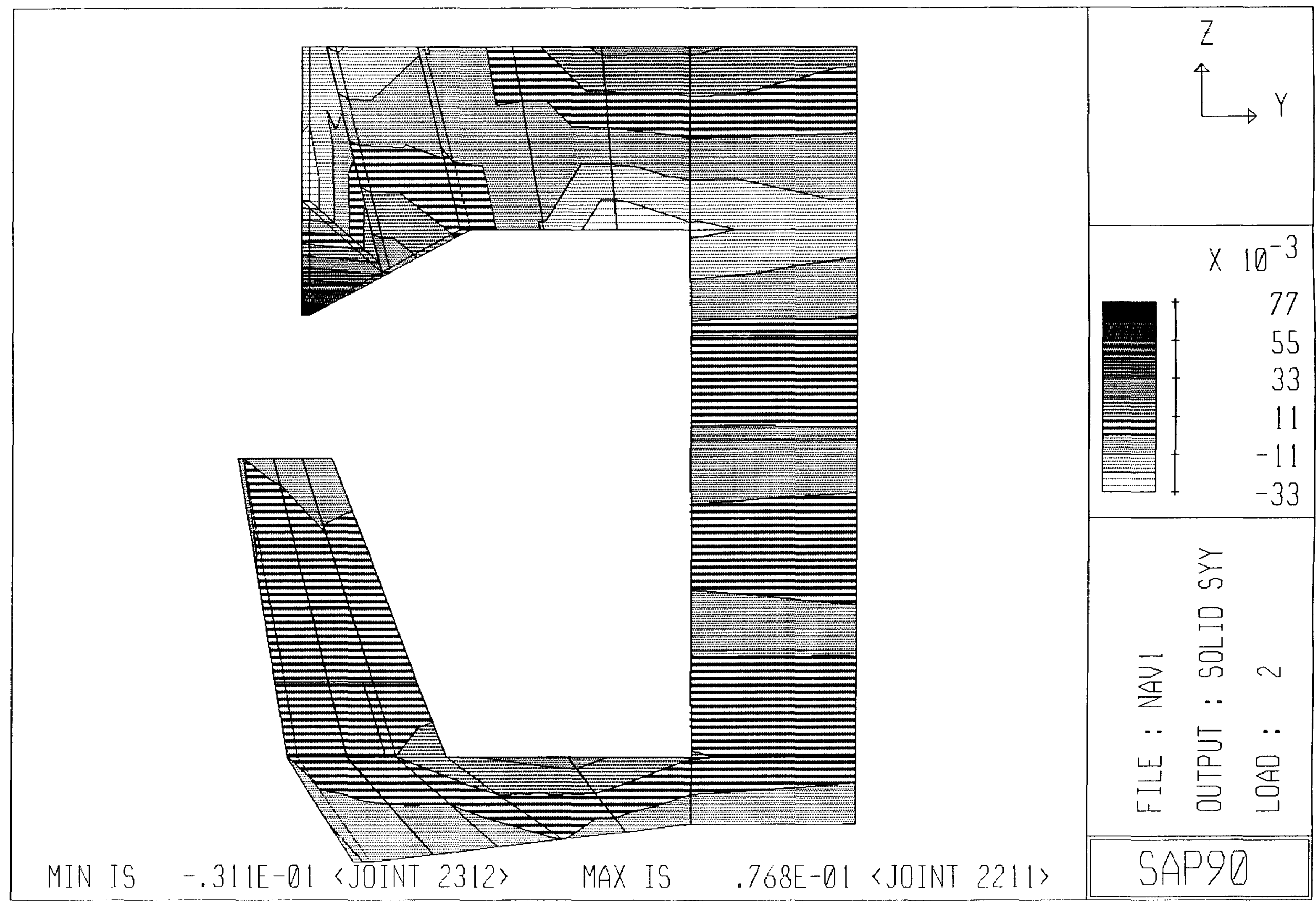


FIGURA 58 - Modelo numérico tridimensional da secção R3 mostrando as isotensões para tensão normal na direção $Y$ sob a ação do peso da máquina. 


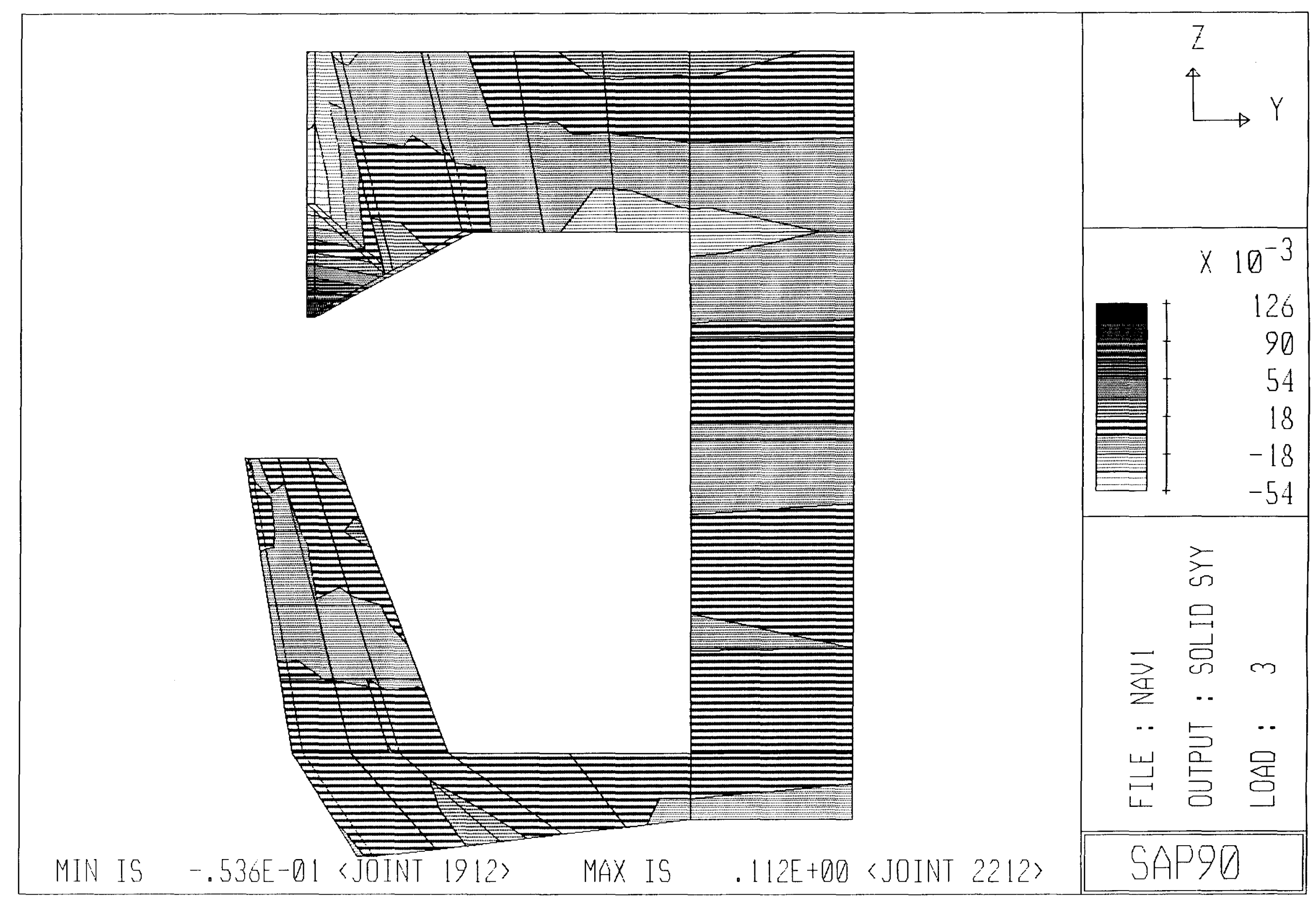


FIGURA 59 - Modelo numérico tridimensional da secção R3 mostrando as isotensões para tensão normal na direção $Y$ sob a ação da protensão dos pré-distribuidores. 


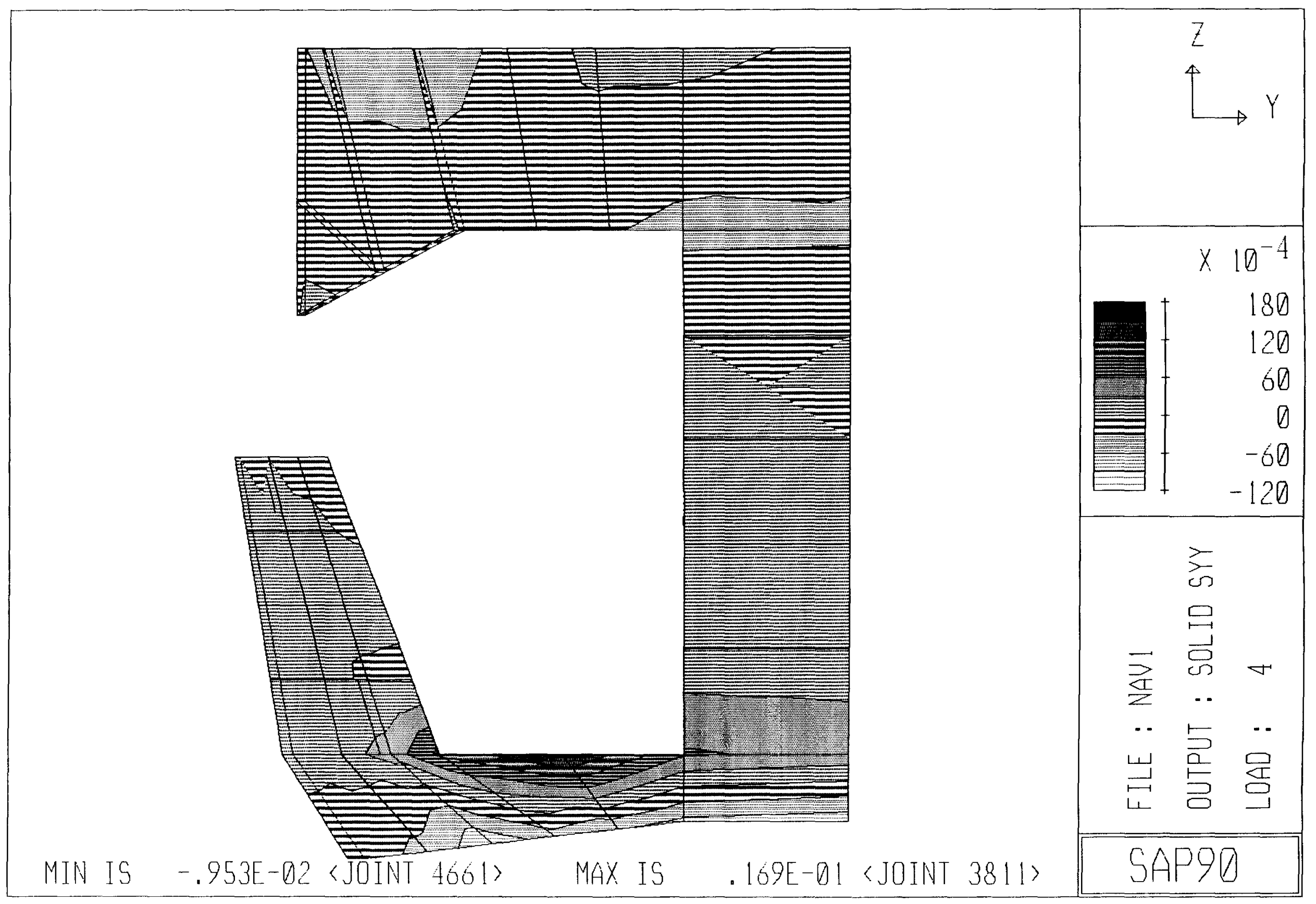


FIGURA 60 - Modelo numérico tridimensional da secção R3 mostrando as isotensões para tensão normal na direção $Y$ sob a ação da carga hidrostática nos paramentos de montante. 


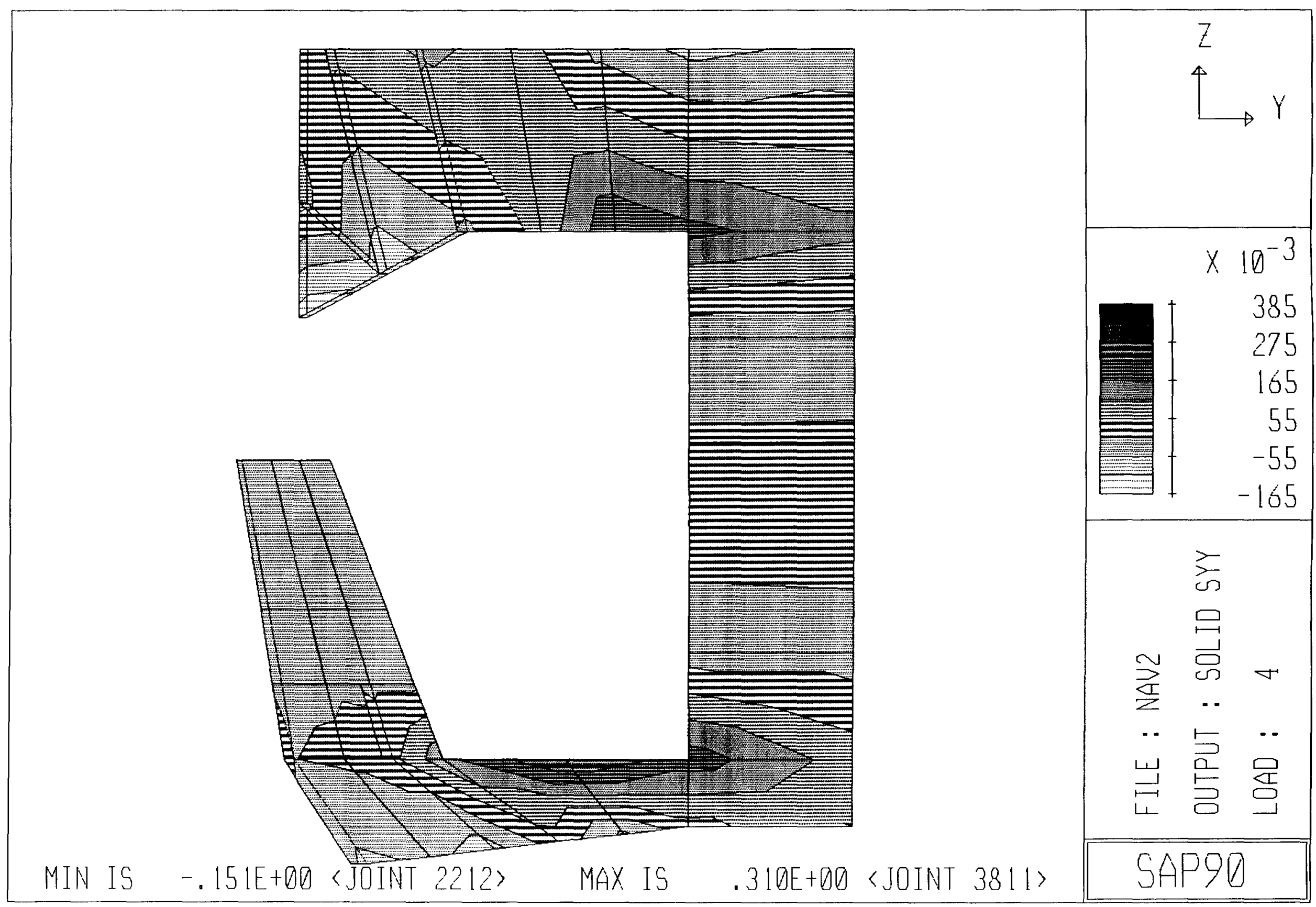


FIGURA 61 - Modelo numérico tridimensional da secção R3 mostrando as isotensões para tensão normal na direção $Y$ sob a ação da pressão hidrostática interna a montante e a jusante. 
As características elásticas do material foram consideradas iguais aos valores medidos em ensaio para o acrílico empregado no modelo físico.

Como o modelo não admitia cargas que não estivessem contidas no plano da secção R3, os carregamentos impostos foram:

1) peso da máquina,

2) protensão dos pré-distribuidores e

3) pressão hidrostática a montante e a jusante

Os resultados consistem nas tensões, provocadas por cada caso de solicitação, nas direções principais, 1,2 e 3 , as duas primeiras contidas no plano considerado, e a terceira, na direção perpendicular.

Por simplicidade, somente as tensões na direção A foram consideradas nas comparações dos resultados do modelo físico com os do modelo matemático tridimensional, apresentadas no capítulo 5 .

As Figuras 62 a 65 mostram o modelo numérico bidimensional da secção R3 da Caixa Espiral com geometrias indeformada e deformadas sob a ação de cada um dos carregamentos.

As curvas de isotensão para tensão normal segundo as direções $\mathrm{Y}$ e $\mathrm{Z}$, sob as diversas solicitações encontram-se nas Figuras 66 a 71. 


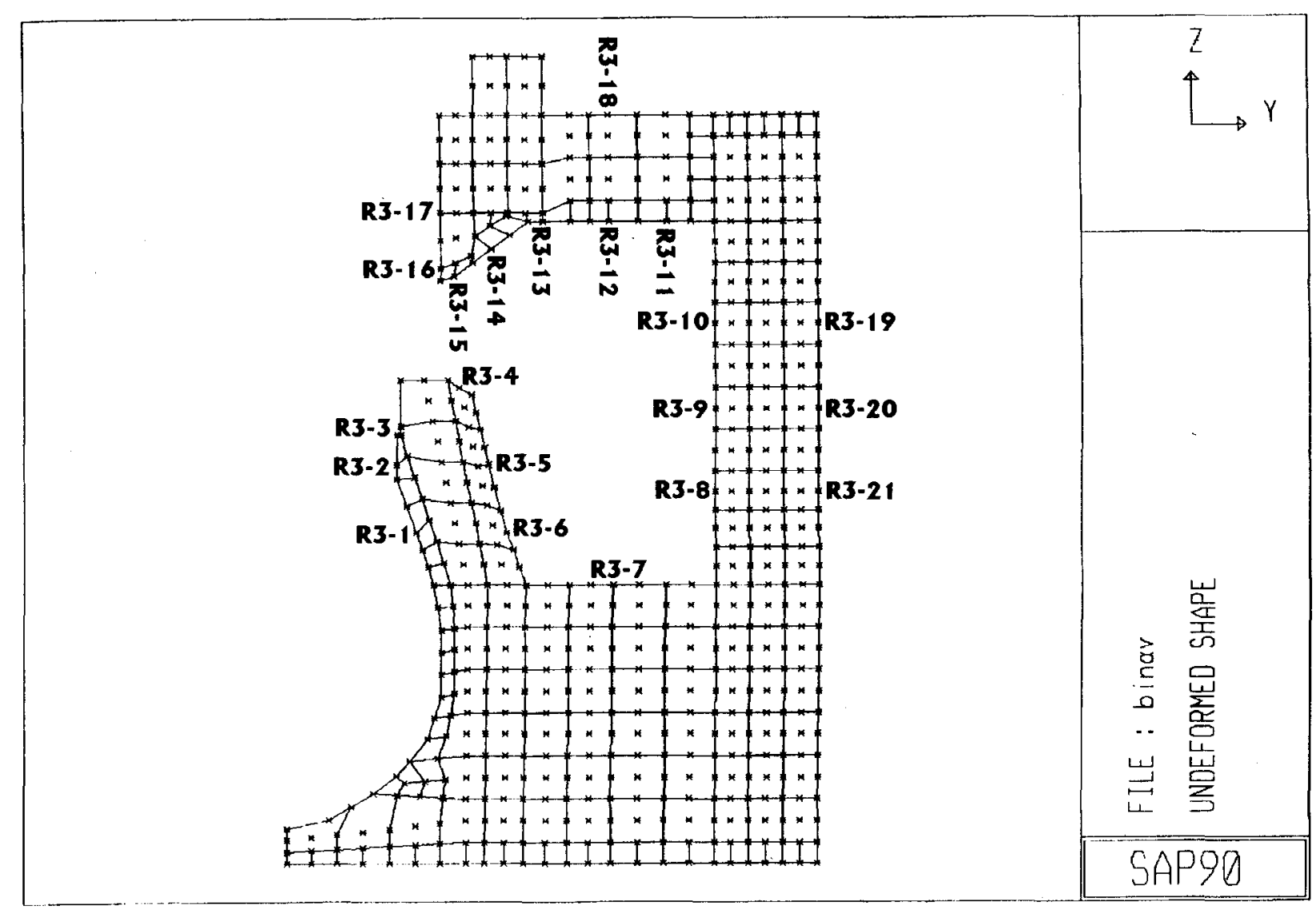

FIGURA 62 - Modelo numérico bidimensional da secção R3 indeformado. 

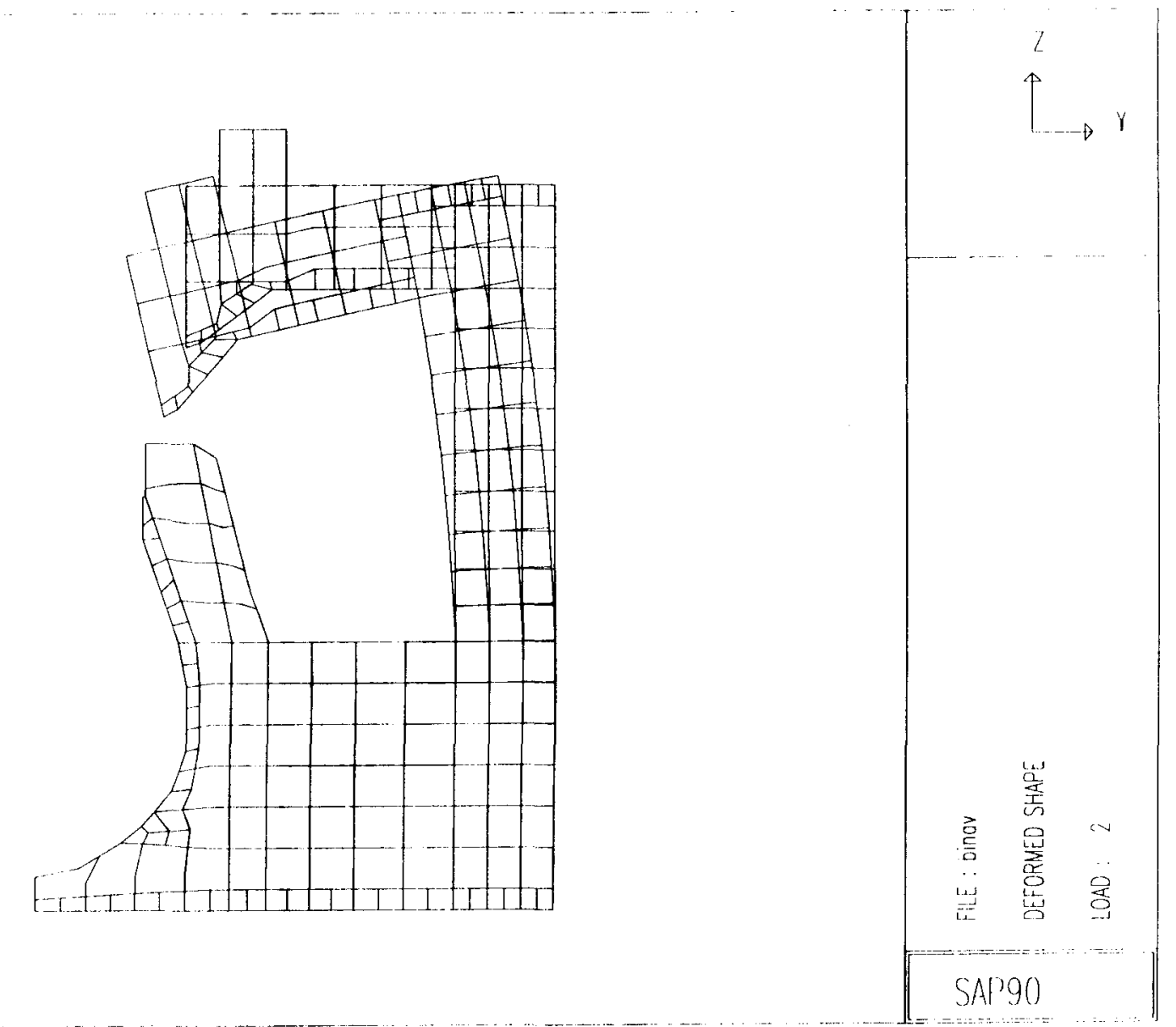

FIGURA 63 - Modelo numérico bidimensional da seç̧ão R3 deformado sob a ação do peso da máquina. 


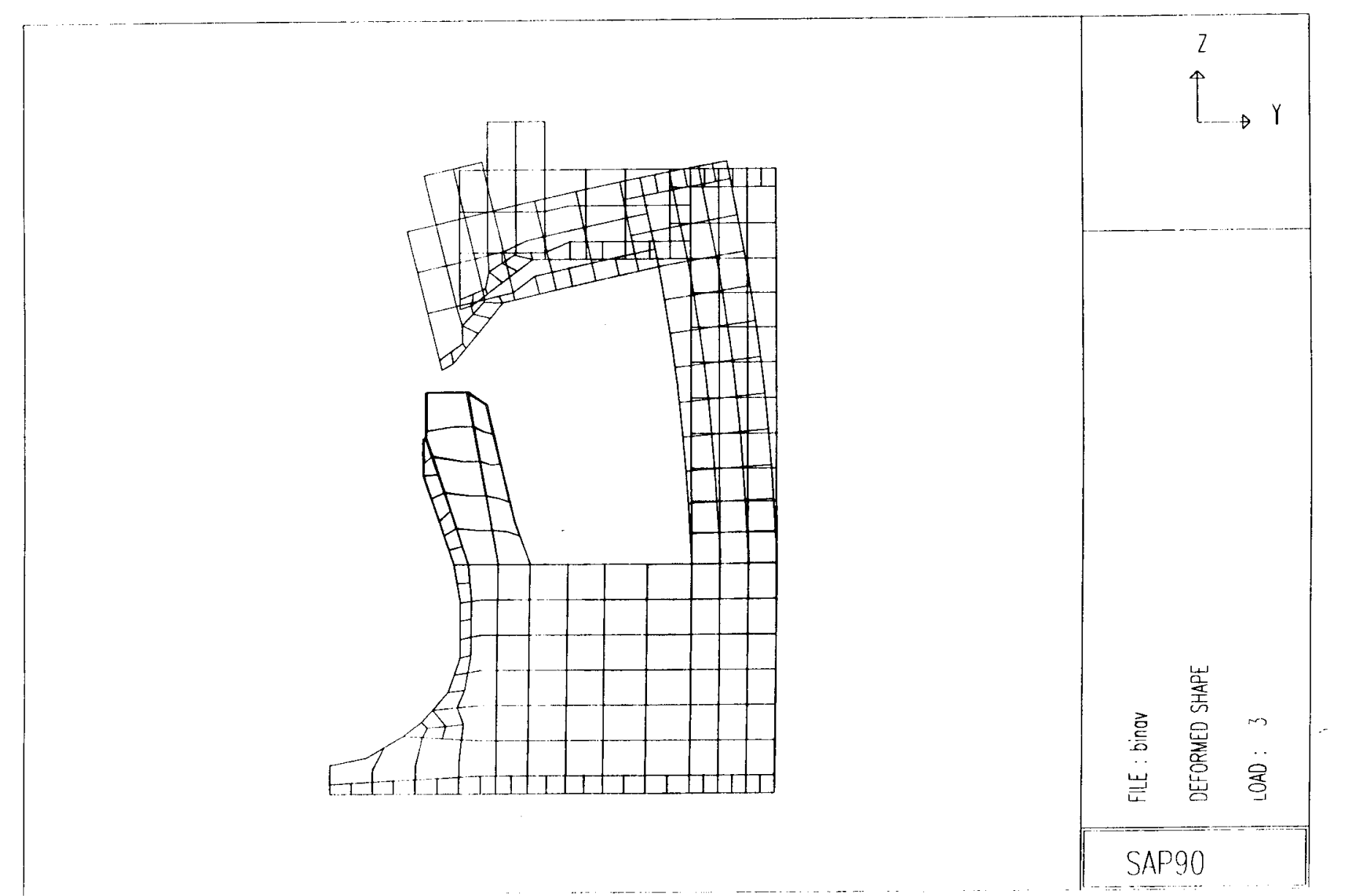

FIGURA 64 - Modelo numérico bidimensional da secção R3 deformado sob a ação da protensão dos pré-distribuidores. 

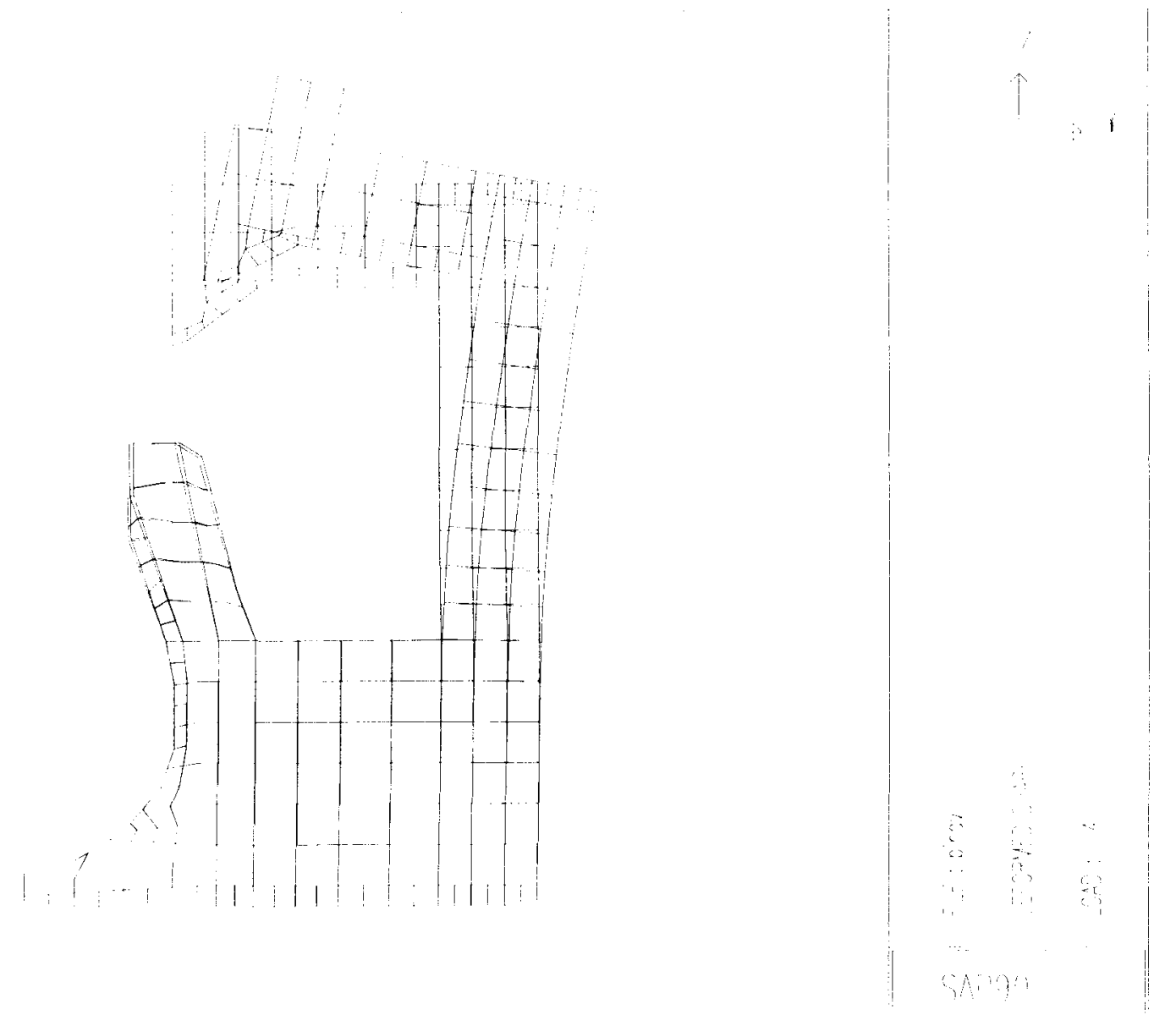

FIGURA 65 - Modelo numérico bidimensional da secção R3 deformado sob a ação da pressão hidrostática interna. 


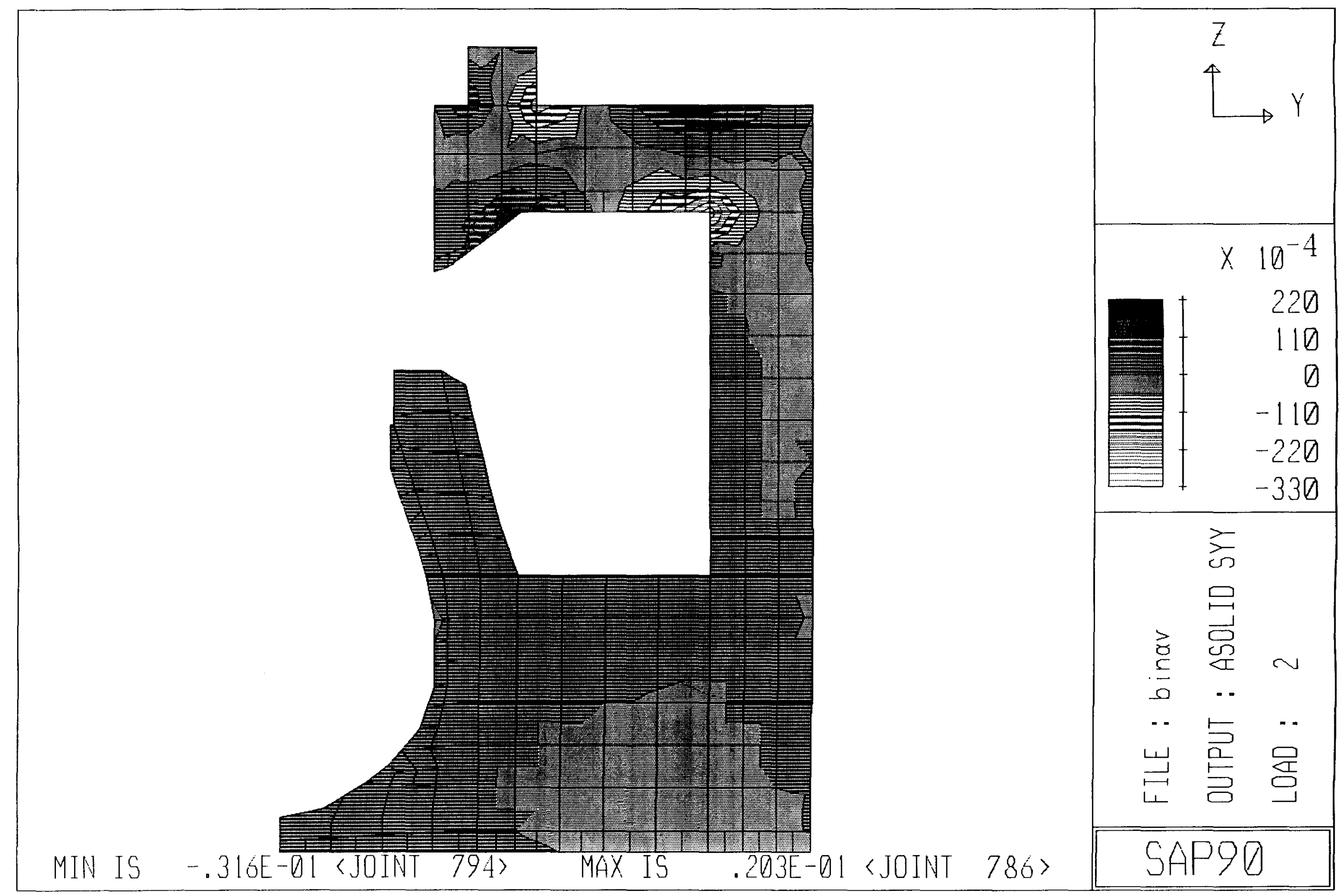


FIGURA 66 - Modelo numérico bidimensional da secção R3 mostrando as isotensões para tensão normal na direção $\mathrm{Y}$ sob a ação do peso da máquina. 


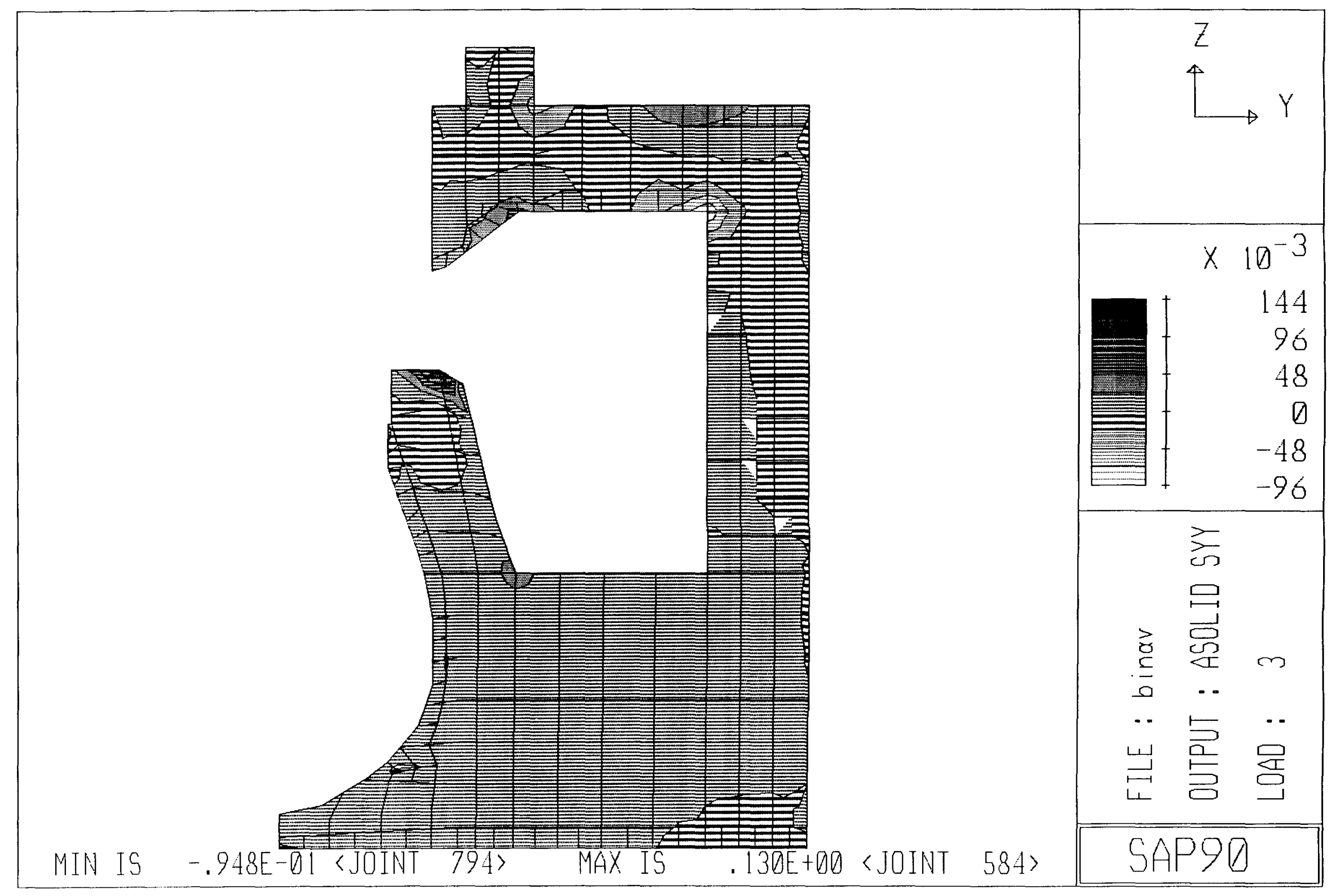


FIGURA 67 - Modelo numérico bidimensional da secção R3 mostrando as isotensões para tensão normal na direção Y sob a ação da protensão dos pré-distribuidores. 


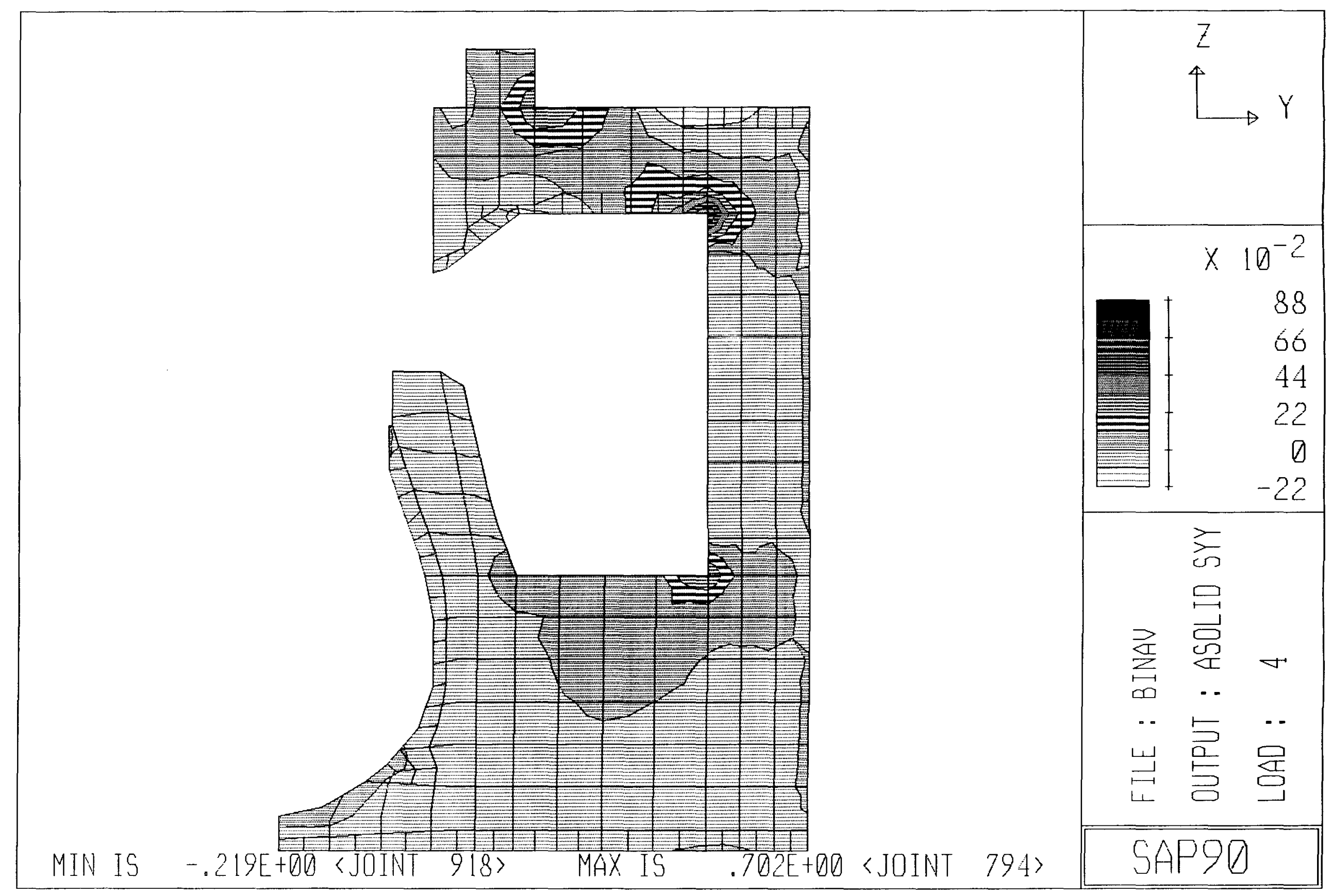


FIGURA 68 - Modelo numérico bidimensional da secção R3 mostrando as isotensões para tensão normal na direção $\mathrm{Y}$ sob a ação da pressão hidrostática interna. 


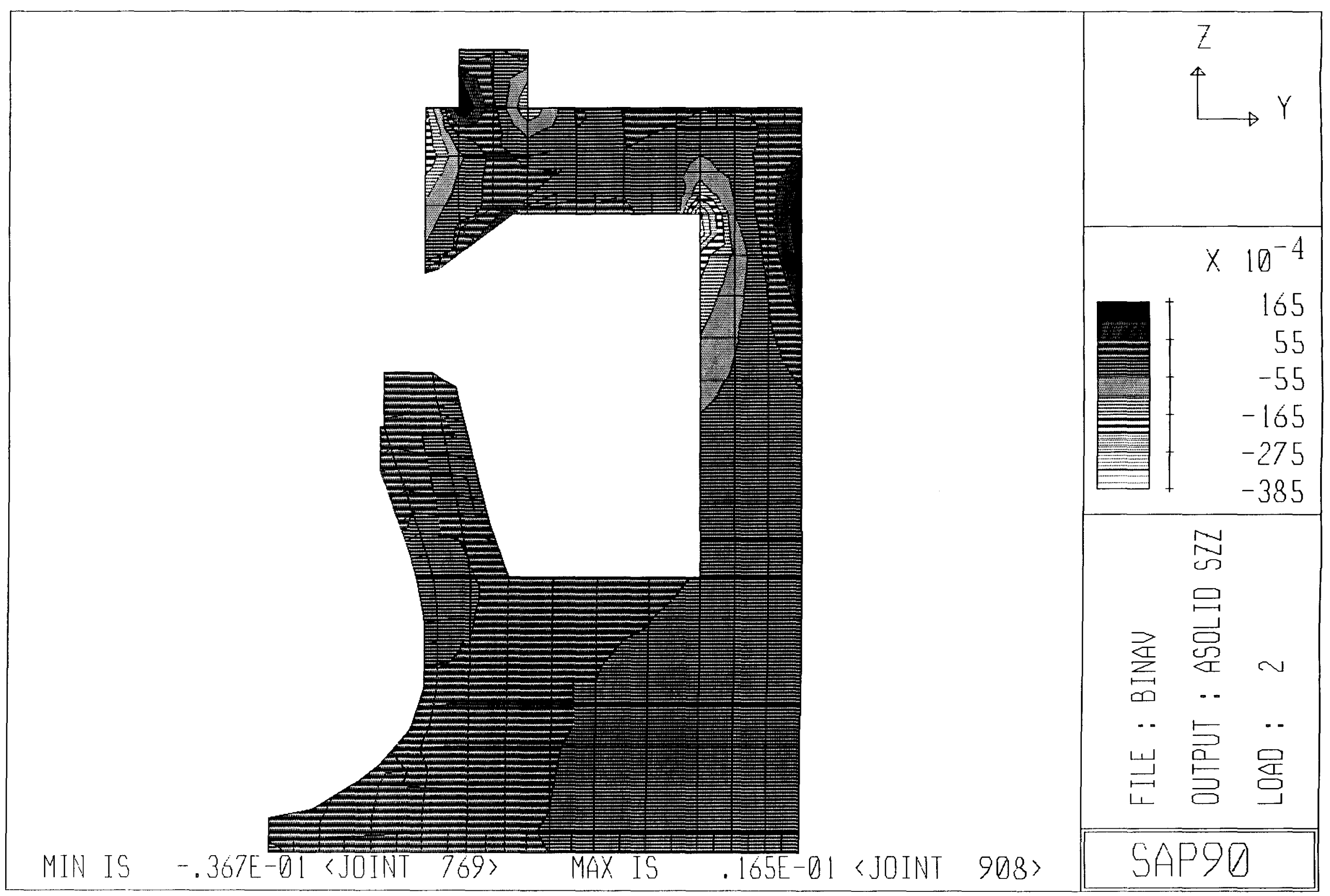


FIGURA 69 - Modelo numérico bidimensional da secção R3 mostrando as isotensões para tensão normal na direção $Z$ sob a ação do peso da máquina. 


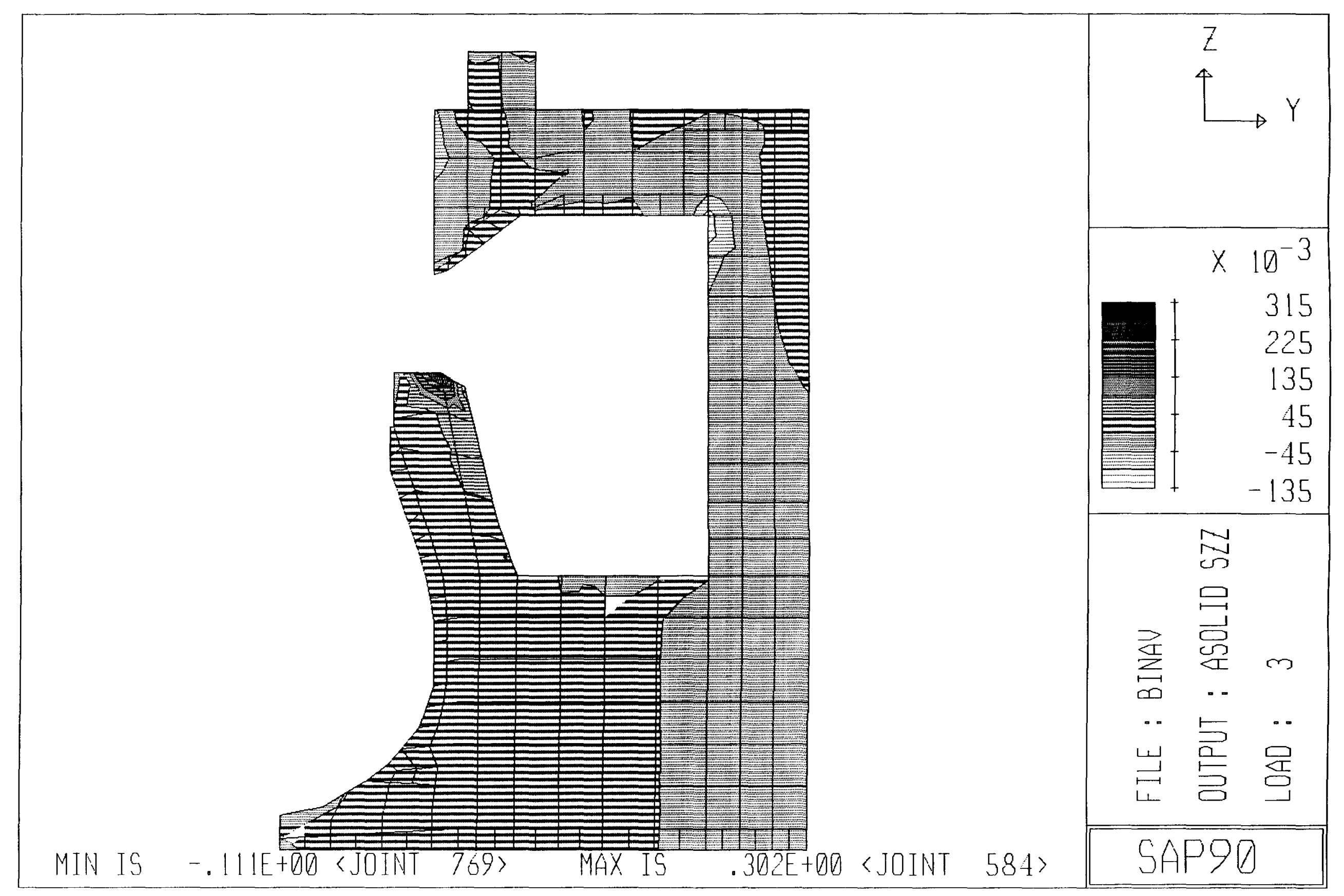


FIGURA 70 - Modelo numérico bidimensional da secção R3 mostrando as isotensões para tensão normal na direção $Z$ sob a ação da protensão dos pré-distribuidores. 


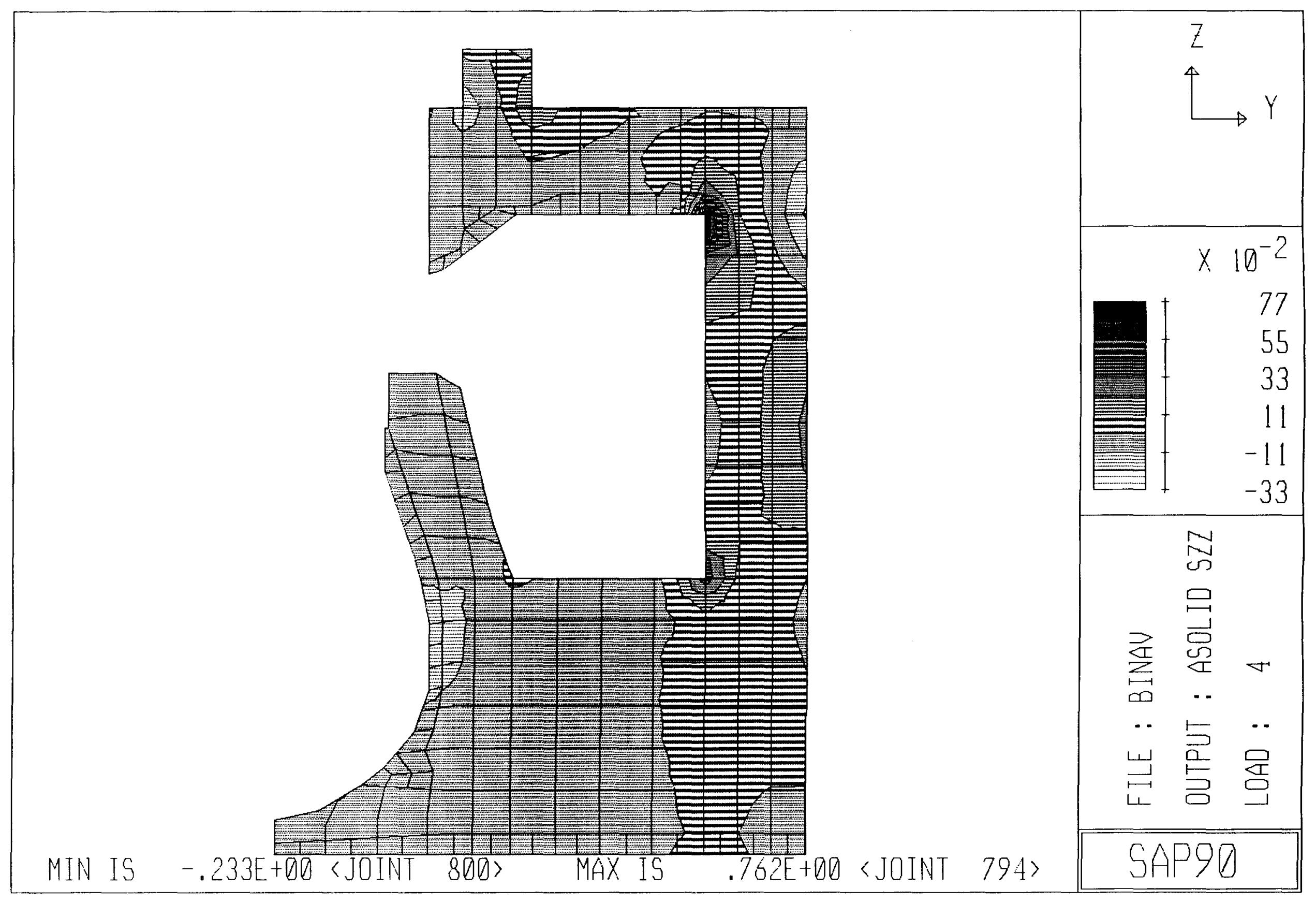


FIGURA 71 - Modelo numérico bidimensional da secção R3 mostrando as isotensões para tensão normal na direção $Z$ sob a ação da pressão hidrostática interna. 


\section{CAPÍTULO 5}

\section{COMPARAÇÕES DOS RESULTADOS}

\subsection{ASPECTOS GERAIS}

Das simulações em computador, ensaios sobre o modelo físico reduzido e auscultação do protótipo foi obtida grande quantidade de resultados, entre os quais foram selecionados alguns com a finalidade de estabelecer comparações.

São apresentados resultados dos modelos físico e numéricos bidimensional e tridimensional, relativos aos pontos da secção R3 da Caixa Espiral em que foram colados extensômetros no modelo físico.

A secção R3 foi escolhida porque, além de ser geométricamente semelhante à maioria das secções, está posicionada no início do duto espiralado, num plano próximo ao formado pelos eixos $\mathrm{Y}$ e $\mathrm{Z}$ do sistema de coordenadas global adotado nas modelagens numéricas.

Em cada ponto existem extensômetros na direção $\mathrm{A}$, contida no plano da seç̧ão R3, na direção $C$, perpendicular ao plano, e na direção $B$, intermediária a 45 graus das demais. No presente trabalho são apresentados apenas os resultados relativos à direção $\mathrm{A}$, por tratar-se da que permite melhor visualização.

As condições de carregamento consideradas para efeito das comparações são as seguintes: 
1) peso da máquina e protensão dos pré-distribuidores,

2) pressão hidrostática nos paramentos de montante e

3) pressão hidrostática interna, a montante e a jusante.

Para a conversão de todos os resultados para a escala natural, possibilitando comparações, recorreu-se à Análise Dimensional, através da utilização do coeficiente $S_{\sigma}$ e do fator de correção $K$ obtidos no capítulo 2. Portanto, as magnitudes das tensões oriundas do primeiro caso de carregamento nos modelos foram multiplicadas por 10 , e as devidas aos demais casos, multiplicadas por 5,5 .

As análises comparativas são feitas levando-se em conta a Caixa Espiral elementar considerada por OLIVEIRA et al.(1986), esquematicamente composta de:

1) tampa anular plana;

2) parede de aspecto cilíndrico, com diretriz aberta e geratrizes verticais, ligada às paredes do quadro terminal da tomada d'água;

3) fundo anular solidário com o suporte tronco-cônico da turbina e

4) conjunto de elementos de ligação (pré-distribuidores da turbina) entre a borda interna da tampa superior e terminal superior do suporte referido.

Primeiramente serão comparados os resultados do modelo físico com os dos modelos numéricos, bidimensional e tridimensional. Em seguida, as comparações serão entre os dois modelos numéricos

Finalmente, confrontam-se os resultados do modelo numérico tridimensional com os do protótipo, procurando estabelecer, por intermédio do primeiro, relação do modelo físico com o segundo, objetivo do presente trabalho.

\subsection{COMPARAÇÃO ENTRE MODELO FÍSICO E MODELO NUMÉRICO BIDIMENSIONAL}

A comparação entre os resultados dos modelos físico e numérico bidimensional são apresentados nas Tabelas 2 e 3 e Figuras 72 e 73 . 
Na Tabela 2 e na Figura 72 mostram-se as tensões normais nas direções A, coplanares à secção $\mathrm{R} 3$ contornando seu perimetro, devidas ao peso do gerador e protensão dos pré-distribuidores.

Nos pontos R3-09, R-13, e R-20 houve dispersão acentuada nos resultados do modelo físico, de modo que não foi possível obter um valor representativo de tensão, sob o presente caso de carregamento, nestes locais.

$\mathrm{Na}$ direção e nos pontos considerados, o modelo físico registra valores máximos de compressão de $-0,4 \mathrm{MPa}$ (ponto R3-17) e tração +0,4 $\mathrm{MPa}$ (R3-14), enquanto o modelo numérico bidimensional apresenta compressão de $-0,6 \mathrm{MPa}$ (R311) e tração de $+0,7 \mathrm{MPa}$ (R3-03).

Tanto os valores absolutos quanto as posições de ocorrência de máximos são divergentes e, do total de 18 leituras mostradas para este caso de carregamento, um terço são nulas no modelo físico (os pontos R3-01 a R3-05, e R3-18), enquanto o modelo numérico indica tensão nula apenas no ponto R3-19

No entanto, as Figuras 63 e 64 mostram as deformadas do modelo numérico sob as mesmas ações, separadamente, onde percebe-se coerência entre os deslocamentos obtidos e as cargas, aplicadas verticalmente, de cima para baixo, na tampa superior da Caixa Espiral.

Tal comportamento também é observado a partir dos sinais das tensões dos dois modelos em todos os pontos, à exceção, óbviamente, daqueles em que ocorre tensão nula.

Análisando as Figuras 49 e 72 conclui-se que a aplicação da protensão nos pré-distribuidores não provocou o registro de tensões na região tronco-cônica de suporte da turbina no modelo físico, uma vez que os pontos R3-01 a R3-05, ali localizados, são os que apresentam tensões nulas. Neste caso, a ocorrência de tensões, conforme o modelo numérico, é mais condizente com a realidade.

A compressão nos pontos R3-08 a R3-12, internos, expressa a tendência de fechamento da secção R3, e a tração nos pontos R3-14 e R3-15 surge em função da proximidade aos pontos de aplicação das cargas, na face superior da tampa, próximo à borda livre. 
TABELA 2 - Tensão (MPa) X Pontos instrumentados da secção R3, comparando resultados dos modelos físico (MFR-1) e numérico bidimensional (BI-1), sob a ação do peso da máquina e protensão dos prédistribuidores.

\begin{tabular}{|c|c|c|}
\hline PONTO & MFR-1 & BI-1 \\
\hline R3-01 & 0 & 0.3 \\
\hline R3-02 & 0 & 0.2 \\
\hline R3-03 & 0 & 0.7 \\
\hline R3-04 & 0 & -0.4 \\
\hline R3-05 & 0 & 0.5 \\
\hline R3-06 & 0.1 & 0.4 \\
\hline R3-07 & 0.1 & 0.1 \\
\hline R3-08 & -0.1 & -0.1 \\
\hline R3-10 & -0.3 & -0.4 \\
\hline R3-11 & -0.1 & -0.6 \\
\hline R3-12 & -0.1 & -0.2 \\
\hline R3-14 & 0.4 & 0.3 \\
\hline R3-15 & 0.1 & 0.2 \\
\hline R3-16 & -0.2 & -0.1 \\
\hline R3-17 & -0.4 & -0.2 \\
\hline R3-18 & 0 & -0.1 \\
\hline R3-19 & 0.1 & 0 \\
\hline R3-21 & -0.1 & -0.1 \\
\hline
\end{tabular}


Tensões - modelo fisico $\times$ modelo numérico bidimensional

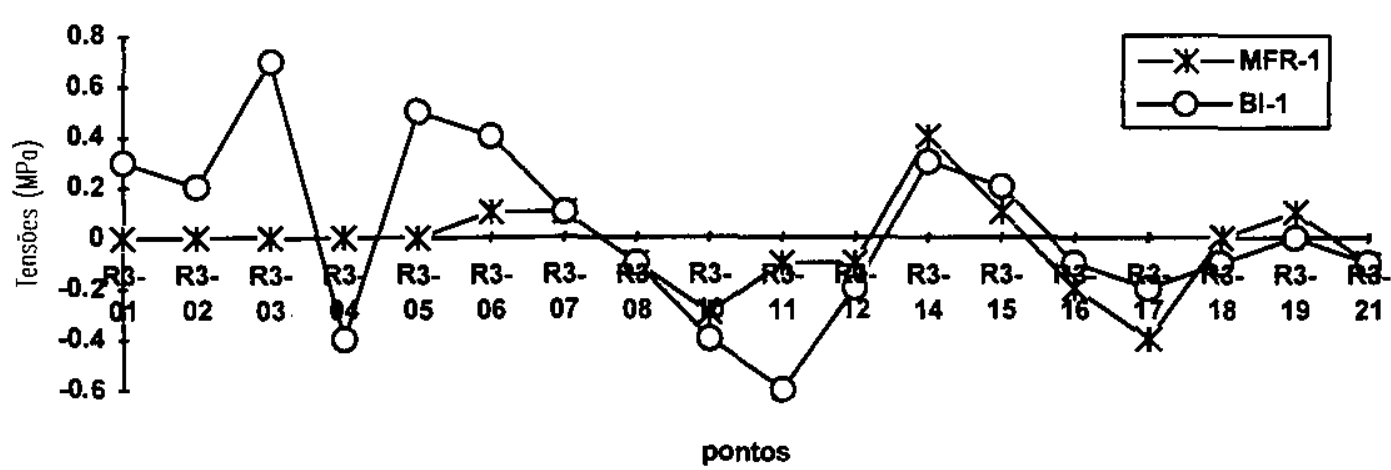

FIGURA 72 - Gráfico Tensão (MPa) X Pontos instrumentados da secção R3, comparando resultados dos modelos físico (MFR-1) e numérico bidimensional (BI-1), sob a ação do peso da máquina e protensão dos pré-distribuidores. 
TABELA 3 - Tensão (MPa) X Pontos instrumentados da secção R3, comparando resultados dos modelos físico (MFR-3) e numérico bidimensional (BI-3), sob a ação da pressão hidrostática interna a montante e a jusante.

\begin{tabular}{|c|c|c|}
\hline PONTO & MFR-3 & BI-3 \\
\hline R3-01 & 0 & -0.2 \\
\hline R3-02 & 0.2 & -0.1 \\
\hline R3-03 & -0.1 & -0.3 \\
\hline R3-04 & -1.5 & 0.1 \\
\hline R3-05 & -1.6 & 0.4 \\
\hline R3-06 & -1.3 & -0.5 \\
\hline R3-07 & 0.5 & 0.2 \\
\hline R3-08 & -0.4 & 0.2 \\
\hline R3-09 & -0.9 & 0.1 \\
\hline R3-10 & -0.3 & 0.6 \\
\hline R3-11 & -0.4 & 0.6 \\
\hline R3-12 & -0.4 & 0.3 \\
\hline R3-13 & -1.1 & -0.6 \\
\hline R3-14 & -3.2 & -0.3 \\
\hline $\mathrm{R} 3-15$ & 13.4 & 0 \\
\hline R3-16 & -1 & -0.3 \\
\hline $\mathrm{R} 3-17$ & -0.3 & -0.3 \\
\hline R3-18 & 0.1 & 0.6 \\
\hline R3-19 & 0.9 & 0.5 \\
\hline R3-20 & 1.7 & 1 \\
\hline R3-21 & 1.2 & 0.9 \\
\hline
\end{tabular}


Tensōes - modelo físico x modelo numérico bidimensional

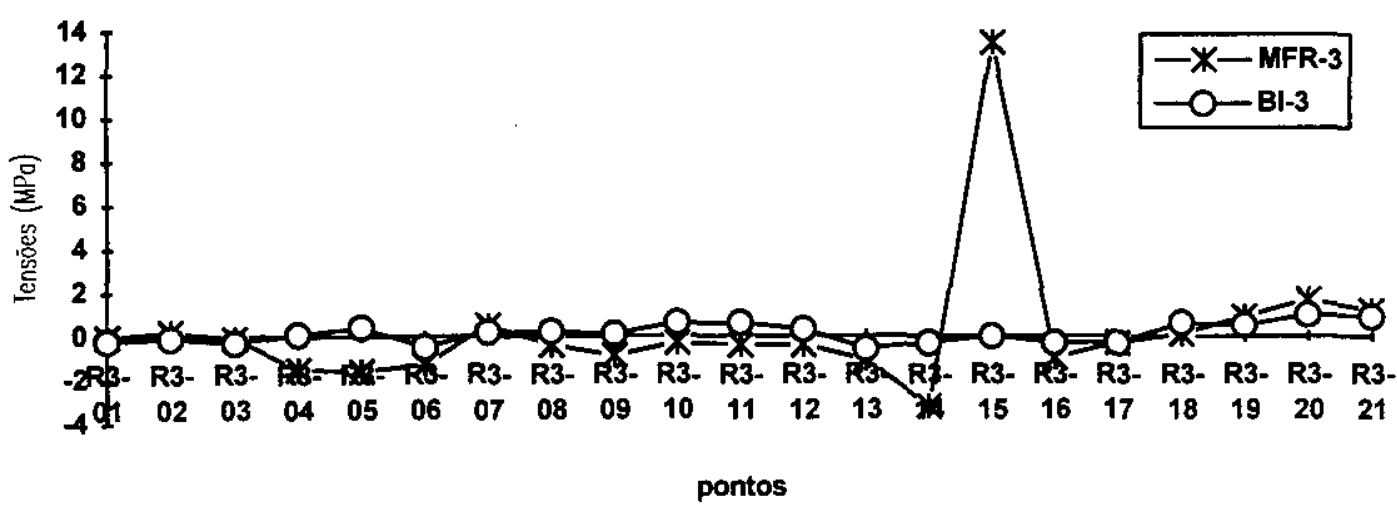

FIGURA 73 - Gráfico Tensão (MPa) X Pontos instrumentados da seç̧ão R3, comparando resultados dos modelos físico (MFR-3) e numérico bidimensional (BI-3), sob a ação da pressão hidrostática interna a montante e a jusante. 


\subsection{COMPARAÇÃO ENTRE MODELO FÍSICO E MODELO NUMÉRICO TRIDIMENSIONAL}

As tensões na secção R-3 dos modelos físico e numérico tridimensional são apresentadas nas Tabelas 4, 5 e 6 e Figuras 74, 75 e 76. Consideram-se como carregamentos, respectivamente, peso da máquina e protensão dos pré-distribuidores, pressão hidrostática nos paramentos de montante, e pressão hidrostática interna a montante e a jusante. Desses, o segundo, aplicado nos paramentos de montante, portanto fora do plano da secção $\mathrm{R} 3$, não pode ser considerado no modelo numérico bidimensional

Sob a ação do peso da máquina e protensão dos pré-distribuidores (Tabela 4 e Figura 74), as máximas tensões de compressão no modelo numérico são observadas no ponto R3-10 correspondendo a -0,9 MPa e.as de tração, a +1,7 MPa no ponto R3-15. No modelo físico, como já foi visto, a máxima compressão é $-0,4$ $\mathrm{MPa}$ e se dá no ponto R3-17, e a segunda maior, $-0,3 \mathrm{MPa}$, em R3-10. A tração máxima é de +0,4 MPa e ocorre no ponto R3-14

Os sinais das tensões coincidem em grande parte dos pontos, excetuandose o ponto R3-21, em que há inversão de sinais, e aqueles em que o modelo físico apresenta tensão nula, R3-18 e, no suporte tronco-cônico da turbina, os pontos R3-01 a R3-05, como observado anteriormente.

Nos pontos R3-08 a R3-12, internos ao duto, a ocorrência de tensões de compressão, simultânea às tensões de tração (pontos R3-19 a R3-20 nos dois modelos e R3-21, no físico) ou de compressão menores (R3-21 no numérico), indicam tendência ao estrangulamento do duto, conforme as deformadas do modelo numérico, mostradas nas Figuras 51 e 52, e coerentemente com o carregamento.

A Tabela 5 e Figura 75 apresentam as tensões obtidas nos modelos fisico e numérico tridimensional sob a ação da pressão hidrostática nos paramentos de montante. A leitura do ponto R3-04 no modelo físico foi expurgada no processo de depuração. 
$\mathrm{O}$ modelo numérico apresenta resultados de pequena magnitude, no máximo compressão de -0,1 MPa (R3-08 a R3-10), e tração de +0,1 MPa (R3-07). Situação semelhante ocorre no modelo físico, onde se atinge compressão de $-0,4$ $\mathrm{MPa}$ (R3-10) e tração máxima de +0,2 MPa.

Desconsidera-se o ponto R3-15 porque apresenta tração de $+11,0 \mathrm{MPa}$, muito acima da média, sugerindo erro de leitura (Figura 75), uma vez que o carregamento é aplicado em pontos distantes, tornando injustificável uma concentração de tensões de tal ordem.

Em função da distância dos pontos de aplicação de cargas, nos demais pontos, os dois modelos apontam baixas tensões, apesar de serem acentuadamente mais intensas no modelo físico. O número de pontos com tensão nula chega a $80 \%$ dos vinte considerados no modelo numérico. 
TABELA 4 - Tensão (MPa) X Pontos instrumentados da secção R3, comparando resultados dos modelos físico (MFR-1) e numérico tridimensional (TRI-1), sob a ação do peso da máquina e protensão dos prédistribuidores.

\begin{tabular}{|c|c|c|}
\hline PONTO & TRI-1 & MFR-1 \\
\hline R3-01 & 0.2 & 0 \\
\hline R3-02 & -0.1 & 0 \\
\hline R3-03 & -0.2 & 0 \\
\hline R3-04 & 0.5 & 0 \\
\hline R3-05 & 0.5 & 0 \\
\hline R3-06 & 0.6 & 0.1 \\
\hline R3-07 & 0.3 & 0.1 \\
\hline R3-08 & -0.6 & -0.1 \\
\hline R3-10 & -0.9 & -0.3 \\
\hline R3-11 & -0.6 & -0.1 \\
\hline R3-12 & -0.2 & -0.1 \\
\hline R3-14 & 0.7 & 0.4 \\
\hline $\mathrm{R} 3-15$ & 1.7 & 0.1 \\
\hline R3-16 & -0.4 & -0.2 \\
\hline $\mathrm{R} 3-17$ & -0.4 & -0.4 \\
\hline R3-18 & 0.1 & 0 \\
\hline R3-19 & 0.6 & 0.1 \\
\hline R3-21 & 0.2 & -0.1 \\
\hline
\end{tabular}


Tensठes - modelo fisico $x$ modelo numérico tridimensional

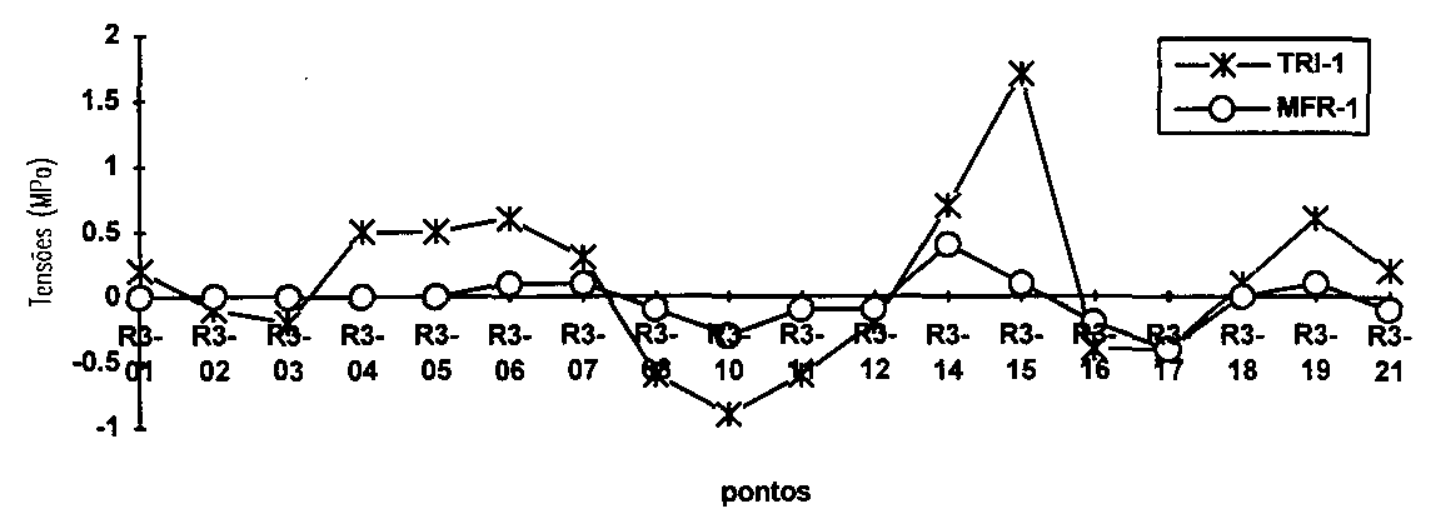

FIGURA 74 - Gráfico Tensão (MPa) X Pontos instrumentados da secção R3, comparando resultados dos modelos físico (MFR-1) e numérico tridimensional (TRI-1), sob a ação do peso da máquina e protensão dos pré-distribuidores. 
TABELA 5 - Tensão (MPa) X Pontos instrumentados da secção R3, comparando resultados dos modelos físico (MFR-2) e numérico tridimensional (TRI-2), sob a ação da pressão hidrostática nos paramentos de montante.

\begin{tabular}{|c|c|c|}
\hline PONTO & TRI-2 & MFR-2 \\
\hline R3-01 & 0 & 0 \\
\hline R3-02 & 0 & 0 \\
\hline R3-03 & 0 & 0 \\
\hline R3-05 & 0 & 0 \\
\hline R3-06 & 0 & 0 \\
\hline R3-07 & 0.1 & 0.2 \\
\hline R3-08 & -0.1 & -0.3 \\
\hline R3-09 & -0.1 & -0.3 \\
\hline R3-10 & -0.1 & -0.4 \\
\hline R3-11 & 0 & 0.1 \\
\hline R3-12 & 0 & 0 \\
\hline R3-13 & 0 & 0 \\
\hline R3-14 & 0 & 0 \\
\hline R3-15 & 0 & 11 \\
\hline R3-16 & 0 & 0 \\
\hline $\mathrm{R} 3-17$ & 0 & 0 \\
\hline R3-18 & 0 & -0.1 \\
\hline R3-19 & 0 & 0.1 \\
\hline R3-20 & 0 & 0 \\
\hline R3-21 & 0 & -0.1 \\
\hline
\end{tabular}


Tensठ̋es - modelo físico x modelo numérico tridimensional

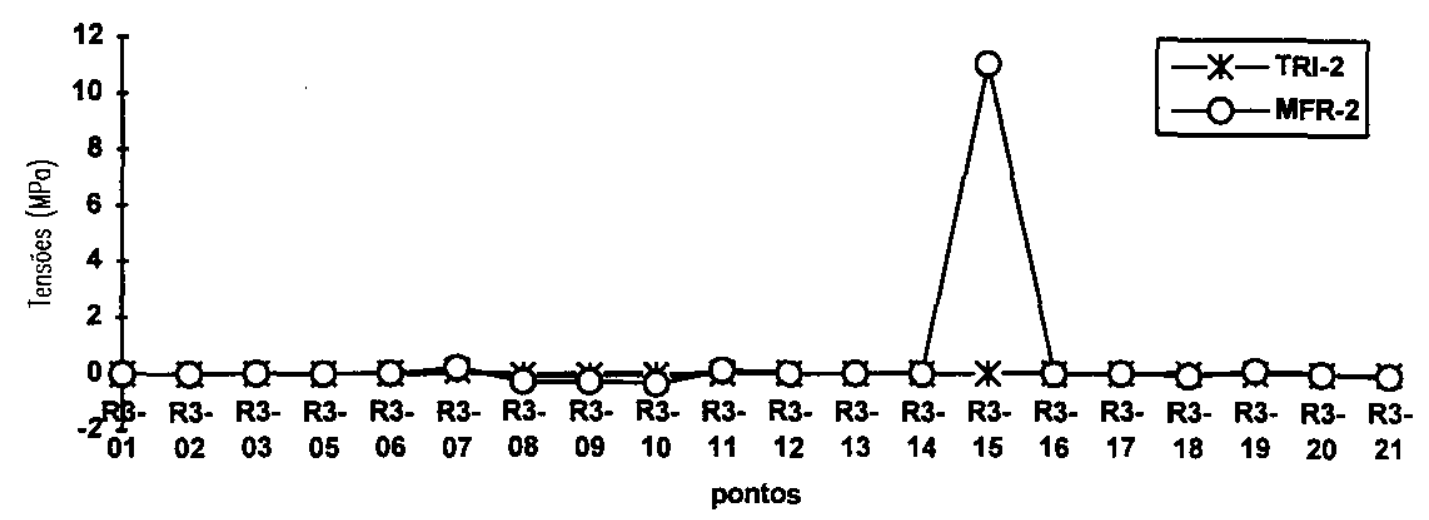

FIGURA 75 - Gráfico Tensão (MPa) X Pontos instrumentados da secção R3, comparando resultados dos modelos físico (MFR-2) e numérico tridimensional (TRI-2), sob a ação da pressão hidrostática nos paramentos de montante. 
A análise da deformada do modelo numérico (Figura 52) mostra que há compatibilidade com o surgimento de tensões de compressão na face interna da parede (R3-08 a R3-10), ocorrida nos dois modelos.

Conclui-se que essas cargas hidráulicas do reservatório sobre os paramentos da barragem não promovem o surgimento de tensões de grande intensidade sobre a Caixa Espiral, e que a impossibilidade de representá-las no modelo numérico bidimensional não o desqualifica como instrumento de análise.

Além disso, nota-se que há correlação entre os resultados dos modelos físico e numérico tridimensional para esse caso de carregamento, mesmo que com diferenças de intensidade.

A atuação da pressão hidrostática internamente provoca o surgimento das tensões mostradas na Tabela 6 e Figura 76, mais intensas que as que ocorrem nos outros casos de carregamento. Oscilam de compressão de -3,2 MPa (R3-14) a tração de $+1,7 \mathrm{MPa}$ (R3-20) no modelo físico, como visto anteriormente. No modelo numérico a máxima compressão é de $-1,0 \mathrm{MPa}(\mathrm{R} 3-15)$ e a máxima tração é de $+1,4$ $\mathrm{MPa}$ (R3-07 e R3-21).

A observação da deformada do modelo numérico (Figura 53) e a análise dos resultados dos pontos localizados na face interna (R3-08 a R3-10) e externa (R319 a R3-21) da parede da Caixa Espiral, mostrando, respectivamente, tensões médias de +0,3 $\mathrm{MPa}$ e +3,2 $\mathrm{MPa}$, no modelo numérico, e de -0,5 $\mathrm{MPa}$ e +3,8 $\mathrm{MPa}$, no modelo físico, indicam a expansão da secção do duto, condizente com o carregamento.

Portanto, do ponto de vista qualitativo há convergência entre resultados dos modelos físico e numérico tridimensional, ocorrendo algumas discrepâncias de ordem quantitativa entre eles. 
TABELA 6 - Tensão (MPa) X Pontos instrumentados da secção R3, comparando resultados dos modelos físico (MFR-3) e numérico tridimensional (TRI-3), sob a ação da pressão hidrostática interna a montante e a jusante.

\begin{tabular}{|c|c|c|}
\hline PONTO & TRI-3 & MFR-3 \\
\hline R3-01 & -0.3 & 0 \\
\hline R3-02 & -0.1 & 0.2 \\
\hline R3-03 & 0 & -0.1 \\
\hline R3-04 & -0.4 & -1.5 \\
\hline R3-05 & -0.5 & -1.6 \\
\hline R3-06 & 0 & -1.3 \\
\hline R3-07 & 1.4 & 0.5 \\
\hline R3-08 & 0 & -0.4 \\
\hline R3-09 & 0.1 & -0.9 \\
\hline R3-10 & 0.8 & -0.3 \\
\hline R3-11 & 1.2 & -0.4 \\
\hline R3-12 & 0.4 & -0.4 \\
\hline R3-13 & 0 & -1.1 \\
\hline R3-14 & -0.4 & -3.2 \\
\hline $\mathrm{R} 3-15$ & -1 & 13.4 \\
\hline R3-16 & 0.1 & -1 \\
\hline R3-17 & -0.3 & -0.3 \\
\hline R3-18 & 0.6 & 0.1 \\
\hline R3-19 & 0.5 & 0.9 \\
\hline R3-20 & 1.3 & 1.7 \\
\hline $\mathrm{R} 3-21$ & 1.4 & 1.2 \\
\hline
\end{tabular}


Tensठ̄es - modelo físico x modelo numérico tridimensional

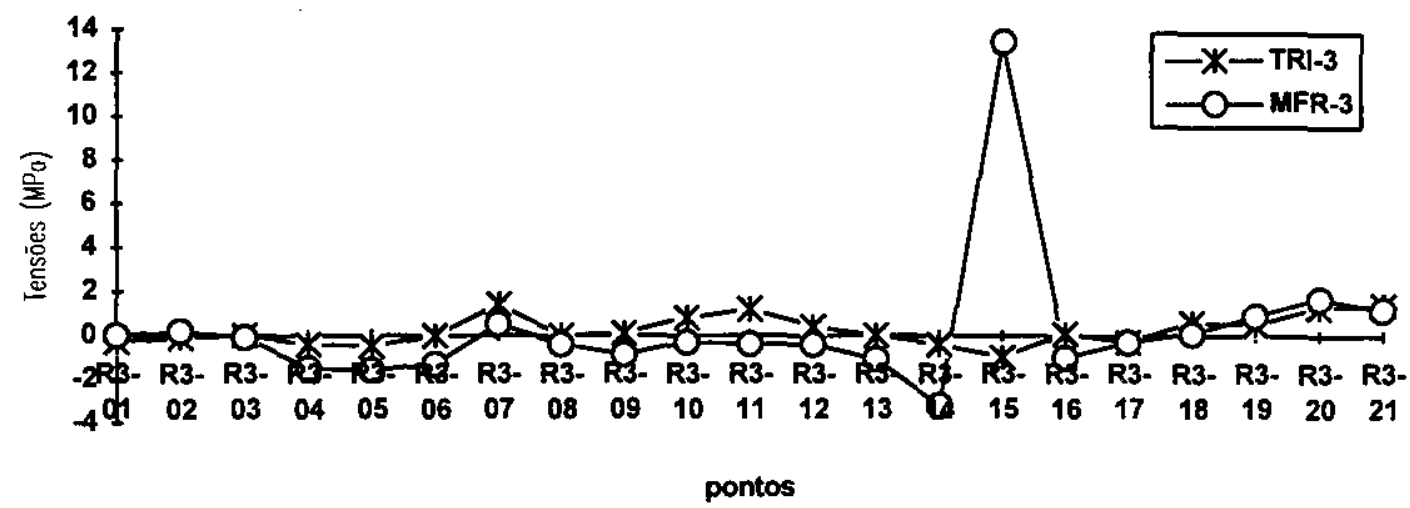

FIGURA 76 - Gráfico Tensão (MPa) X Pontos instrumentados da secção R3, comparando resultados dos modelos físico (MFR-3) e numérico tridimensional (TRI-3), sob a ação da pressão hidrostática interna a montante e a jusante. 


\subsection{COMPARAÇÃO ENTRE OS MODELOS NUMÉRICOS BIDIMENSIONAL E TRIDIMENSIONAL}

A comparação entre resultados de processamento dos modelos numéricos bidimensional e tridimensional é apresentada nas Tabelas 7, 8 e 9 e Figuras 77,78 e 79 , respectivamente sob ação do peso da máquina, da protensão dos prédistribuidores e da pressão hidrostática interna.

Anteriormente, foram apresentados os resultados somados dos dois primeiros casos de carregamento, a fim de possibilitar a comparação com os resultados do modelo fisico, cujo ensaio combinou as cargas. Entre os modelos numéricos é possível separar os dois casos.

$O$ efeito do peso da máquina no modelo tridimensional (Tabela 7 e Figura 77) se traduz em compressão máxima de $-0,5 \mathrm{MPa}(\mathrm{R} 3-10)$ e tração máxima de $+0,9$ MPa (R3-15). No bidimensional, só não são nulas as tensões nos pontos R3-10 a R314, com máximos de compressão de -0,2 MPa (R3-11) e de tração de +0,2 MPa (R313).

Devido ao baixo nível de tensões surgem discrepâncias quantitativas relativamente grandes, apesar de todos os valores não nulos no modelo bidimensional convergirem. As Figuras 50 e 63 mostram as deformadas dos dois modelos a a semelhança qualitativa.

A aplicação da protensão nos pré-distribuidores permite observar resultados aproximados tanto do ponto de vista quantitativo (Tabela 8 e Figura 78), quanto qualitativo (Figuras 51 e 64).

A compressão máxima no modelo tridimensional vale -0,5 MPa (R3-10), e no bidimensional alcança $-0,4 \mathrm{MPa}$ (R3-11). As trações máximas são, respectivamente, +0,8 $\mathrm{MPa}(\mathrm{R} 3-15)$ e $+0,7 \mathrm{MPa}(\mathrm{R} 3-03)$.

Os valores de compressão, bem como sua localização aproximam-se satisfatoriamente. Já os valores de tração alcançam valores semelhantes, mas em posições muito diferentes. 
TABELA 7 - Tensão (MPa) X Pontos instrumentados da secção R3, comparando resultados dos modelos numéricos tridimensional (TRI-11) e bidimensional (BI-11), sob a ação do peso da máquina.

\begin{tabular}{|c|c|c|}
\hline PONTO & TRI-11 & BI-11 \\
\hline R3-01 & -0.1 & 0 \\
\hline R3-02 & 0 & 0 \\
\hline R3-03 & 0 & 0 \\
\hline R3-04 & 0 & 0 \\
\hline R3-05 & 0 & 0 \\
\hline R3-06 & 0.1 & 0 \\
\hline R3-07 & 0.2 & 0 \\
\hline R3-08 & -0.3 & 0 \\
\hline R3-09 & -0.4 & 0 \\
\hline R3-10 & -0.5 & -0.1 \\
\hline R3-11 & -0.3 & -0.2 \\
\hline R3-12 & -0.1 & -0.1 \\
\hline R3-13 & 0.1 & 0.2 \\
\hline R3-14 & 0.3 & 0.1 \\
\hline R3-15 & 0.9 & 0 \\
\hline R3-16 & -0.1 & 0 \\
\hline R3-17 & 0.6 & 0 \\
\hline R3-18 & 0.1 & 0 \\
\hline R3-19 & 0.3 & 0 \\
\hline R3-20 & 0.2 & 0 \\
\hline R3-21 & 0.1 & 0 \\
\hline
\end{tabular}


Tensões - modelo s numéricos

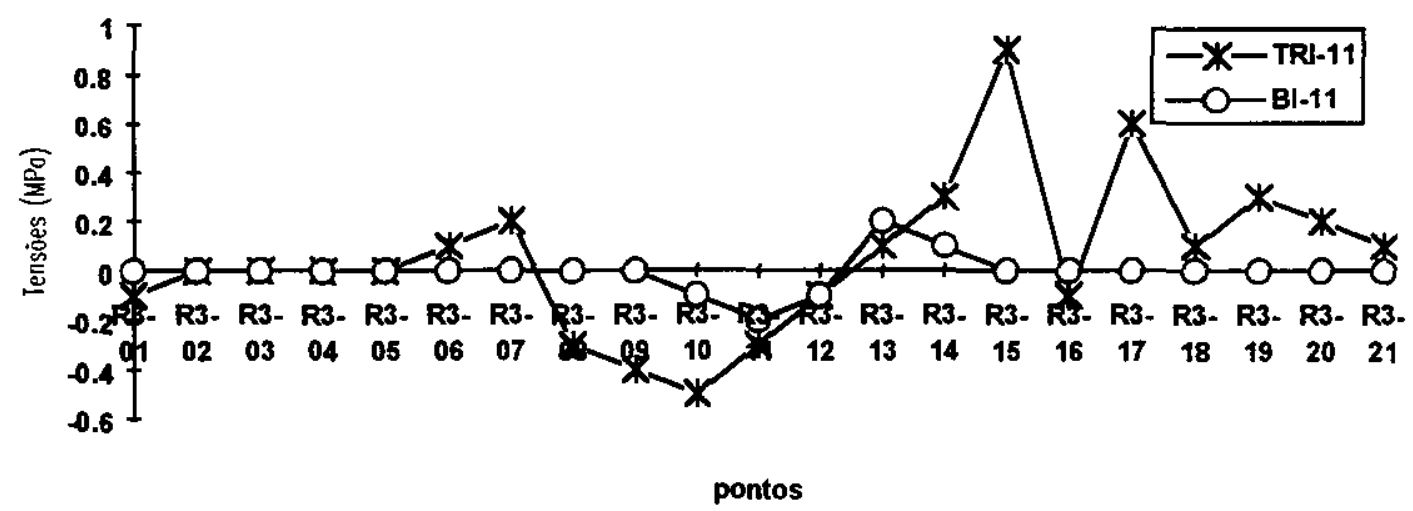

FIGURA 77 - Gráfico Tensão (MPa) X Pontos instrumentados da secção R3, comparando resultados dos modelos numéricos tridimensional (TRI11) e bidimensional (BI-11), sob a ação do peso da máquina. 
TABELA 8 - Tensão (MPa) X Pontos instrumentados da seç̧ão R3, comparando resultados dos modelos numéricos tridimensional (TRI-12) e bidimensional (BI-12), sob a ação da protensão dos pré-distribuidores.

\begin{tabular}{|c|c|c|}
\hline PONTOS & TRI-12 & BI-12 \\
\hline R3-01 & 0.2 & 0.3 \\
\hline R3-02 & 0 & 0.2 \\
\hline R3-03 & -0.2 & 0.7 \\
\hline R3-04 & 0.5 & -0.4 \\
\hline R3-05 & 0.5 & 0.5 \\
\hline R3-06 & 0.5 & 0.4 \\
\hline R3-07 & 0.1 & 0.1 \\
\hline R3-08 & -0.3 & -0.1 \\
\hline R3-09 & -0.4 & -0.2 \\
\hline R3-10 & -0.5 & -0.3 \\
\hline R3-11 & -0.3 & -0.4 \\
\hline R3-12 & -0.1 & -0.1 \\
\hline R3-13 & 0.1 & 0.4 \\
\hline R3-14 & 0.4 & 0.2 \\
\hline R3-15 & 0.8 & 0.2 \\
\hline R3-16 & -0.3 & -0.1 \\
\hline R3-17 & -1 & -0.2 \\
\hline R3-18 & 0.1 & -0.1 \\
\hline R3-19 & 0.3 & 0 \\
\hline R3-20 & 0.2 & 0 \\
\hline R3-21 & 0.1 & -0.1 \\
\hline
\end{tabular}


Tensōes - modelos numéricos

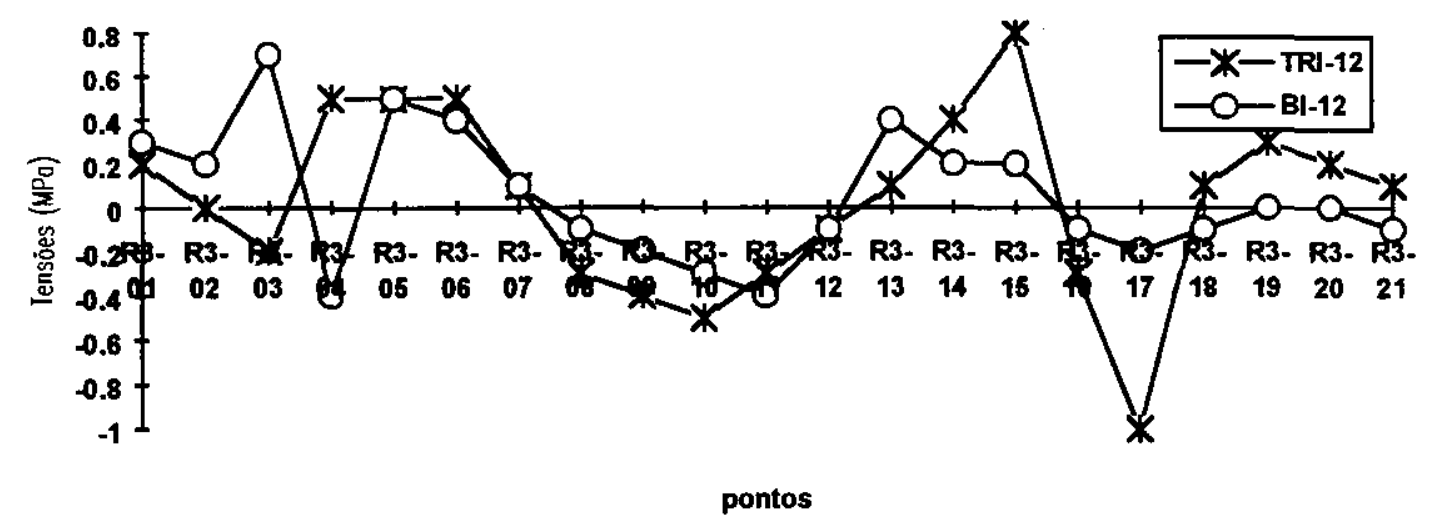

FIGURA 78 - Gráfico Tensão (MPa) X Pontos instrumentados da secção R3, comparando resultados dos modelos numéricos tridimensional (TRI12) e bidimensional (BI-12), sob a ação da protensão dos prédistribuidores. 
Sob o carregamento com pressão hidrostática interna (Tabela 9 e Figuras 53, 65 e 79), o comportamento varia de acordo com o trecho da seç̧ão R3. Na região tronco-cônica (R3-01 a R3-06) ocorrem grandes discrepâncias. A correlação torna-se perceptível no trecho seguinte, no interior do duto (R3-07 a R3-14) e tornase muito boa no exterior da estrutura, nos pontos R3-17 a R3-21, chegando a coincidir totalmente nos três primeiros pontos deste intervalo.

O modelo numérico bidimensional foi concebido com a finalidade de fornecer subsídios para análise do número de nós utilizados na malha do outro modelo. É composto de 616 nós, enquanto o tridimensional apresenta apenas 78 .

No trabalho, apresentado por BARBOSA et al. (1994) no XXI Seminário Nacional de Grandes Barragens, os autores comparam os campos de tensões e deslocamentos do concreto envoltório da Caixa Espiral da U.H.E. de Xingó, equipada com turbina tipo Francis, obtidos através de dois modelos matemáticos, um tridimensional e outro axissimétrico, também utilizando o software SAP-90, e chegam a resultados próximos.

No presente trabalho, não se alcançou o mesmo grau de aproximação. A utilização de um número de nós no modelo tridimensional significativamente inferior ao do bidimensional, a geometria das caixas espiral de turbinas tipo Kaplan, menos axissimétricas e com paredes mais esbeltas que no caso de turbinas Francis, e a localização da seç̧ão analisada (R3), causaram algumas discrepâncias entre os resultados dos modelos.

Apesar disso, porém, a análise mostrou que há correlação entre os modelos numéricos e que as discrepâncias surgidas estão dentro de limites razoáveis 
TABELA 9 - Tensão (MPa) X Pontos instrumentados da secção R3, comparando resultados dos modelos numéricos tridimensional (TRI-3) e bidimensional (BI-3), sob a ação da pressão hidrostática interna a montante e a jusante.

\begin{tabular}{|c|c|c|}
\hline PONTO & TRI-3 & BI-3 \\
\hline R3-01 & -0.3 & -0.2 \\
\hline R3-02 & -0.1 & -0.1 \\
\hline R3-03 & 0 & -0.3 \\
\hline R3-04 & -0.4 & 0.1 \\
\hline R3-05 & -0.5 & 0.4 \\
\hline R3-06 & 0 & -0.5 \\
\hline R3-07 & 1.4 & 0.2 \\
\hline R3-08 & 0 & 0.2 \\
\hline R3-09 & 0.1 & 0.1 \\
\hline R3-10 & 0.8 & 0.6 \\
\hline R3-11 & 1.2 & 0.6 \\
\hline R3-12 & 0.4 & 0.3 \\
\hline R3-13 & 0 & -0.6 \\
\hline R3-14 & -0.4 & -0.3 \\
\hline R3-15 & -1 & 0 \\
\hline R3-16 & 0.1 & -0.3 \\
\hline R3-17 & -0.3 & -0.3 \\
\hline R3-18 & 0.6 & 0.6 \\
\hline R3-19 & 0.5 & 0.5 \\
\hline R3-20 & 1.3 & 1 \\
\hline R3-21 & 1.4 & 0.9 \\
\hline
\end{tabular}




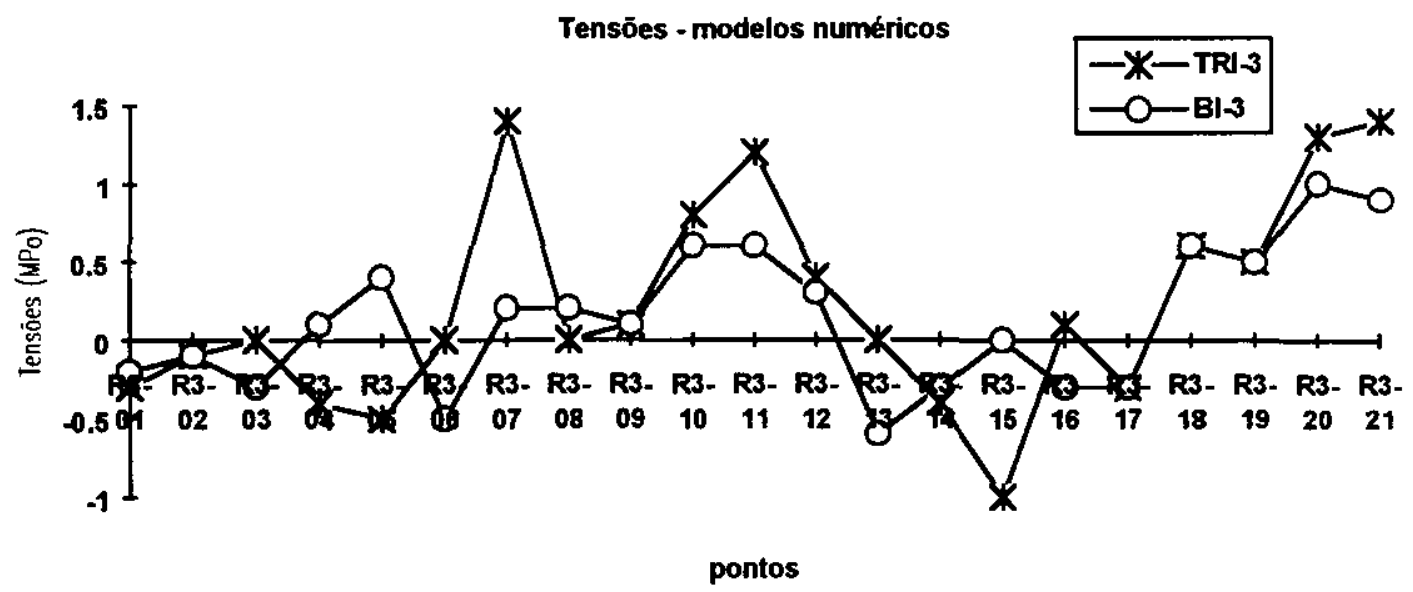

FIGURA 79 - Gráfico Tensão (MPa) X Pontos instrumentados da secção R3, comparando resultados dos modelos numéricos tridimensional (TRI-3) e bidimensional (BI-3), sob a ação da pressão hidrostática interna a montante e a jusante. 


\subsection{COMPARAÇÃO ENTRE MODELO NUMÉRICO TRIDIMENSIONAL E PROTÓTIPO}

São comparados modelo numérico tridimensional e protótipo, considerando os pontos da Casa de Força instrumentados com Tensômetros para Concreto. Como a instrumentação para tensões na Caixa Espiral só consta de Tensômetros para Concreto Armado, que medem tensões na armadura, não foi possivel comparar diretamente resultados da estrutura e dos modelos físico e numérico bidimensional.

OLIVEIRA et al.(1986) estabeleceram comparação entre tensões calculadas através de analogias com o cálculo clássico de Concreto Armado e medidas nas armaduras da Caixa Espiral da Usina Nova Avanhandava, concluindo que o comportamento observado é satisfatório em $70 \%$ dos instrumentos instalados no Grupo Gerador número 1, analisado em seu trabalho

Os resultados da instrumentação do protótipo não traduzem necessariamente de maneira fiel as tensões que ocorrem na barragem real, uma vez que são passiveis de influências externas. Uma inundação das galerias, ocorrida no período de 29/09/81 a 06/10/81, por exemplo, ocasionou umidade nos cabos elétricos, alterando leituras de alguns instrumentos realizadas após essa data.

No entanto, no presente trabalho, esses resultados serão utilizados como parâmetros para avaliar os demais, uma vez que o objetivo final de toda análise de estruturas é a construção em escala natural.

A seguir são apresentadas as Tabelas 10 e 11 e Figuras 80 e 81 , com as comparações entre resultados de auscultação do protótipo, e entre protótipo e modelo numérico tridimensional.

Os casos de carregamento considerados nos processamentos do modelo numérico tridimensional foram todos combinados, somando-se todos os resultados obtidos, na tentativa de se aproximar da situação real.

Durante a fase de enchimento do reservatório, é realizado intenso acompanhamento da estrutura através de freqüentes leituras da instrumentação. Relatório da INTERNACIONAL DE ENGENHARIA (1983a) traz as tensões médias 
lidas durante aquela fase nos Tensômetros para Concreto considerados no presente trabalho (TC-304, TC-306 e TC-313).

A Tabela 10 e a Figura 80 mostram comparação entre as médias das leituras realizadas na fase de enchimento, realizado de $13 / 09 / 82$ a $22 / 10 / 82$, e na fase de operação, no período de janeiro de 1986 a dezembro de 1994, com dados do Sistema Segurança de Barragens.

Percebem-se diferenças nas medidas obtidas pelos três instrumentos nos dois períodos. O TC-304 apresenta média de leituras $11 \%$ menores, enquanto o TC306 e o TC-313 indicam majorações de $44 \%$ e $25 \%$, respectivamente. Fenômenos como variação das cargas hidráulicas oriundas do reservatório, acomodação da estrutura e mesmo possíveis ocorrências de umidade nos cabos explicam essas alterações. A ordem de grandeza das medidas, no entanto, permanece em torno de $1,0 \mathrm{MPa}$.

Quando confrontam-se os resultados do protótipo com os do modelo numérico (Tabela 11 e Figura 81), surgem divergências de ordem quantitativa e qualitativa. A menor tensão observada no protótipo, de -0,8 MPa (TC-304), é o dobro da maior obtida no modelo numérico, $-0,4 \mathrm{MPa}$. Os outros resultados do processamento matemático são um de tensão nula e outro de tração, totalmente inesperado já que os Tensômetros para Concreto somente lêem tensão de compressão.

Portanto o modelo apresenta resultado aceitável em apenas um dos três pontos analisados, mostrando-se não representativo da realidade observada pelos Tensômetros para Concreto. 
TABELA 10 - Tensão (MPa) medida durante o enchimento do reservatório (PROTIGO) e de operação da usina (PROTUAL) X Pontos instrumentados com Tensômetros para Concreto no Protótipo.

\begin{tabular}{|c|c|c|}
\hline PONTOS & PROTIGO & PROTUAL \\
\hline TC-304 & -0.9 & -0.8 \\
\hline TC-306 & -0.9 & -1.3 \\
\hline TC-313 & -1.2 & -1.5 \\
\hline
\end{tabular}

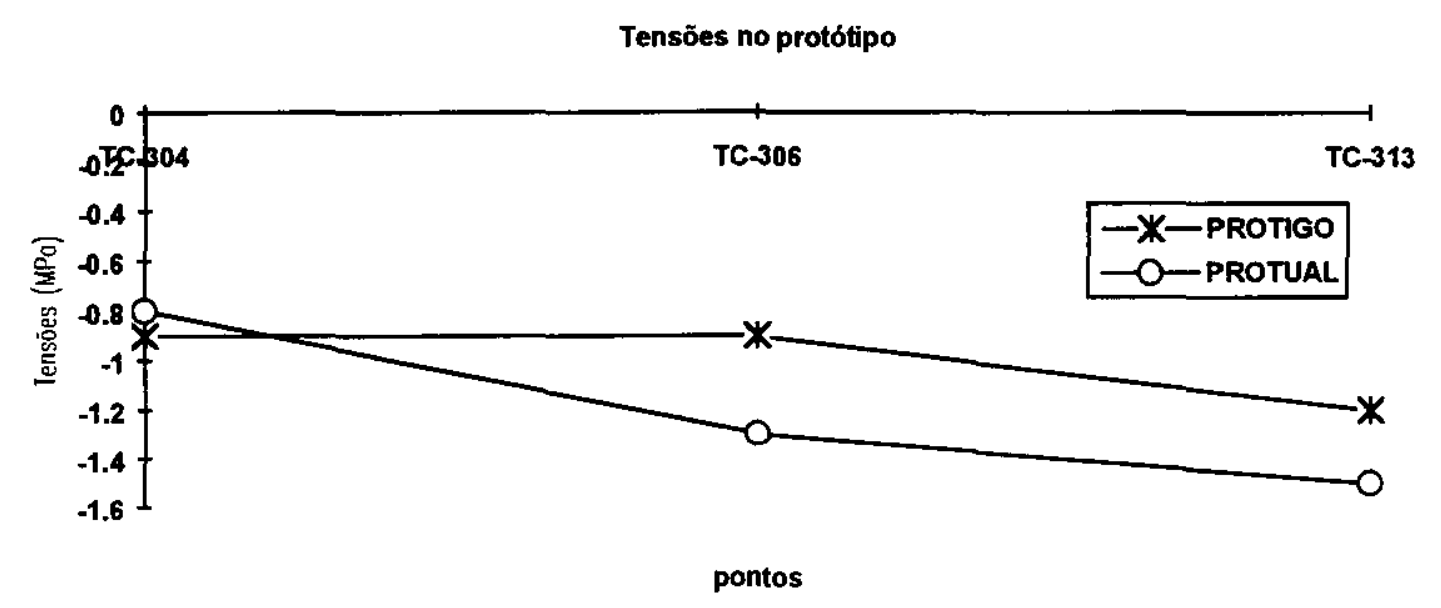

FIGURA 80 - Gráfico Tensão (MPa) medida durante o enchimento do reservatório (PROTIGO) e operação da usina (PROTUAL) X Pontos instrumentados com Tensômetros para Concreto no Protótipo 
TABELA 11 - Tensão (MPa) X Pontos instrumentados com Tensômetros para Concreto no Protótipo, comparando resultados do modelo numérico tridimensional (TRI-TOTAL) e do Protótipo (PROTUAL).

\begin{tabular}{|c|c|c|}
\hline PONTO & PROTUAL & TRI-TOTAL \\
\hline TC-304 & -0.8 & 0 \\
\hline TC-306 & -1.3 & 0.4 \\
\hline TC-313 & -1.5 & -0.4 \\
\hline
\end{tabular}

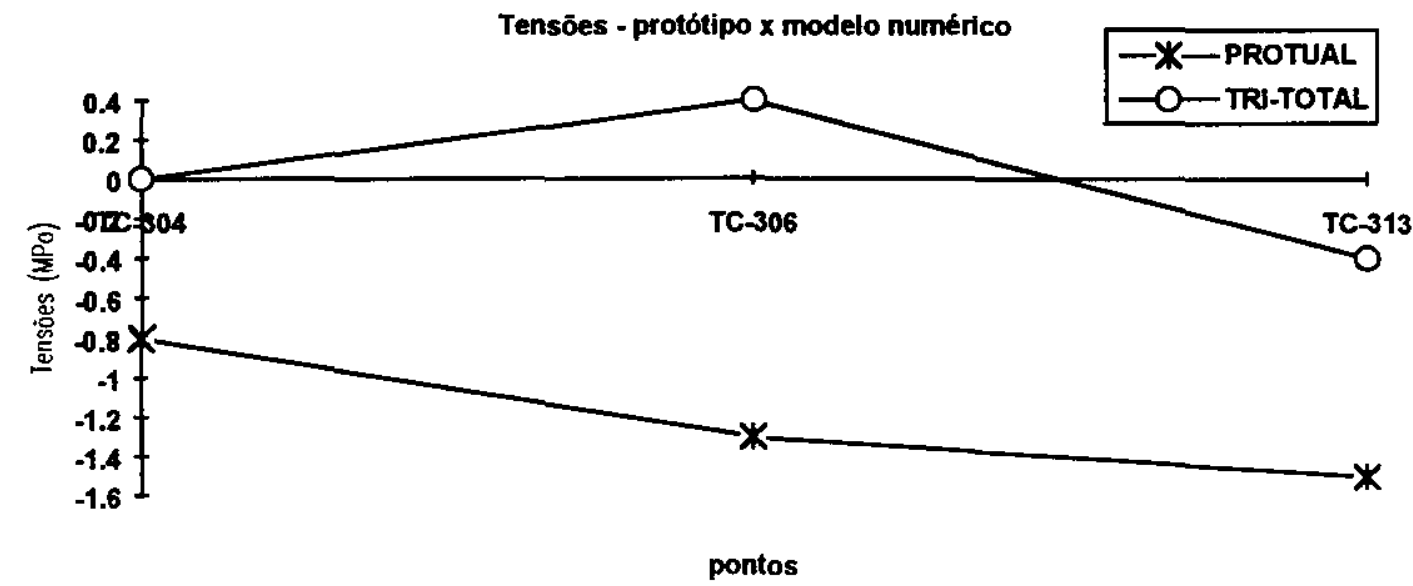

FIGURA 81 - Gráfico Tensão (MPa) X Pontos instrumentados com Tensômetros para Concreto no Protótipo, comparando resultados do modelo numérico tridimensional (TRI-TOTAL) e do Protótipo (PROTUAL). 


\subsection{RESUMO DAS COMPARAÇÕES}

De maneira geral, conclui-se que existe correlação entre os resultados do modelos numéricos tridimensional e bidimensional e do modelo físico reduzido.

Há alguns problemas, como a ocorrência de tensões no suporte troncocônico da turbina sob atuação da protensão dos pré-distribuidores, mostrada nos modelos numéricos tridimensional e bidimensional e não registrada no modelo fisico.

A discrepância entre os resultados obtidos experimentalmente e os provenientes de processamento numérico é maior do que a esperada, uma vez que o material acrílico, de que é composto o modelo físico, tem propriedades próximas das idealizadas na Teoria da Elasticidade, quanto à homogeneidade e isotropia. Além disso, os ensaios foram realizados em regime elástico, evitando-se a ocorrência de fenômenos não-lineares.

Algumas explicações para esse fato referem-se a problemas de experimentação, outras, a dificuldades no processamento numérico.

Os extensômetros elétricos de resistência que compuseram a instrumentação do modelo físico, são muito sensíveis a alterações de temperatura e umidade. Apesar de todos os esforços para manter um ambiente devidamente aclimatado, dos cuidados na preparação das superficies, colagem dos sensores, isolamento da cablagem e utilização do bloco de compensação, alguns extensômetros não apresentaram bom comportamento.

Esse fato foi observado na depuração dos resultados, que, em alguns pontos, levou a um número muito grande de expurgos de leituras, por isso seus valores nem aparecem em algumas tabelas. O ponto R3-15, por exemplo, mostra erros de leitura nos dois ensaios sob simulação de cargas hidrostáticas.

Com relação ao modelo numérico tridimensional, o número de nós, apesar de grande, talvez tenha sido insuficiente frente às proporções da estrutura. Foram atingidos, no entanto, os números máximos de nós e de graus de liberdade estabelecidos pela versão utilizada do software. A utilização de outra versão, ou de outro software, com maior capacidade, conduziria a resultados mais confiáveis. 
O modelo numérico bidimensional serviu como um elemento complementar na análise, objetivando verificar a influência do número de nós no modelo tridimensional.

Já uma análise qualitativa dos modelos físico e numérico tridimensional mostra que seu funcionamento se deu dentro do esperado. Para o caso de carregamento em que são considerados o peso da máquina e a protensão dos prédistribuidores, a tampa superior da Caixa Espiral desloca-se para baixo, descrevendo aproximadamente uma flexão.

Submetido ao carregamento da pressão hidrostática nos paramentos de montante, o modelo numérico tridimensional descreve um movimento de inclinação para a frente, conforme a Figura 47. Carregado com pressão hidrostática interna, mostra expansão da Caixa Espiral, como mostrado na Figura 48.

Uma vez que os modelos numéricos e fisico apresentam comportamento similar, a comparação entre os resultados do numérico tridimensional e do protótipo traduz a relação deste com o modelo físico.

As simplificações assumidas nos modelos, deixando de considerar nos carregamentos a ação do peso próprio, dos fenômenos hidrodinâmicos e vibrações, e o reduzido número de pontos instrumentados no protótipo são fatores que tornaram impossível observar concordância entre seus resultados e os dos modelos. 


\section{CAPÍTULO 6}

\section{CONCLUSÕES}

O presente trabalho se propôs a estabelecer uma comparação entre os resultados de ensaios em modelo fisico da Caixa Espiral de uma turbina tipo Kaplan, realizados pela CESP e os resultados de auscultação do protótipo, utilizando modelos numéricos como intermediários, uma vez que a localização dos extensômetros, no modelo físico reduzido, não coincidiam com as posições dos tensômetros para concreto, no protótipo.

Com tal finalidade, foram mostrados os procedimentos seguidos na construção e ensaios do modelo físico, os métodos de coleta e análise de dados de auscultação de barragens utilizados pela CESP e as modelagens plana e tridimensional para processamento numérico das estruturas da Caixa Espiral da Barragem Nova Avanhandava.

Não foi possível estabelecer correlação satisfatória entre os resultados de modelagem e de auscultação do protótipo.

No entanto, observam-se tensões de pequena magnitude, atingindo trações e compressões de no máximo $4,0 \mathrm{MPa}$. A utilização de concretos com fck de 10,15 e até $18 \mathrm{MPa}$, conforme INTERNACIONAL DE ENGENHARIA (1983b), indica que há margem para redução de custos neste tipo de obra, ainda que se considere que os resultados analisados no presente trabalho não correspondam necessariamente às direções principais, e referem-se sómente a uma seç̧ão determinada.

É necessário prosseguir nos estudos sobre tensões nessas estruturas, pois há a possibilidade de chegar-se a economias significativas em novas obras, seja com 
dimensionamentos mais aprimorados ou com a utilização de materiais mais adequados.

Nesse caso, a utilização de métodos numéricos será interessante, pois, com o barateamento de equipamentos e o surgimento de programas baseados no Método dos Elementos Finitos, cada vez mais aperfeiçoados, os analistas podem obter bons resultados a baixo custo.

A conclusão de um modelo similar do Conjunto Tomada D'Água/Casa de Força da Usina Porto Primavera, em execução no LCEC, certamente contribuirá para o avanço do conhecimento nessa área.

As possibilidades de seqüência deste estudo apontam para a elaboração de outros modelos numéricos, com malhas mais refinadas, eventualmente utilizando elementos finitos sólidos com 20 nós, e considerando alguns fatores aqui omitidos, como peso próprio e fenômenos hidrodinâmicos.

Com a realização deste trabalho, espera-se ter contribuído para a divulgação dos métodos de análise estrutural de barragens, obras que consomem bilhões de dólares e, em cujo campo, o desenvolvimento de pesquisas pode levar a economias significativas. 


\section{REFERÊNCIAS BIBLIOGRÁFICAS}

AMERICAN SOCIETY OF CIVIL ENGINEERS; UNITED STATES COMITTEE ON LARGE DAMS. (1967) Joint ASCE-USCOLD Comittee on current United States practice in the design and construction of arch dams, embankment dams, concrete gravity dams. New York, ASCE.

AZEVEDO, M.C.; FERREIRA, M.J.E.; COSTA, C.P. (1987) Equipamentos para aplicação de carga e para medição de deslocamentos. Lisboa, Laboratório Nacional de Engenharia Civil. (Laboratório Nacional de Engenharia Civil. Memória, 691)

BARBOSA, R.L.; CAVALCANTI, A.J.C.T.; DEGASPARE, J.C. (1994) Métodos de projeto estrutural de caixa espiral para turbinas Francis. In: SEMINÁRIO NACIONAL DE GRANDES BARRAGENS, 21., Rio de Janeiro, 1994. Anais. Rio de Janeiro, Furnas. v.2, p.183-92.

BRAZILIAN COMMITTEE ON LARGE DAMS. (1982). Main brazilian dams: design, construction and performance. Rio de Janeiro.

CARNEIRO, F.L.L (1993). Análise dimensional e teoria da semelhança e dos modelos fisicos. Rio de Janeiro, UFRJ. 
CARPENTER, L.R. et al (1988) Instrumentation. In: JANSEN, R.B., ed. Advanced dam engineering: for design, construction and rehabilitation. New York, Van Nostrand Reinhold. Cap. 25, p.751-76.

COMITÊ BRASILEIRO DE GRANDES BARRAGENS. (1982). Barragens no Brasil. Rio de Janeiro.

COMITÊ BRASILEIRO DE GRANDES BARRAGENS. Comissão Técnica de Segurança de Barragens. (1986) Segurança de barragens: recomendações para a formulação e verificação de critérios e procedimentos. Rio de Janeiro.

COMPANHIA ENERGÉTICA DE SÃO PAULO. Laboratório Central deEngenharia Civil. (1980a) UHE Nova Avanhandava: ensaio do modelo fisico de uma unidade típica da casa de força. Ilha Solteira. (Relatório E-01/80)

COMPANHIA ENERGÉTICA DE SÃo PAULO. Laboratório Central de Engenharia Civil. (1980b) UHE Nova Avanhandava: ensaio do modelo fisico de uma unidade típica da casa de força. Tha Solteira. (Relatório E-01/80- Anexo 1)

COMPANHIA ENERGÉTICA DE SÃO PAULO. Laboratório Central de Engenharia Civil (1980c) UHE Nova Avanhandava: ensaio do modelo fisico de uma unidade típica da casa de força. Iha Solteira. (Relatório E-01/80- Anexo 2)

COMPANHIA ENERGÉTICA DE SÃo PAULO. Laboratório Central de Engenharia Civil. (1980d) UHE Nova Avanhandava: ensaio do modelo físico de uma unidade típica da casa de força. Ilha Solteira. (Relatório E-01/80- Anexo 3)

COMPANHIA ENERGÉTICA DE SÃO PAULO. Laboratório Central de Engenharia Civil. (1980e) UHE Nova Avanhandava: ensaio do modelo fisico de uma unidade típica da casa de força. Ilha Solteira. (Relatório E-01/80- Anexo 4)

COMPANHIA ENERGÉTICA DE SÃo PAULO. Laboratório Central de Engenharia Civil. (1981a) Usina Nova Avanhandava: instrumentação de 
auscultação das obras de terra, concreto e fundações, no período de setembro de 1980 a março de 1981. Ilha Solteira. (Relatório CB-23/81)

COMPANHIA ENERGÉTICA DE SÃO PAULO. Laboratório Central de Engenharia Civil. (1981b) Usina Nova Avanhandava: instalação de tensômetros para concreto nas estruturas da casa de força. Ilha Solteira. (Relatório CB-54/81)

COMPANHIA ENERGÉTICA DE SÃO PAULO. Laboratório Central de Engenharia Civil. (1982) Usina Nova Avanhandava: instaiação de tensômetros para concreto armado na casa de força. Ilha Solteira. (Relatório CB-42/82)

COMPANHIA ENERGÉTICA DE SÃO PAULO. Laboratório Central de Engenharia Civil. (1988) Atividades do Setor de Segurança e Controle de Barragens, no acompanhamento do desempenho estrutural dos aproveitamentos hidrelétricos da CESP. Itha Solteira. (Relatório LEC-CB-26/88)

COMPANHIA ENERGÉTICA DE SÃO PAULO. Laboratório Central de Engenharia Civil. (1992) Instrumentação de barragens. Ilha Solteira.

CORNS, C.F.; SCHRADER, E.K.; TARBOX, G.S. (1988) Gravity dam design. In: JANSEN, R.B., ed. Advanced dam engineer-ing: for design, construction and rehabilitation. New York, Van Nostrand Reinhold. Cap. 16, p.466-92.

HETÉNYI, M., ed. (1950) Handbook of experimental stress analysis. New York, J.Wiley/London, Chapman \& Hall.

HOSSDORF, H. (1974) Model analysis of structures. Trad. de C. Van Amerongen. New York, Van Nostrand Reinhold.

INTERNACIONAL DE ENGENHARIA. (1983a) Aproveitamento múltiplo de Nova Avanhandava: projeto executivo. Análise do comportamento das estruturas de concreto das obras de geração do aproveitamento múltiplo Nova Avanhandava até Dezembro/1982. São Paulo. 
INTERNACIONAL DE ENGENHARIA. (1983b) Aproveitamento múltiplo de Nova Avanhandava: projeto executivo. Manual de procedimentos de supervisão e inspeção da barragem durante as fases de enchimento do reservatório e de operação. São Paulo.

MACKERLE, J. (1986) Finite element codes for microcomputers: a review. Computers \& Structures, v.24, n.4, p.657-82.

MACKERLE, J. (1988) Finite element codes for microcomputers: an addendum. Computers \& Structures, v.28, n.6, p.797-814.

MASON, J. (1988). Estruturas de aproveitamentos hidrelétricos. Rio de Janeiro, Campus.

MEASUREMENTS GROUP. (1993) Errors due to transverse sensitivity in strain gages. Raleigh. (Text Note, 509)

OLIVEIRA, A.R.; MIYAII, Y.; RESCK, J.T. (1986) Análise comparativa das tensões calculadas e medidas, através de tensômetros elétricos, na caixa espiral da Usina Nova Avanhandava. São Paulo, CESP./Separata do VIII Seminário Nacional de Produção e Transmissão de Energia Elétrica/

OS PERCALÇOS da instrumentação de obras. (1987) Dirigente Construtor, v.23, n. 10, p. $21-6$, out.

PEDRO, J.O.; FLORENTINO, C.A. (1989) Critérios e métodos de observação de barragens de betão. Lisboa, Laboratório Nacional de Engenharia Civil. (Laboratório Central de Engenharia Civil. Memória, 740)

ROCHA, M.;SERAFIM, J.L. (1986) Model tests of Santa Luzia Dam. In: AZEVEDO, M.C., coord. Experimental study of concrete arch dams: 40 years of LNEC experience. Lisboa, Laboratório Nacional de Engenharia Civil. v.1, p.11-52. 
ROCHA, M.; SILVEIRA, A.F.; AZEVEDO, M.C.C. (1964) Note on some comparisons between experimental and analytical values of the stresses and displacements of concrete dams. In: AZEVEDO, M.C., coord. Experimental study of concrete arch dams: 40 years of LNEC experience. Lisboa, Laboratório Nacional de Engenharia Civil. v.2, p.669-99.

SABNIS, G.M. et al. (1983) Structural modeling and experimental techniques. Englewood Cliffs, Prentice-Hall. (Prentice-Hall Civil Engineering and Engineering Mecha-nics Series)

SAINI, S.S. (1988) Monitoring Bhakra dam. International Water Power and Dam Construction, v.40, n.1, p.29-34.

SERAFIM, J.L; COSTA, J.P. (1960) Métodos e materiais para o estudo, em modelos das tensões devidas ao peso próprio em barragens. Lisboa, Laboratório Nacional de Engenharia Civil. (Laboratório Nacional de Engenharia Civil. Memó-ria,154)

SIL VEIRA, A.F.; AZEVEDO, M.C.; FERREIRA; M.J.E. (1987) Contribution to the structural study of a hydroelectric power station resting on a deformable foundation. Lisboa, Laboratório Nacional de Engenharia Civil. (Laboratório Nacional de Engenharia Civil. Memória,688)

SILVEIRA, J.F.A. et al. (1994) A automação da instrumentação da UHE de Xingó e os custos envolvidos. In: SEMINÁRIO NACIONAL DE GRANDES BARRAGENS, 21., Rio de Janeiro, 1994. Anais. Rio de Janeiro, Furnas. v.1, p.111-21.

UNITED STATES. Department of the Interior. Bureau of Reclamation. (1987). Avaliação de segurança de barragens existentes. Trad. de Maria Lucia de Almeida Prata, Hamilton Pollis e Carlos Octavio Pavel. Rio de Janeiro, Eletrobrás. 
UNITED STATES. Department of the Interior. Bureau of Reclamation. (1976) Design of gravity dams: design manual for concrete gravity dams. Denver. (A Water Resources Technical Publication)

UNIVERSIDADE DE SÃO PAULO. Escola Politécnica. Núcleo de Ligação Industrial. (1989) Cursos de atualização. São Paulo, FDTE/EPUSP/IEE/IPT.

VARGAS, M. (1985). Metodologia da pesquisa tecnológica. Rio de Janeiro, Globo.

VIOLANTE, J.C.S. (1980). Relatório de estágio. Ilha Solteira, Companhia Energética de São Paulo/Laboratório Central de Engenharia Civil.

WALZ, A.H. (1989) Automated data management for dam safety evaluations. International Water Power and Dam Constru-ction, v.41,n.4, p.23-5, apr.

WILSON, E.L.; HABIBULLAH, A. (1989) SAP90TM-A series of computer programs for the static and dynamic finite element analysis of structures: users manual. Berkeley, Computers and Structures.

ZAGOTTIS, D. (1976) Os modelos matemáticos no projeto estrutural de barragens. São Paulo, USP-POLI./Separata do XI Seminário Nacional de Grandes Barragens.

ZIENKIEWICZ, O.Z. et al. (1975) Comparison of analytical and experimental results in the design of a hollow gravity dam. Lisboa, Laboratório Nacional de Engenharia Civil. (Laboratório Nacional de Engenharia Civil. Memória,466) 